\title{
Knowledge, practice, and coverage (KPC) survey: Baseline report, Mansehra District
}

Munir Afridi

Saman Naz

Nayyer Munir

Follow this and additional works at: https://knowledgecommons.popcouncil.org/departments_sbsr-rh

Part of the Demography, Population, and Ecology Commons, Environmental Public Health Commons, Family, Life Course, and Society Commons, International Public Health Commons, and the Medicine and Health Commons How does access to this work benefit you? Let us know!

\section{Recommended Citation}

Afridi, Munir, Saman Naz, and Nayyer Munir. 2007. "Knowledge, practice, and coverage (KPC) survey: Baseline report, Mansehra District." Islamabad: Population Council. 


\section{Knowledge, Practice and Coverage} Baseline Survey

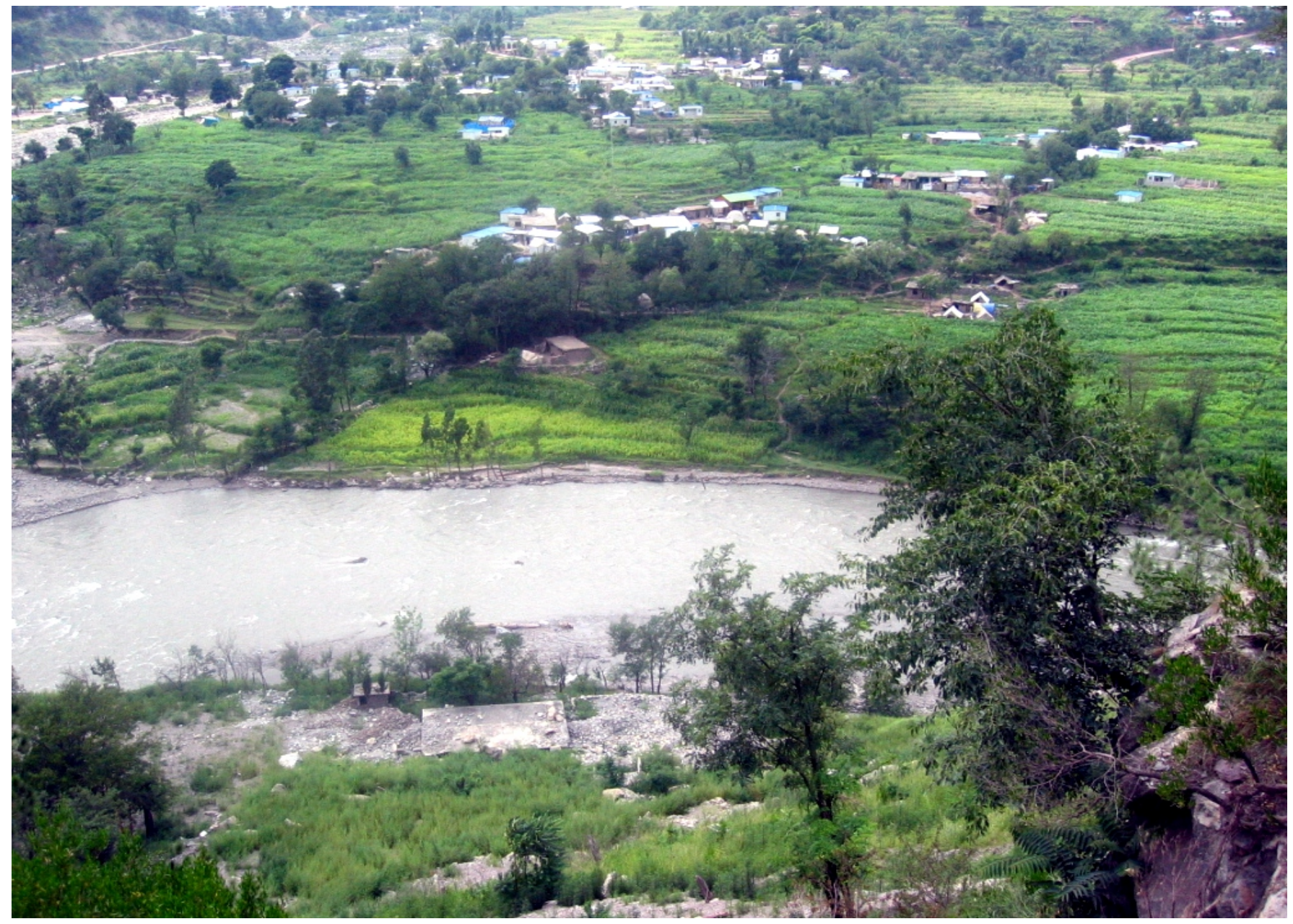

Munir Afridi

Saman Naz

Nayyer Munir

(2) Population Council

Mansehra District September 2007 


\section{Knowledge, Practice and Coverage (KPC) Survey}

\section{Baseline Report}

Mansehra District 
PRIDE Project is committed to Better Health for the people of Bagh and Mansehra Districts through improved health systems, improved health services and community participation. The project is generously supported by the American people through the United States Agency for International Development (USAID). PRIDE is implemented by a consortium of international partners including The International Rescue Committee (IRC) as the lead agency;

Management Sciences for Health (MSH) supporting health system strengthening; JHPIEGO, an affiliate of Johns Hopkins University, supporting health service strengthening; and The Population Council supporting monitoring and evaluation.

\section{(2) Population Council}

The Population Council, an international, non-profit, non-governmental organization established in 1952, seeks to improve the well-being and reproductive health of current and future generations around the world and to help achieve a humane, equitable, and sustainable balance between people and resources.

The Council analyzes population issues and trends; conducts research in the reproductive sciences; develops new contraceptives; works with public and private agencies to improve the quality and outreach of family planning and reproductive health services; helps governments design and implement effective population policies; communicates the results of research in the population field to diverse audiences; and helps strengthen professional resources in developing countries through collaborative research and programs, technical exchanges, awards, and fellowships.

For inquiries, please contact:

Population Council

\#7, Street 62, F-6/3, Islamabad, Pakistan

Tel: 92512277439

Fax: 92512821401

Email: info@pcpak.org

web: http://www.popcouncil.org

\section{PRIDE}

House \# 138 , St \# 14, E-7, Islamabad, Pakistan

Tel: + 92(0)51-2654142

Email: munir.afridi@pride.org.pk

Layout \& Design: Ali Ammad

Title design: Tanvir Malik

This report is made possible by the generous support of the American people through the United States Agency for International Development (USAID). The contents are the responsibility of the PRIDE project and do not necessarily reflect the views of USAID or the United States Government. 


\section{Contents}

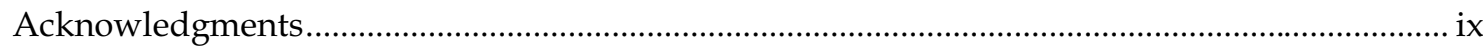

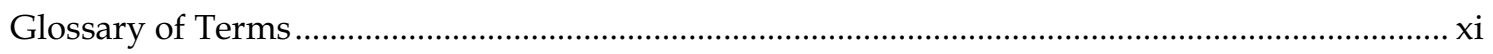

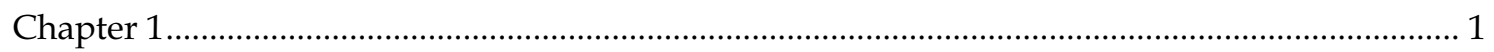

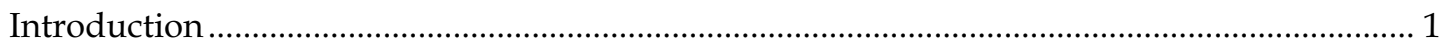

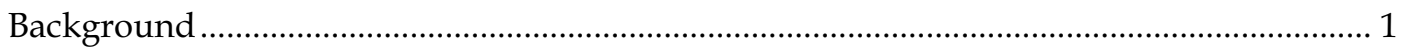

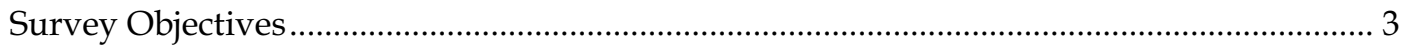

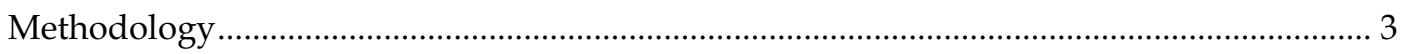

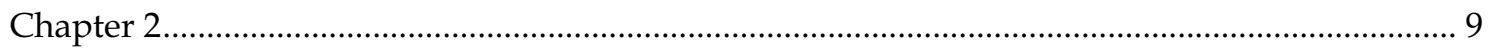

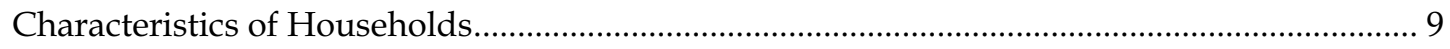

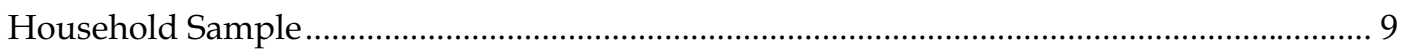

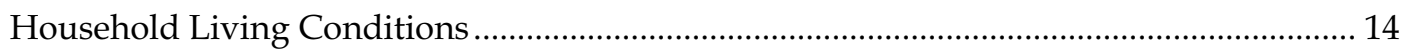

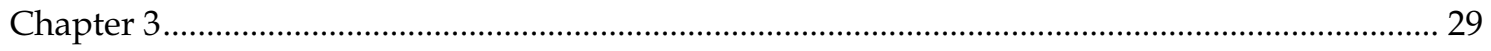

Characteristics of Married Women of Reproductive Age .......................................................... 29

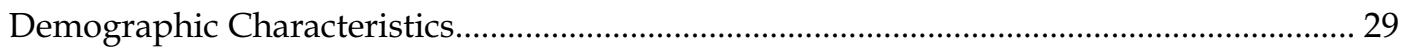

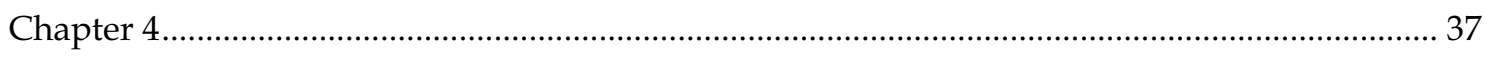

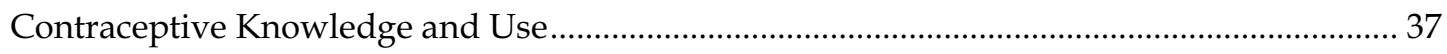

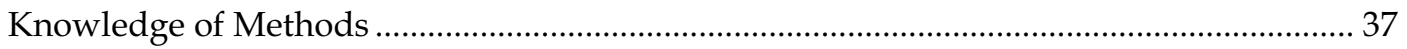

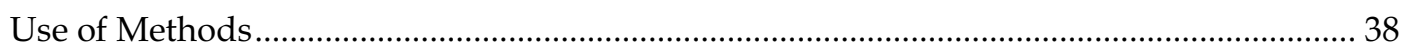

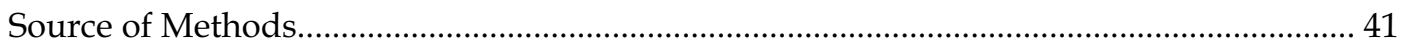

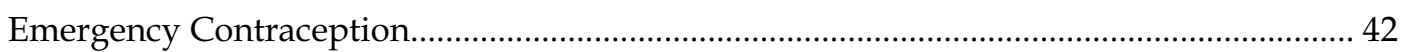

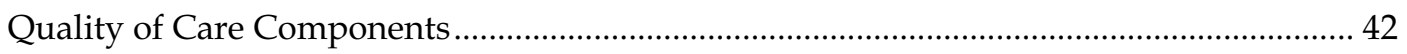

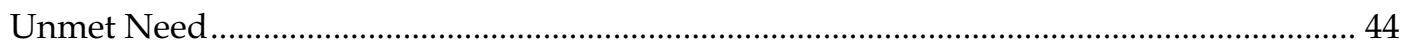

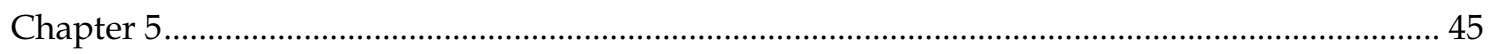

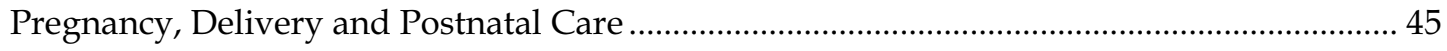

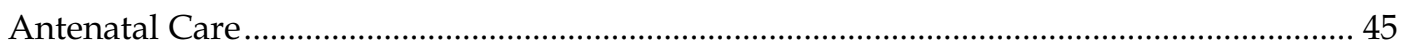

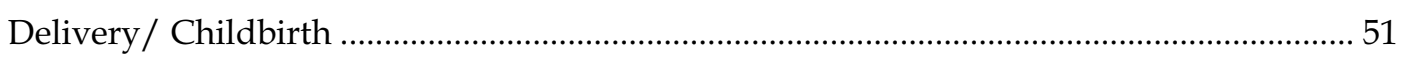

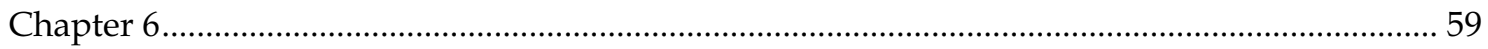

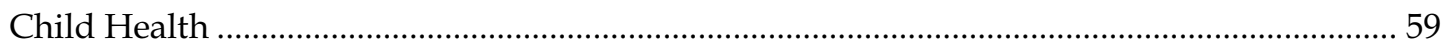

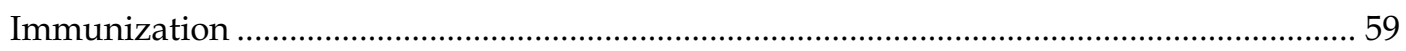

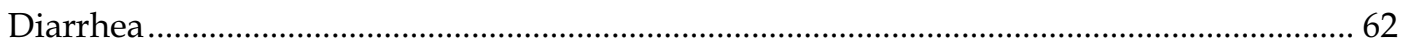

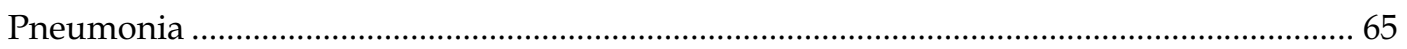

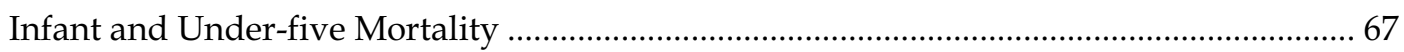

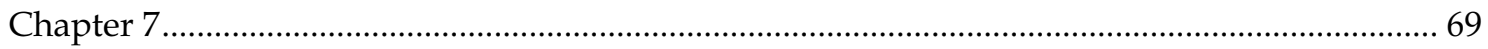

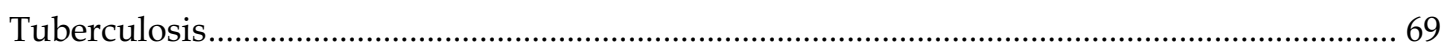

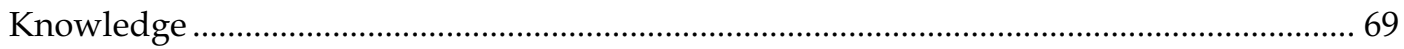

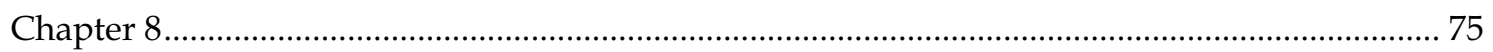

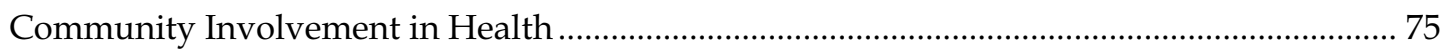

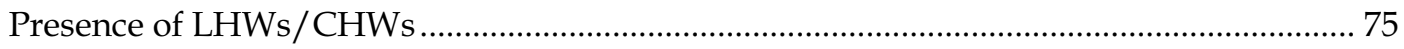

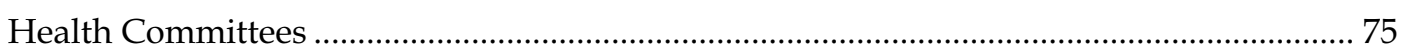




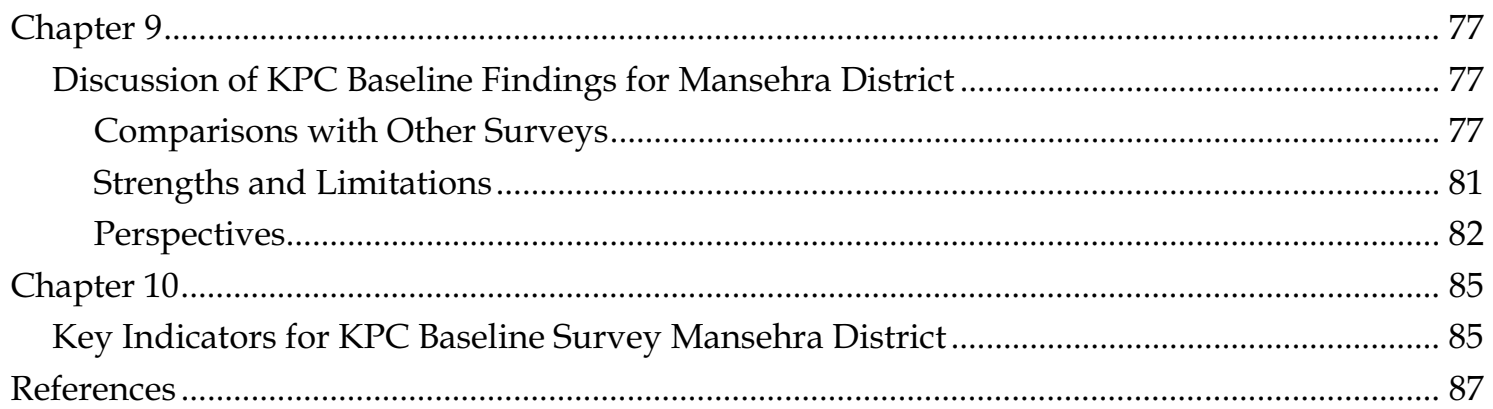

\section{List of Tables}

Table 1.1: Number of blocks/villages and households selected, and proportion of population,

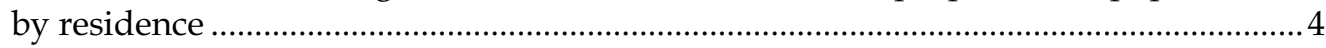

Table 2.1: Number of households, sampled and interviewed, and household members, by

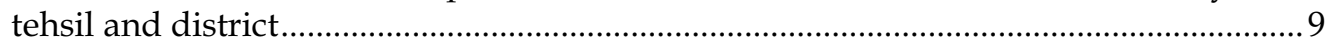

Table 2.2: Percentage distribution of household population, by age and sex ...............................10

Table 2.3: Percentage of household population (ages 15 and over) according to age, sex and

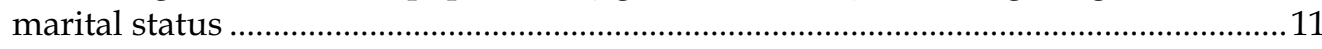

Table 2.4: Household population ages 5 years and above according to sex, age and schooling.12

Table 2.5: Sources of drinking water, by tehsil and district .........................................................15

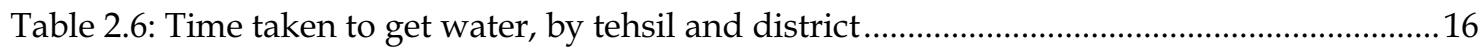

Table 2.7: Treatment of drinking water to make it safer, by tehsil ............................................... 17

Table 2.8: Type of toilet facility used by household members, by tehsil and district .................. 18

Table 2.9: Type of fuel used for cooking, by tehsil and district.....................................................19

Table 2.10: Ownership of household commodities / animals, by tehsil and district....................20

Table 2.11: Type of salt usually used, by tehsil and district.............................................................2

Table 2.12: Source of knowledge about iodized salt, by tehsil and district ....................................23

Table 2.13: Measures taken to avoid mosquito bites, by tehsil and district.....................................26

Table 3.1: Ever-married women of reproductive age interviewed for the KPC baseline survey, by tehsil and district .................................................................................................. 29

Table 3.2: Age, age at marriage and mean age at marriage of eligible women, by tehsil and

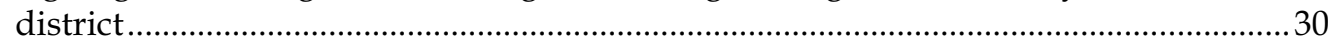

Table 3.3: Marital status of eligible women, by tehsil and district...................................................31

Table 3.4: Education level of eligible women and their husbands, by tehsil and district.............32

Table 3.5: Mother tongue of eligible women, by tehsil and district................................................33

Table 3.6: Age of eligible women according to number of children ever born, number of women, and comparison of PRIDE and 1998 Census data for mean number of

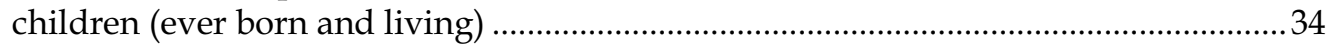

Table 3.7: Occupation of eligible women's husbands, by tehsil and district..................................35

Table 4.1: Contraceptive methods ever used by currently married women, by tehsil and district. 
Table 4.2: Percent of current use of contraceptive methods by currently married women, by tehsil and district...

Table 4.3: Percent of currently married women who are current contraceptive users according to the source of their last supply, by tehsil and district.

Table 5.1: Eligible women according to the number of antenatal visits they had, by tehsil and district.....

Table 5.2: Eligible women according to the location where antenatal care was given, by tehsil and district

Table 5.3: Providers of antenatal care, by tehsil and district .47

Table 5.4: Women who had a live birth in the last 3 years according to number of ANC visits, by reason for first ANC visit

Table 5.5: Eligible women according to reason for not having antenatal visits, by tehsil and district.

Table 5.6: Eligible women according to type of person attending at delivery and skill level, by tehsil and district.

Table 5.7: History of postnatal care. .56

Table 6.1: Children under age 3 who received polio vaccination during national immunization day campaigns.

Table 6.2: Danger signs of diarrhea requiring immediate treatment cited by mothers of children ages 0-23 months, by tehsil and district

Table 6.3: Identification of signs/symptoms of pneumonia by mothers of children 0-23 months, by tehsil and district.

Table 7.1: Ever-married women who knew about TB according to their knowledge about ways in which TB can be spread from person to person, by tehsil and district............70

Table 7.2: Ever-married women who believed TB to be treatable according to their beliefs about the duration of TB treatment, by tehsil and district ............................................. 71

Table 7.3: Ever-married women according to whether or not anyone in their family ever suffered from TB, by tehsil and district .72

Table 7.4: Ever-married women who cited symptoms of TB according to symptom, by tehsil and district

Table 9.1: Comparison of Mansehra KPC indicators with selected national survey data ............78

Table 9.2: Comparison of Mansehra KPC data with MICS 2001 and PSLM 2005-06 data from Mansehra district

Table 10.1: PRIDE key indicators from KPC baseline survey, Mansehra district

\section{List of Figures}

Figure 2.1: Marital status of household population (ages 15 years and over), by sex...................12

Figure 2.2: Years of schooling for males and females ages 5 years and over (percent).................14

Figure 2.3: Sources of drinking water for Mansehra district ........................................................15

Figure 2.4: Ownership of selected household goods, by tehsil (percent)........................................ 21

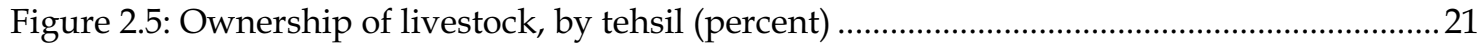

Figure 2.6: Awareness of iodized salt among non-users, by tehsil (percent) ..................................23 
Figure 2.7: Reported manifestations of iodine deficiency, by tehsil (percent) ............................... 24

Figure 2.8: Knowledge about ill effects of iodine deficiency, by tehsil (percent)........................... 25

Figure 2.9: Action taken or not taken to prevent mosquito bites, by tehsil (percent) ................... 26

Figure 3.1: Age at marriage (by age groups) of eligible women in Mansehra district..................31

Figure 3.2: Mother tongue of eligible women in Mansehra district................................................33

Figure 4.1: Currently married women's knowledge of specific contraceptive methods (percent) ...................................................................................................................... 38

Figure 4.2: Ever use of specific contraceptive methods by currently married women (percent) 39

Figure 4.3: Currently married women's knowledge and ever use of emergency contraception, by tehsil and district (percent) ........................................................................................4 42

Figure 4.4: Quality of care components at ANC visits for currently married women (\%) ...........43

Figure 4.5: Currently married women who were non-users of FP according to their future intention to use a contraceptive method, by tehsil (percent) . .43

Figure 4.6: Currently married women who were pregnant or non-pregnant, by their

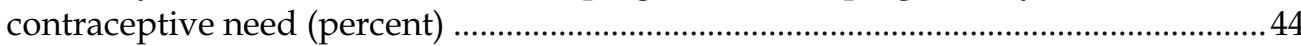

Figure 5.1: Services performed during antenatal check-up, by tehsil and district (percent)........ 48

Figure 5.2: First antenatal care visit according to the reason for the visit, by tehsil and district (percent)

Figure 5.3: Tetanus toxoid injections received during last pregnancy, by tehsil and district

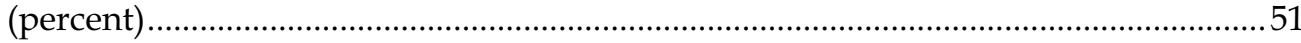

Figure 5.4: Place of last delivery, by tehsil and district (percent)...................................................52

Figure 5.5: Women who experienced a problem(s) during their last delivery and postpartum period, by type of problem experienced (percent) .....................................................5 54

Figure 5.6: Safe delivery practices used at home births, by tehsil and district (percent) ...............55

Figure 5.7: Percentage of respondents who had knowledge about danger signs in newborns, by tehsil and district (percent)

Figure 5.8: Women's knowledge of the number of danger signs in a newborn within one hour of birth, by tehsil and district (percent).

Figure 6.1: Children ages 12-23 months who were fully immunized, based on records and recall, by tehsil and district (percent)

Figure 6.2: Children ages 12-23 months according to immunizations received, by tehsil and district (percent)

Figure 6.3: Status of immunization cards of mothers of children ages 12-23 months, by tehsil and district (percent)

Figure 6.4: Children ages 0-23 months according to whether or not they had had diarrhea during the last two weeks, by tehsil and district (percent)

Figure 6.5: Mothers of children ages 0-23 months who sought advice or treatment from service providers for episodes of diarrhea, by tehsil and district (percent)

Figure 6.6: Mothers according to whether or not they treated the last bout of diarrhea in their children ages $0-23$ months with ORT, by tehsil and district (percent).

Figure 6.7: Mothers of children ages 0-23 months who had heard about pneumonia, by tehsil and district (percent).

Figure 6.8: Mothers of children ages 0-23 months according to what should be done if their child breathes fast with difficulty, by tehsil and district (percent) 
Figure 7.1: Ever-married women who had or had not heard about tuberculosis, by tehsil (percent).

Figure 7.2: Ever-married women according to whether or not they knew that TB was a treatable disease, by tehsil (percent)

Figure 7.3: Ever-married women who reported whether or not they could identify at least one

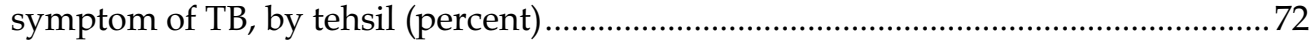

Figure 8.1: Percentage of 60 selected communities that have VHCs/CBOs....................................76 



\section{Acknowledgments}

The PRIDE KPC Baseline Survey will be an important part of the foundation of the PRIDE project as a whole. For this reason, we would first like to acknowledge the United States Agency for International Development (USAID) for their financial support.

The Population Council was primarily responsible for designing the study, carrying out the fieldwork, monitoring the quality of the data collection, analyzing the data, and writing the reports. Dr. Arshad Mahmood, Director of Monitoring and Evaluation, used his capable technical and managerial skills to oversee the entire study with enthusiasm and energy and contributed substantially from the design phase to the analysis of the data and report preparation.

The study was carried out by several Population Council staff members, from design and pre-testing to final report writing. We would particularly like to acknowledge Dr. Munir Afridi, Nayyar Munir, Saman Naz and Ashfa Hashmi for monitoring fieldwork and ensuring quality data collection in the field. Irfan Masood managed the entry and cleaning of the data. Saman Naz, Nayyar Munir and Muhammad Ashraf prepared graphs and tables under the guidance of Dr. Arshad Mahmood. Dr. Munir Afridi and Saman Naz jointly prepared the first draft of the KPC survey report. We are grateful to Peter C. Miller who wrote the discussion section for this report and Minhaj ul Haque for his computation support.

We also acknowledge the administrative support to the field teams by the PRIDE district offices. The quality of data collection depends on the training of field staff; we greatly appreciate the training provided by Dr. Gul Rashida and her team.

Ali Ammad was responsible for designing the layout and formatting the report. Chantelle Allen reviewed the report and suggested very useful changes. Pamela Ledbetter carefully edited and proofread this report.

Finally, we must express our gratitude to the women of Mansehra, who gave their time freely and cooperated with us in order to make this study possible. We hope to repay them by using the information they provided to improve primary healthcare services, including maternal and neonatal health services, in the district of Mansehra. 



\title{
Glossary of Terms
}

\author{
ACMW All Currently Married Women \\ ADHO Assistant District Health Officer \\ ANC Antenatal Care \\ BCC Behavior Change Communication \\ BCG Bacille Calmette-Guérin \\ BHU Basic Health Unit \\ CBO Community Based Organization \\ CHW Community Health Worker \\ CMR Child Mortality Rate \\ CPR Contraceptive Prevalence Rate \\ DHQ District Headquarter Hospital \\ DPT Diphtheria, Pertussis and Tetanus \\ EC Emergency Contraception \\ EDO $(\mathrm{H}) \quad$ Executive District Officer (Health) \\ FP Family Planning \\ IMR Infant Mortality Rate \\ IR Intermediate Result \\ IRC International Rescue Committee \\ IUD Intra Uterine Device \\ JHPIEGO Johns Hopkins Program for International Education in Gynecology and \\ Obstetrics \\ KPC Knowledge, Practice and Coverage \\ LHW Lady Health Worker \\ MO Medical Officer \\ $\mathrm{MCH} \quad$ Maternal and Child Health \\ MICS Multiple Indicators Cluster Survey \\ MSH Management Sciences for Health \\ MWRA Married Women of Reproductive Age \\ NGO Non-government Organization \\ NIPS National Institute of Population Studies \\ NNS National Nutrition Survey \\ NWFP North West Frontier Province \\ ORT Oral Rehydration Therapy \\ PAIMAN Pakistan Initiative for Mothers and Newborns \\ PC Population Council \\ PHC Primary Health Care \\ PRHFPS Pakistan Reproductive Health and Family Planning Survey \\ PRIDE Primary Healthcare Revitalization, Integration and Decentralization in \\ Earthquake-affected Areas \\ PSLM Pakistan Social and Living Standard Measurement Survey \\ PSU Primary Sampling Unit \\ RHC Rural Health Center \\ RHSC A Reproductive Health Services Center- A \\ SMART Safe Motherhood Applied Research and Training \\ TB Tuberculosis \\ TBA Traditional Birth Attendant \\ TFR Total Fertility Rate
}




$\begin{array}{ll}\text { THQ } & \text { Tehsil Headquarter Hospital } \\ \text { TOR } & \text { Term of Reference } \\ \text { TT } & \text { Tetanus Toxoid } \\ \text { USAID } & \text { United State Agency for International Development } \\ \text { VHC } & \text { Village Health Committee } \\ \text { WHO } & \text { World Health Organization } \\ \text { WMO } & \text { Woman Medical Officer }\end{array}$




\section{Chapter 1}

\section{Introduction}

\section{Background}

The Primary Healthcare Revitalization, Integration and Decentralization in Earthquake-affected Areas (PRIDE) program is designed to improve primary healthcare services and health outcomes for populations in Bagh and Mansehra districts in northern Pakistan that were affected by the devastating earthquake that struck the region on 8 October 2005. PRIDE, which began in August 2006, is a fouryear program funded by the United States Agency for International Development (USAID). The project's aim is to strengthen the financial and human resource management capacities of district health authorities and primary healthcare providers. Access to and quality of primary healthcare services will be improved through an essential package of health services and improved skills of primary healthcare personnel. Community demand for quality services will be improved through an innovative social mobilization process aimed at increasing knowledge and care-seeking behaviors.

PRIDE is implemented by a consortium of international partners working with local government stakeholders and communities. The International Rescue Committee (IRC) is the Recipient Agency responsible for overall management of the program and on-the-ground implementation. Management Sciences for Health (MSH) is primarily responsible for support for improved performance of public health services and management systems at district and sub-district levels. JHPIEGO, an affiliate of Johns Hopkins University, supports improved access to and quality of primary health care services. In addition to overall program management, IRC focuses on increased community participation in health services and healthier behaviors at household and community levels. The Population Council provides support to overall monitoring and evaluation functions within the project. 
The target population of PRIDE is over 1.5 million earthquake-affected people living in Bagh and Mansehra districts of northern Pakistan. PRIDE achieves its aims by serving the needs of this target population at several levels, assisting communities, providers and administrators in establishing a quality primary healthcare system in which all can take pride. This is a system that motivates and supports all who participate in it, while specifically addressing the health needs of the most vulnerable: women, children, the elderly, and families ravaged by the earthquake. The levels of intervention are outlined below:

- At the district level: PRIDE builds and institutes local capacity, building the managerial practices of health administrators.

- At the primary healthcare facility and provider level: PRIDE ensures accessible and essential primary healthcare services, improving the clinical practices of health providers.

- At the community level: PRIDE empowers communities to actively plan, access, and monitor health services, improving the health practices of communities.

- At the household level: PRIDE promotes healthy behaviors and improved health outcomes.

The PRIDE program is contributing to the achievement of USAID/Pakistan "Strategic Objective 7: Improved Health of Vulnerable Population." All PRIDE activities support the broad goal of this USAID strategic objective of improving the primary healthcare system in selected earthquake-hit districts.

To ensure that the success of PRIDE is properly ascertained and that the appropriate lessons are learned, PRIDE developed a Performance Management Plan. Included in this plan is the establishment of baseline measures for a set of indicators to be used for the evaluation of the success of the project. These indicators are provided in Table 10.1 (Chapter 10); they are also highlighted throughout this report. The plan calls for a baseline household survey, which was carried out in Bagh and Mansehra districts. There are two baseline household survey reports, one for each district. This report, Knowledge, Practice and Coverage (KPC) Survey: Baseline Report. Mansehra District, which was written by Population Council staff involved in the survey, presents data for Mansehra district and its tehsils (Balakot, Oghi and Mansehra). 


\section{Survey Objectives}

The KPC survey objectives include reference to PRIDE indicators; note that PRIDE key indicators, referred to in the survey objectives, are shown in Table 10.1 (Chapter

10) and are highlighted throughout this report. The KPC survey objectives are:

1. To obtain district data to measure Intermediate Results 2 and 3 indicators.

2. To obtain district data necessary to measure PRIDE indicators for household-level health practices of communities.

3. To obtain baseline information for PRIDE indicators, such as infant mortality rate (IMR) and child mortality rate (CMR).

4. To obtain information on maternal and child health, and related issues. ${ }^{1}$

5. To obtain information required for the detailed design of the interventions and activities of the PRIDE project. ${ }^{2}$

\section{Methodology}

\section{Study Population}

PRIDE is primarily a district-level project that is intended to improve the health of the entire population, particularly women and children, during the project period. To this end, the study included community residents - notably children, mothers and prospective mothers - in order to understand and measure general knowledge, specific health behaviors and coverage of different relevant events (e.g., pregnancies and deliveries). Hence, the study population for the baseline Knowledge Practice and Coverage Survey included all married women of reproductive age (15-49 years) living in Mansehra district, and, more specifically, women who had experienced a pregnancy during the last three years and the children born to these women during this period.

\footnotetext{
${ }^{1}$ This information may be of use to district health departments for planning and management.

${ }^{2}$ This includes information on behavior change communication, public/private partnerships, and health system strengthening.
} 


\section{Sample}

\section{Design and size}

The baseline household KPC survey was carried out in urban and rural areas all over Mansehra district, excluding the Tribal Area of Kalla Dhaka. Sampling of the population was carried out to provide data representative of the district, in addition to estimates for the entire project area. The number of blocks and villages selected in urban and rural areas, as well as the respective number of households selected, are shown in Table 1.1.

Table 1.1: Number of blocks/villages and households selected, and proportion of population, by residence

\begin{tabular}{lrrr} 
Residence & $\begin{array}{r}\text { Proportion of population } \\
\text { (1998 Census) }\end{array}$ & $\begin{array}{r}\text { Number of } \\
\text { blocks/villages }\end{array}$ & $\begin{array}{r}\text { Number of } \\
\text { households }\end{array}$ \\
\hline Urban & 5.6 & 4 & 100 \\
\hline Rural & 94.4 & 56 & 1,396 \\
Total & 100.0 & 60 & 1,496
\end{tabular}

The sampling method used in this survey was multistage stratified cluster sampling. The main focus, as described above, was on women of reproductive age and their children. Data on the health facilities available in these women's communities and on these women's household conditions were also collected.

The sample size was based primarily on the need to collect indicators based on the most recent pregnancy during the past 3 years for determination of practices surrounding pregnancy, childbirth, postpartum and child feeding and vaccination practices. For this purpose, a sample size of about 1,000 households would have been sufficient. However, an additional important indicator was under-5 mortality, for which the denominator would be births. A representative sample of 3,000 households for the two districts combined (1,500 for each district) was selected in order to be able to detect a 12 percent decline in the combined childhood mortality rate with 95 percent confidence. Among these households, all currently married women were interviewed.

\section{Urban sample}

The required number of enumeration blocks was selected with probability proportional to size (number of census circles) by adopting a multistage stratified sampling design. Firstly, the "enumeration circle," that is the smallest unit available in the 1998 Population District Census Reports as demarcated by the Population 
Census Organization, was selected. The maps of these circles, obtained from the Population Census Organization, were divided into blocks of approximately 250-300 households, depending on the number of households in each circle. Later, a block was randomly selected. The enumeration teams then carried out the listing of each block before selecting the sampled households. A fixed number of households (25 households) was drawn from each sample enumeration block by using the systematic random technique.

\section{Rural sample}

The 1998 Census list of villages was used as the sampling frame for the selection of the rural sample. Villages in rural areas have been treated as primary sampling units (PSUs). Sample PSUs were selected with probability proportional to size (number of households). Households within the sample PSUs were considered secondary sampling units. The listing of each village was then updated by the enumeration teams before selecting the sampled households. A fixed number of households (25 households) was drawn from each sample enumeration village by the systematic random technique.

\section{Questionnaires}

\section{Design}

Three different questionnaires -- for women, households and communities -- were developed by the Population Council based on a combination of current general demographic and health survey methodologies and the questionnaires developed by Population Council for the Safe Motherhood Applied Research and Training (SMART) project and the Pakistan Initiative for Mothers and Newborns (PAIMAN) baseline household survey. The questionnaires contained data sufficient to estimate those PRIDE indicators that were to be collected by the household KPC survey, as well as other relevant information.

\section{Pre-test}

PRIDE monitoring and evaluation partners and other interested stakeholders reviewed the KPC survey questionnaires, which were then pre-tested in urban and rural areas of Islamabad. The main objective of the pre-testing was to examine the suitability of questions and their effectiveness in eliciting adequate responses, to find out if there were any linguistic problems faced either by interviewers or respondents, and to determine the approximate time required to complete a questionnaire. 
In the pre-test, female interviewers were used and they were advised to note down their experiences with regard to each question. After making all of the revisions indicated by the pre-test, the questionnaires were finalized and translated into Urdu. A brief description of the three questionnaires follows.

\section{Household questionnaire}

The respondent for this questionnaire was either the head of each household or any available adult (male or female) of the household who was knowledgeable about household matters. The household questionnaire included information on the following indicators for the household:

- Age-sex composition.

- Socioeconomic conditions (e.g., household assets, source of drinking water and toilet facilities).

- Knowledge and practices regarding use of iodized salt and prevention of malaria.

\section{Women's questionnaire}

The respondents for this questionnaire were all married women of reproductive age in each household visited. The following information was collected about individual women through this questionnaire:

- Socioeconomic status.

- Fertility, pregnancy history and reproductive intentions.

- Attitude toward pregnancy, delivery and postpartum.

- Knowledge, attitude and practice of contraceptive methods.

- Child vaccination and health.

- Knowledge about symptoms and treatment of tuberculosis.

- Health seeking behavior.

\section{Community questionnaire}

The respondents for this questionnaire were three to four influential members of the community. The community questionnaire was designed to collect information regarding involvement of the community in health planning, designing and management at the local level. 


\section{Fieldwork}

\section{Hiring}

To be sensitive to cultural issues, it was decided to use female interviewers to interview females and male interviewers to interview males. Based on the constitution of each team, hiring of the required number of female and male interviewers was done. In recruiting interviewers, priority was given to those with knowledge of the local language and experience in similar work.

\section{Training}

Training of interviewers is key to the quality of data collection. To ensure high quality and uniformity in each interviewer's understanding of the definitions and concepts behind the language of the questions, training of the interviewers was conducted only in Islamabad.

The trained staff of the Population Council imparted training on the questionnaires and survey procedures. The training was conducted in different sessions for ten days. During the training, interviewers also visited a few communities to conduct interviews in order to practice how to ask the questions.

It is important that interviewers understand the methodology for sampling households; therefore, training on these aspects (e.g., the importance of the criteria for selecting primary sampling units, mapping and listing procedure, sample selection and field operation procedures, and selection of the particular households and respondents) was done by the sampling experts.

Training was also carried out for team leaders and those responsible for reviewing completed questionnaires once they were sent to the office (see quality assurance).

\section{Field teams}

There were three teams deployed in Mansehra district with a team leader in each team. Each team consisted of four female interviewers and a male interviewer. The work plan of each team was prepared in a prescribed format indicating the name of the team members and the sample area name with enumeration dates. This system helped in monitoring the fieldwork by the Population Council monitoring teams and PRIDE partners. 


\section{Quality assurance}

To ensure the quality of the data, Population Council provided extensive monitoring of the field teams. Experienced Population Council field staff were used for this purpose. While supervising the fieldwork, the Population Council supervisory staff provided on-the-spot guidance to interviewers if any part of the questionnaire was not clear; this supervision helped to ensure completeness of each questionnaire. In addition, the team leaders, who were given editing instructions, conducted preliminary editing of completed questionnaires during the enumeration period. These instructions emphasized the completeness of each questionnaire, with correct identification of each eligible respondent and completeness of household composition. Extensive training of the editing staff responsible for reviewing the completed questionnaires in Islamabad was also imparted.

\section{Data processing}

Data processing started in the field with the checking of each questionnaire. Each team leader conducted on-the-spot editing of all questionnaires filled in by the interviewers, as they were trained to do.

On receipt of the questionnaires at the Islamabad office, a special team of experienced and well-trained staff edited the completed questionnaires. After having been edited and coded, questionnaires were dispatched to the data entry center.

Population Council was responsible for data entry using data entry (CSPro) and edit programs. Data entry was carried out concurrently with fieldwork; that is, data were entered as soon as they were received from the field, and errors were immediately returned for correction. After data entry and editing, a clean dataset was produced.

\section{Data analysis}

Data were analyzed using SPSS for Windows. Once basic data tables were prepared, they were shared with PRIDE partners and other district-level stakeholders. 


\section{Chapter 2}

\section{Characteristics of Households}

This chapter presents post-earthquake household characteristics for Mansehra district. Information was collected on some of the demographic and socioeconomic characteristics of district households, such as the source of drinking water, sanitation facilities and possession of durable goods. Information on the characteristics of district households is essential for the interpretation of survey findings. The definition of household used in this survey was "person or a group of persons, related or unrelated, who live together in the same dwelling unit and share a common source of food."

\section{Household Sample}

The number of households that were sampled and in which interviews were conducted is presented by tehsil in Table 2.1. There were 9,977 individuals living in the 1,496 households in which interviews were conducted.

Table 2.1: Number of households, sampled and interviewed, and household members, by tehsil and district

\begin{tabular}{|c|c|c|c|c|c|c|}
\hline \multirow{3}{*}{ Tehsil } & \multicolumn{4}{|c|}{ Households } & \multirow{2}{*}{\multicolumn{2}{|c|}{$\begin{array}{c}\text { Household } \\
\text { members }\end{array}$}} \\
\hline & \multicolumn{2}{|c|}{ Sampled } & \multicolumn{2}{|c|}{ Interviewed } & & \\
\hline & $N$ & $\%$ & $N$ & $\%$ & $N$ & $\%$ \\
\hline Balakot & 325 & 21.7 & 323 & 21.6 & 1,953 & 19.6 \\
\hline Oghi & 300 & 20.0 & 300 & 20.1 & 1,962 & 19.7 \\
\hline Mansehra & 875 & 58.3 & 873 & 58.4 & 6,062 & 60.8 \\
\hline Total & 1,500 & 100.0 & 1,496 & 100.0 & 9,977 & 100.0 \\
\hline
\end{tabular}




\section{Demographic Characteristics}

\section{Age and sex}

Of the 9,977 individuals living in interviewed households, 49 percent were male and 51 percent were female. The age and sex distribution of these household members is presented in Table 2.2. When stratified by sex, both males and females had a similar age distribution, except in the 60 plus age group in which there were more males (11 percent) than females ( 6 percent). The largest age group, by a small amount, was 10 14 years (13 percent).

Mansehra district has a young population. Half of the total population (51 percent) was under the age of 20, with another 10 percent in the 20-24 year age group. The male population appears to be slightly less than the female population, resulting in a sex ratio of 97 males for every 100 females, which was recorded as 98 males per 100 females in the 1998 Population Census (Population Census Organization 2000).

Table 2.2: Percentage distribution of household population, by age and sex

\begin{tabular}{lrrrrrr} 
& \multicolumn{2}{c}{ Male } & \multicolumn{2}{c}{ Female } & \multicolumn{3}{c}{ Total } \\
& $N$ & $\%$ & $N$ & $\%$ & $N$ & $\%$ \\
\cline { 2 - 8 }$<5$ & 622 & 12.7 & 637 & 12.5 & 1,259 & 12.6 \\
\hline $5-9$ & 596 & 12.2 & 650 & 12.8 & 1,246 & 12.5 \\
\hline $10-14$ & 676 & 13.8 & 610 & 12.0 & 1,286 & 12.9 \\
\hline $15-19$ & 607 & 12.4 & 652 & 12.8 & 1,259 & 12.6 \\
\hline $20-24$ & 457 & 9.3 & 533 & 10.5 & 990 & 9.9 \\
\hline $25-29$ & 384 & 7.8 & 438 & 8.6 & 822 & 8.2 \\
\hline $30-34$ & 255 & 5.2 & 292 & 5.8 & 547 & 5.5 \\
\hline $35-39$ & 221 & 4.5 & 277 & 5.5 & 498 & 5.0 \\
\hline $40-44$ & 188 & 3.8 & 192 & 3.8 & 380 & 3.8 \\
\hline $45-49$ & 145 & 3.0 & 126 & 2.5 & 271 & 2.7 \\
\hline $50-54$ & 115 & 2.3 & 197 & 3.9 & 312 & 3.1 \\
\hline $55-59$ & 118 & 2.4 & 149 & 2.9 & 267 & 2.7 \\
\hline $60+$ & 516 & 10.6 & 324 & 6.4 & 840 & 8.5 \\
Total & 4,900 & 100.0 & 5,077 & 100.0 & 9,977 & 100.0
\end{tabular}

\section{Marital status}

The marital status of all household members above the age of 14 is given in Table 2.3. Overall, 42 percent of males had never been married compared to one-third of the females (32 percent). The percentage of married women under the age of 35 was 
considerably higher than the percentage of married men in the same age group (13 and under 2 percent, respectively), indicating that females tend to marry at an earlier age than males. Also, more women than men were widowed/divorced/separated at each age than men, largely because of higher mortality among husbands (who were usually older).

Table 2.3: Percentage of household population (ages 15 and over) according to age, sex and marital status

\begin{tabular}{lrrrrrr} 
& \multicolumn{2}{c}{ Male } & \multicolumn{3}{c}{ Female } \\
\cline { 3 - 7 } Age & $\begin{array}{r}\text { Never } \\
\text { married }\end{array}$ & $\begin{array}{r}\text { Currently } \\
\text { married }\end{array}$ & $\begin{array}{r}\text { Widowed/ } \\
\text { divorced/ } \\
\text { separated }\end{array}$ & $\begin{array}{r}\text { Never } \\
\text { married }\end{array}$ & $\begin{array}{r}\text { Currently } \\
\text { married }\end{array}$ & $\begin{array}{r}\text { divorced/ } \\
\text { separated }\end{array}$ \\
\hline $20-24$ & 98.5 & 1.5 & 0.0 & 86.7 & 13.3 & 0.0 \\
\hline $25-29$ & 84.3 & 15.7 & 0.0 & 52.8 & 45.5 & 1.7 \\
\hline $30-34$ & 51.6 & 47.6 & 0.8 & 24.1 & 73.6 & 2.3 \\
\hline $35-39$ & 19.7 & 77.6 & 2.8 & 9.3 & 88.7 & 2.1 \\
\hline $40-44$ & 9.1 & 86.8 & 4.1 & 4.7 & 90.6 & 4.7 \\
\hline $45-49$ & 2.1 & 97.3 & 0.5 & 3.1 & 89.5 & 7.3 \\
\hline $50-54$ & 1.4 & 95.2 & 3.4 & 1.6 & 87.3 & 11.1 \\
\hline $55-59$ & 1.8 & 94.7 & 3.5 & 1.5 & 82.1 & 16.3 \\
\hline $60-64$ & 0.0 & 93.2 & 6.8 & 2.0 & 77.2 & 20.8 \\
\hline $65+$ & 0.6 & 88.5 & 10.9 & 1.9 & 66.4 & 31.8 \\
\hline Total & 0.6 & 78.6 & 20.9 & 1.4 & 44.3 & 54.3 \\
\hline
\end{tabular}

Figure 2.1 shows the distribution of the household population 15 years of age and over by sex and marital status, where marital status is classified as 'never married,' 'currently married,' and 'widowed/divorced/separated' (labeled as 'formerly married'). Forty-two percent of the males compared to 32 percent of the females were never married, whereas 4 percent of the males had a status of formerly married compared to 9 percent of females. 
Figure 2.1: Marital status of household population (ages 15 years and over), by sex
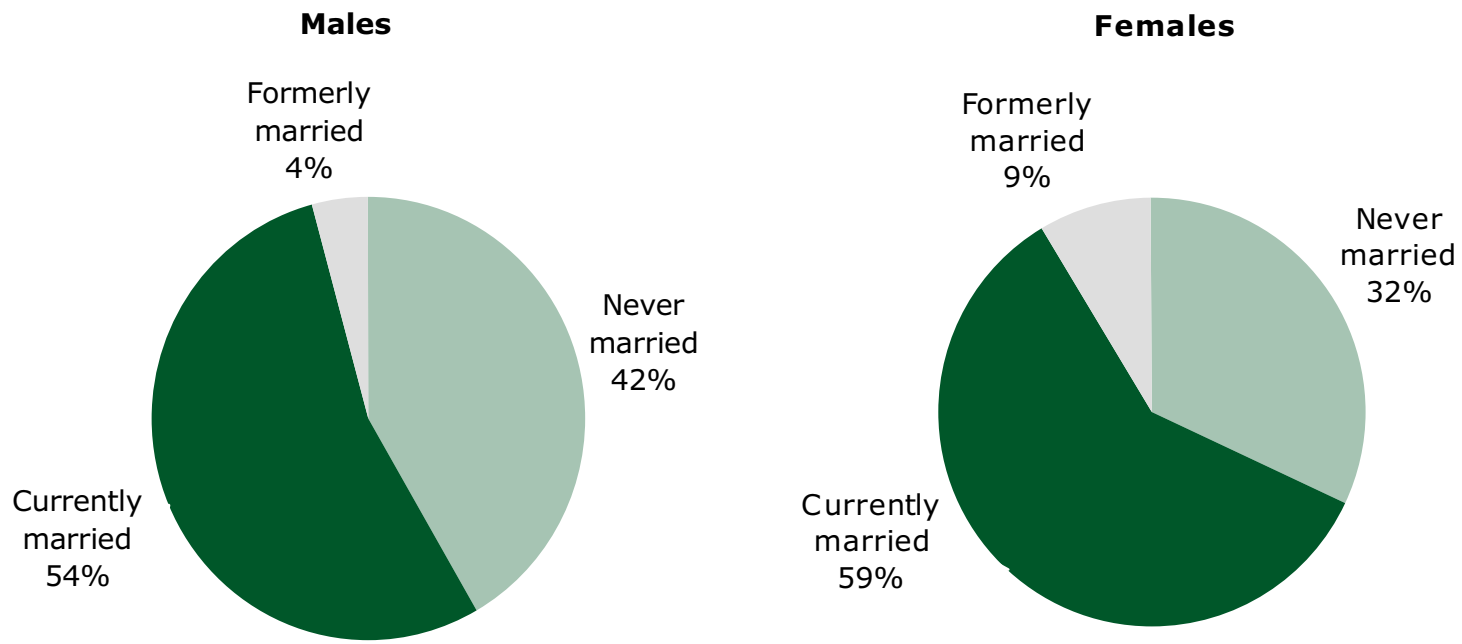

\section{Education}

Since education is the most important indicator for social development, a question on the educational level of all individuals aged five years and older was included (see Table 2.4). The level of education attained by the females in Mansehra district was consistently lower than the level of education attained by the males in each age group, except for 1-5 years of schooling where females had a higher rate of education.

Table 2.4: Household population ages 5 years and above according to sex, age and schooling

\begin{tabular}{lrrrrr} 
& \multicolumn{5}{c}{ Years of schooling } \\
Sex and age & No schooling & $1-5$ years & $6-10$ years & $11+$ years & Total \\
\cline { 2 - 6 } Male & $\%$ & $\%$ & $\%$ & $\%$ & $N$ \\
\hline $5-9$ & & & & & \\
\hline $10-14$ & 69.0 & 31.0 & 0.0 & 0.0 & 583 \\
\hline $15-19$ & 9.7 & 70.8 & 19.5 & 0.0 & 671 \\
\hline $20-24$ & 7.3 & 22.9 & 62.9 & 6.9 & 606 \\
\hline $25-29$ & 6.8 & 18.0 & 58.9 & 16.3 & 455 \\
\hline $30-34$ & 10.2 & 13.9 & 58.9 & 17.0 & 382 \\
\hline $35-39$ & 16.1 & 13.0 & 55.5 & 15.4 & 254 \\
\hline $40-44$ & 24.7 & 14.2 & 42.5 & 18.7 & 219 \\
\hline $45-49$ & 23.4 & 18.1 & 41.5 & 17.0 & 188 \\
\hline $50-54$ & 37.1 & 17.5 & 32.2 & 13.3 & 143 \\
\hline
\end{tabular}


Years of schooling

\begin{tabular}{|c|c|c|c|c|c|}
\hline Sex and age & No schooling & $1-5$ years & $6-10$ years & $11+$ years & Total \\
\hline & $\%$ & $\%$ & $\%$ & $\%$ & $N$ \\
\hline $55-59$ & 48.3 & 17.8 & 28.8 & 5.1 & 118 \\
\hline $60-64$ & 59.5 & 12.9 & 21.5 & 6.1 & 163 \\
\hline $65+$ & 64.6 & 16.2 & 16.5 & 2.6 & 345 \\
\hline Total & 28.1 & 27.5 & 36.2 & 8.3 & 4,241 \\
\hline \multicolumn{6}{|l|}{ Females } \\
\hline $5-9$ & 66.4 & 33.6 & 0.0 & 0.0 & 633 \\
\hline $10-14$ & 20.2 & 63.7 & 16.1 & 0.0 & 609 \\
\hline $15-19$ & 28.9 & 29.4 & 37.1 & 4.6 & 650 \\
\hline $20-24$ & 35.9 & 24.1 & 26.5 & 13.5 & 532 \\
\hline $25-29$ & 44.0 & 21.3 & 22.2 & 12.4 & 436 \\
\hline $30-34$ & 58.4 & 19.6 & 15.5 & 6.5 & 291 \\
\hline $35-39$ & 71.5 & 15.5 & 10.5 & 2.5 & 277 \\
\hline $40-44$ & 72.6 & 17.4 & 7.9 & 2.1 & 190 \\
\hline $45-49$ & 80.0 & 12.8 & 5.6 & 1.6 & 125 \\
\hline $50-54$ & 84.1 & 13.3 & 2.1 & 0.5 & 195 \\
\hline $55-59$ & 91.7 & 4.2 & 2.8 & 1.4 & 144 \\
\hline $60-64$ & 88.6 & 8.6 & 2.9 & 0.0 & 105 \\
\hline $65+$ & 95.7 & 2.9 & 1.4 & 0.0 & 209 \\
\hline Total & 52.5 & 27.5 & 15.6 & 4.3 & 4,396 \\
\hline
\end{tabular}

Overall in Mansehra district, just over a quarter of the males, as compared to about half of the females, had never been to school ( 28 and 53 percent, respectively), whereas, quite interestingly, more than one-fourth of both males and females had attained primary-level education (28 percent each). However, for higher levels of schooling, males took the lead compared to females: 36 percent of males had 6 or more years of schooling compared to only 16 percent of females. Only 8 percent of males and 4 percent of females had 11 or more years of schooling.

Figure 2.2 gives a pictorial presentation of the educational attainment of all males and females ages 5 years of age and older in Mansehra district. 
Figure 2.2: Years of schooling for males and females ages 5 years and over (percent)

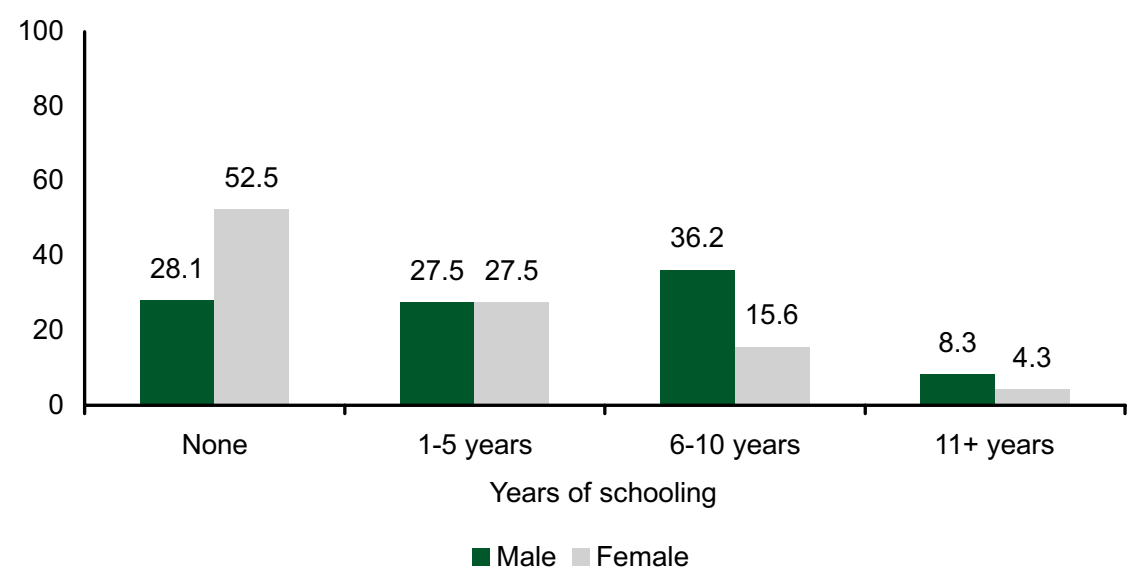

\section{Household Living Conditions}

\section{Drinking Water}

In order to obtain a clear understanding of the living conditions and level of hygiene of the households, it was necessary to record the source of drinking water available to respondents and their families. Also, to create a clearer picture of the level of awareness of water purification, information was gathered from households on both their main source of water, and what method they used to make the water suitable for drinking.

Looking at the three tehsils individually, the most common source of drinking water in both Balakot and Oghi was spring water (43 and 30 percent, respectively) followed by tap water inside the house (34 and 29 percent, respectively). In Mansehra, the most common source was tap water inside the house (34 percent) followed by indoor and outdoor wells combined (30 percent). 
Table 2.5: Sources of drinking water, by tehsil and district

\begin{tabular}{lrrrrrrrr} 
& \multicolumn{9}{c}{ Tehsil } \\
& \multicolumn{1}{c}{ Balakot } & \multicolumn{1}{c}{ Oghi } & Mansehra & \multicolumn{2}{c}{ Total } \\
\cline { 2 - 9 } Source & $N$ & $\%$ & $N$ & $\%$ & $N$ & $\%$ & $N$ & $\%$ \\
$\begin{array}{l}\text { Govt. supply (tap } \\
\text { water inside) }\end{array}$ & 108 & 33.6 & 86 & 28.7 & 284 & 33.9 & 478 & 32.8 \\
\hline $\begin{array}{l}\text { Govt. supply } \\
\text { (communal) }\end{array}$ & 20 & 6.2 & 19 & 6.3 & 58 & 6.9 & 97 & 6.7 \\
\hline $\begin{array}{l}\text { Motorized/hand } \\
\text { pump (inside) }\end{array}$ & 2 & 0.6 & 9 & 3.0 & 65 & 7.8 & 76 & 5.2 \\
\hline $\begin{array}{l}\text { Motorized/hand } \\
\text { pump (outside) }\end{array}$ & 5 & 1.6 & 11 & 3.7 & 46 & 5.5 & 62 & 4.3 \\
\hline Well (inside) & 2 & 0.6 & 18 & 6.0 & 106 & 12.7 & 126 & 8.6 \\
\hline Well (outside) & 18 & 5.6 & 52 & 17.3 & 143 & 17.1 & 213 & 14.6 \\
\hline River/canal/stream & 15 & 4.7 & 8 & 2.7 & 18 & 2.2 & 41 & 2.8 \\
\hline Pooled/pond water & 4 & 1.2 & 1 & 0.3 & 20 & 2.4 & 25 & 1.7 \\
\hline Springs & 137 & 42.7 & 90 & 30.0 & 79 & 9.4 & 306 & 21.0 \\
\hline Other & 10 & 3.1 & 6 & 2.0 & 18 & 2.2 & 34 & 2.3 \\
\hline Total & 321 & 100.0 & 300 & 100.0 & 837 & 100.0 & 1,458 & 100.0
\end{tabular}

Figure 2.3 shows the sources of drinking water for the district as a whole, indicating tap water, spring water and indoor/out door wells as the main sources.

Figure 2.3: Sources of drinking water for Mansehra district

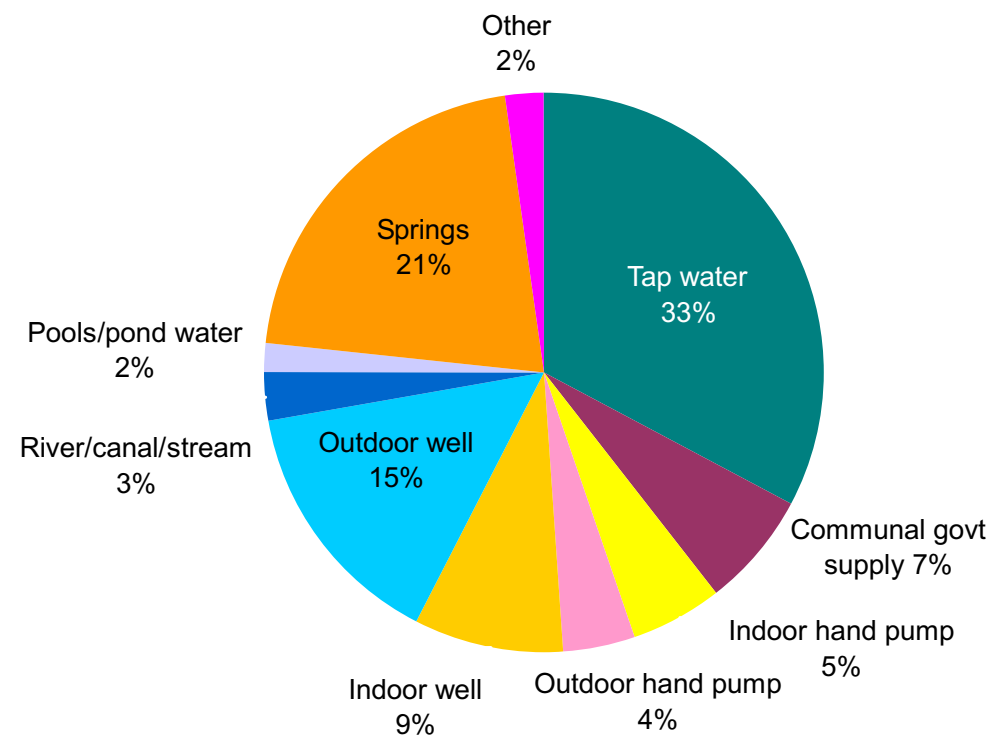




\section{Time to get water}

Household women were asked to indicate how much time it took them to get drinking water. Only half of the households had drinking water facilities available within their premises; it was necessary for the rest to travel some distance to get water. Table 2.6 shows the time taken to get to water (in minutes).

Table 2.6: Time taken to get water, by tehsil and district

\begin{tabular}{lrrrrrrrr} 
& \multicolumn{9}{c}{ Tehsil } \\
\cline { 2 - 8 } Minutes & \multicolumn{1}{c}{ Balakot } & \multicolumn{2}{c}{ Oghi } & \multicolumn{2}{c}{ Mansehra } & \multicolumn{2}{c}{ Total } \\
\cline { 2 - 9 } 0 (on premises) & $N$ & $\%$ & $N$ & $\%$ & $N$ & $\%$ & $N$ & $\%$ \\
\hline $0-10$ & 152 & 47.1 & 113 & 38.3 & 494 & 59.3 & 759 & 52.3 \\
\hline $11-30$ & 30 & 9.3 & 31 & 10.5 & 78 & 9.4 & 139 & 9.6 \\
\hline $31-60$ & 76 & 23.5 & 82 & 27.8 & 151 & 18.1 & 309 & 21.3 \\
\hline $60+$ & 39 & 12.1 & 52 & 17.6 & 76 & 9.1 & 167 & 11.5 \\
\hline Total & 26 & 8.0 & 17.0 & 5.8 & 34 & 4.1 & 77 & 5.3 \\
\hline & 323 & 100.0 & 295 & 100.0 & 833 & 100.0 & 1,451 & 100.0 \\
\hline
\end{tabular}

One out of every thirteen households (8 percent) in Balakot tehsil had to travel more than an hour to get to the source of drinking water, as compared to one out of every seventeen households (6 percent) in Oghi.

\section{Treatment of drinking water}

A question was also included in the questionnaire asking what methods, if any, were used by individual households to treat drinking water to make it safe (potable).

Responses are shown in Table 2.7. Nine out of ten households said they did not treat water before drinking. Of those who reported treating water, almost half reported that they made water safer to drink by just straining it through a cloth. More than one-third said they boiled it, although this number was higher in Oghi (46 percent). Thirteen percent of households in Balakot and 15 percent in Oghi said they let the water stand and settle. 
Table 2.7: Treatment of drinking water to make it safer, by tehsil

\begin{tabular}{lllllllll} 
& \multicolumn{9}{c}{ Tehsil } & & \multicolumn{2}{c}{} \\
Response & Balakot & Oghi & & Mansehra & \multicolumn{2}{c}{ Total } \\
\hline & $N$ & $\%$ & $N$ & $\%$ & $N$ & $\%$ & $N$ & $\%$ \\
\hline
\end{tabular}

Drinking water is treated to make it safer

\begin{tabular}{lrrrrrrrr}
\hline Yes & 39 & 12.1 & 13 & 4.3 & 104 & 12.4 & 156 & 10.7 \\
\hline No & 284 & 87.9 & 287 & 95.7 & 735 & 87.6 & 1,306 & 89.3 \\
\hline Total & 323 & 100.0 & 300 & 100.0 & 839 & 100.0 & 1,462 & 100.0 \\
\hline
\end{tabular}

Ways of making water safer to drink

\begin{tabular}{lrrrrrrrr}
\hline Boil & 15 & 38.5 & 6 & 46.2 & 41 & 39.4 & 62 & 39.7 \\
\hline Add bleach/chlorine & 2 & 5.1 & 1 & 7.7 & 5 & 4.8 & 8 & 5.1 \\
\hline Strain through cloth & 21 & 53.8 & 5 & 38.5 & 54 & 51.9 & 80 & 51.3 \\
\hline Use water filter & 1 & 2.6 & 1 & 7.7 & 6 & 5.8 & 8 & 5.1 \\
\hline Let it stand and settle & 5 & 12.8 & 2 & 15.4 & 3 & 2.9 & 10 & 6.4 \\
\hline Other & 1 & 2.6 & 0 & 0.0 & 3 & 2.9 & 4 & 2.6 \\
Total & 39 & na & 13 & na & 104 & na & 156 & na
\end{tabular}

na = Not applicable; respondents could give more than one response.

\section{Toilet Facilities}

Sanitation also affects the health of the household. The type of toilet facility a family has access to reflects their living condition, as well as the type of sanitary conditions prevalent in the household. This is important for children, especially newborns, and for pregnant mothers, as these groups are particularly vulnerable to diseases associated with unhygienic toilet facilities.

Overall, more than half of the households (54 percent) reported using flush systems connected to septic tanks, and more than one-third (37 percent) said that they used open fields as toilet facilities. The majority of people in Mansehra tehsil used flush systems connected to septic tanks, and only 27 percent said that they use open fields. In Oghi and Balakot, about half of the households did not have any toilet facility and used fields for this purpose (51 and 47 percent, respectively). 
Table 2.8: Type of toilet facility used by household members, by tehsil and district

\begin{tabular}{|c|c|c|c|c|c|c|c|c|}
\hline \multirow{3}{*}{ Toilet facility } & \multicolumn{6}{|c|}{ Tehsil } & & \\
\hline & \multicolumn{2}{|c|}{ Balakot } & \multicolumn{2}{|c|}{ Oghi } & \multicolumn{2}{|c|}{ Mansehra } & \multicolumn{2}{|c|}{ Total } \\
\hline & $N$ & $\%$ & $N$ & $\%$ & $N$ & $\%$ & $N$ & $\%$ \\
\hline Flush to sewerage & 0 & 0.0 & 0 & 0.0 & 38 & 4.6 & 38 & 2.6 \\
\hline $\begin{array}{l}\text { Flush connected to } \\
\text { septic tank }\end{array}$ & 149 & 46.3 & 140 & 46.8 & 488 & 58.7 & 777 & 53.5 \\
\hline $\begin{array}{l}\text { Flush connected to } \\
\text { open drain }\end{array}$ & 2 & 0.6 & 3 & 1.0 & 33 & 4.0 & 38 & 2.6 \\
\hline Raised latrine & 2 & 0.6 & 0 & 0.0 & 13 & 1.6 & 15 & 1.0 \\
\hline Pit latrine & 17 & 5.3 & 4 & 1.3 & 30 & 3.6 & 51 & 3.5 \\
\hline In fields & 152 & 47.2 & 152 & 50.8 & 227 & 27.3 & 531 & 36.6 \\
\hline Other & 0 & 0.0 & 0 & 0.0 & 2 & 0.2 & 2 & 0.1 \\
\hline Total & 322 & 100.0 & 299 & 100.0 & 831 & 100.0 & 1,452 & 100.0 \\
\hline
\end{tabular}

\section{Cooking Fuel}

The fuel used for cooking is also a socioeconomic and health indicator, as wood fires, especially indoor fires, are linked to health problems, most particularly to respiratory illnesses: "The fuel used for cooking affects the health of household members, specially the children, because the children are more likely to catch diseases more quickly than elders and children are more vulnerable to this environment" (Mahmood 2003).

Table 2.9 shows the fuel used for cooking. Eighty-five percent of the respondents reported that they used wood as their main fuel for cooking, although this was higher in Balakot and Oghi (about 94 percent for each) than in Mansehra (79 percent). Oneeighth (12 percent) of the houses in Mansehra tehsil used natural gas for cooking, compared to none in Balakot and Oghi where no natural gas connections were available yet. A very small percentage (under 5 percent in Balakot and Oghi and fewer than 8 percent in Mansehra) said they used gas cylinders for cooking. 
Table 2.9: Type of fuel used for cooking, by tehsil and district

\begin{tabular}{|c|c|c|c|c|c|c|c|c|}
\hline \multirow{3}{*}{ Fuel } & \multicolumn{6}{|c|}{ Tehsil } & & \\
\hline & \multicolumn{2}{|c|}{ Balakot } & \multicolumn{2}{|c|}{ Oghi } & \multicolumn{2}{|c|}{ Mansehra } & \multicolumn{2}{|c|}{ Total } \\
\hline & $N$ & $\%$ & $N$ & $\%$ & $N$ & $\%$ & $N$ & $\%$ \\
\hline Cylinder gas & 14 & 4.4 & 13 & 4.3 & 64 & 7.6 & 91 & 6.2 \\
\hline Natural gas & 0 & 0.0 & 0 & 0.0 & 101 & 12.0 & 101 & 6.9 \\
\hline Wood & 304 & 94.7 & 282 & 94.3 & 660 & 78.7 & 1,246 & 85.4 \\
\hline Other & 3 & 0.9 & 4 & 1.3 & 14 & 1.7 & 21 & 1.4 \\
\hline Total & 321 & 100.0 & 299 & 100.0 & 839 & 100.0 & 1,459 & 100.0 \\
\hline
\end{tabular}

\section{Household Commodities}

Ownership of various household commodities is a significant indicator of socioeconomic status and of living conditions. It also provides valuable information on sources of information for households, for example, television, radio, and telephones. This information also helps maximize the efficiency and outreach of social services and public health campaigns. Since the areas concerned are predominantly rural, with many households depending on their own livestock, these were also included in the list of possessions.

When comparing all three tehsils (see Table 2.10), the households in Mansehra tehsil generally had more household commodities. Ninety-three percent of households in Mansehra had electricity, as compared to 72 percent in Balakot and just 60 percent in Oghi. While more households in Mansehra had televisions compared to the other tehsils (almost half, compared to around a quarter), 4 out of 10 households in all tehsils said they had radios. This seems to suggest that in Balakot and Oghi radio is the better source of communicating information about health as compared to Mansehra, where both televisions and radios could be used for the same purpose. Nearly two-thirds of the households (63 percent) in all three tehsils reported owning a telephone, whether land line or mobile.

About 10 percent of the respondents said that they had some form of transport (including bicycle, motorcycle, car, jeep, and tractor), with the proportion noticeably higher in Mansehra tehsil. Eight percent of households in Mansehra tehsil had personal computers, with lower numbers in Balakot and Oghi ( 3 and 5 percent, respectively).

To illustrate the information in Table 2.10, Figure 2.4 depicts possession of important household goods by tehsil. 
Table 2.10: Ownership of household commodities / animals, by tehsil and district

\begin{tabular}{|c|c|c|c|c|c|c|c|c|}
\hline \multirow{3}{*}{ Commodity } & \multicolumn{6}{|c|}{ Tehsil } & & \\
\hline & \multicolumn{2}{|c|}{ Balakot } & \multicolumn{2}{|c|}{ Oghi } & \multicolumn{2}{|c|}{ Mansehra } & \multicolumn{2}{|c|}{ Total } \\
\hline & $N$ & $\%$ & $N$ & $\%$ & $N$ & $\%$ & $N$ & $\%$ \\
\hline Electricity & 233 & 72.1 & 181 & 60.3 & 784 & 93.4 & 1,198 & 81.9 \\
\hline Radio & 130 & 40.2 & 116 & 38.7 & 343 & 40.8 & 589 & 40.3 \\
\hline Television & 81 & 25.1 & 85 & 28.3 & 405 & 48.2 & 571 & 39.0 \\
\hline Refrigerator & 60 & 18.6 & 56 & 18.7 & 274 & 32.6 & 390 & 26.7 \\
\hline $\begin{array}{l}\text { Mobile/land } \\
\text { telephone }\end{array}$ & 206 & 63.8 & 173 & 57.7 & 547 & 65.1 & 926 & 63.3 \\
\hline $\begin{array}{l}\text { Room cooler/ air } \\
\text { conditioner }\end{array}$ & 7 & 2.2 & 7 & 2.3 & 22 & 2.6 & 36 & 2.5 \\
\hline Washing machine & 94 & 29.1 & 82 & 27.3 & 483 & 57.5 & 659 & 45.0 \\
\hline Water pump & 6 & 1.9 & 20 & 6.7 & 116 & 13.8 & 142 & 9.7 \\
\hline Bicycle & 3 & 0.9 & 1 & 0.3 & 25 & 3.0 & 29 & 2.0 \\
\hline Motorcycle & 3 & 0.9 & 3 & 1.0 & 18 & 2.1 & 24 & 1.6 \\
\hline Jeep/car & 11 & 3.4 & 12 & 4.0 & 43 & 5.1 & 66 & 4.5 \\
\hline Tractor & 3 & 0.9 & 6 & 2.0 & 27 & 3.2 & 36 & 2.5 \\
\hline Bed & 134 & 41.5 & 157 & 52.3 & 571 & 68.1 & 862 & 59.0 \\
\hline Chairs & 145 & 44.9 & 177 & 59.0 & 591 & 70.4 & 913 & 62.4 \\
\hline Almirah/ cabinet & 77 & 23.8 & 110 & 36.8 & 392 & 46.7 & 579 & 39.6 \\
\hline Clock & 152 & 47.1 & 200 & 66.7 & 662 & 78.8 & 1,014 & 69.3 \\
\hline Sofa & 72 & 22.3 & 69 & 23.0 & 349 & 41.5 & 490 & 33.5 \\
\hline Sewing machine & 92 & 28.5 & 150 & 50.0 & 461 & 54.9 & 703 & 48.1 \\
\hline Camera & 16 & 5.0 & 25 & 8.3 & 75 & 8.9 & 116 & 7.9 \\
\hline Personal computer & 11 & 3.4 & 15 & 5.0 & 68 & 8.1 & 94 & 6.4 \\
\hline $\begin{array}{l}\text { Camel and/or } \\
\text { horse }\end{array}$ & 11 & 3.4 & 1 & 0.3 & 7 & 0.8 & 19 & 1.3 \\
\hline Oxen & 43 & 13.4 & 37 & 12.4 & 28 & 3.3 & 108 & 7.4 \\
\hline Buffalo and/or cow & 141 & 43.7 & 152 & 50.7 & 211 & 25.1 & 504 & 34.5 \\
\hline Goat and/or sheep & 140 & 43.3 & 133 & 44.3 & 203 & 24.2 & 476 & 32.5 \\
\hline $\begin{array}{l}\text { Donkey and/or } \\
\text { mule }\end{array}$ & 19 & 5.9 & 27 & 9.1 & 62 & 7.4 & 108 & 7.4 \\
\hline $\begin{array}{l}\text { Chicken and/or } \\
\text { duck }\end{array}$ & 162 & 50.2 & 181 & 60.3 & 341 & 40.6 & 684 & 46.8 \\
\hline
\end{tabular}


Figure 2.4: Ownership of selected household goods, by tehsil (percent)

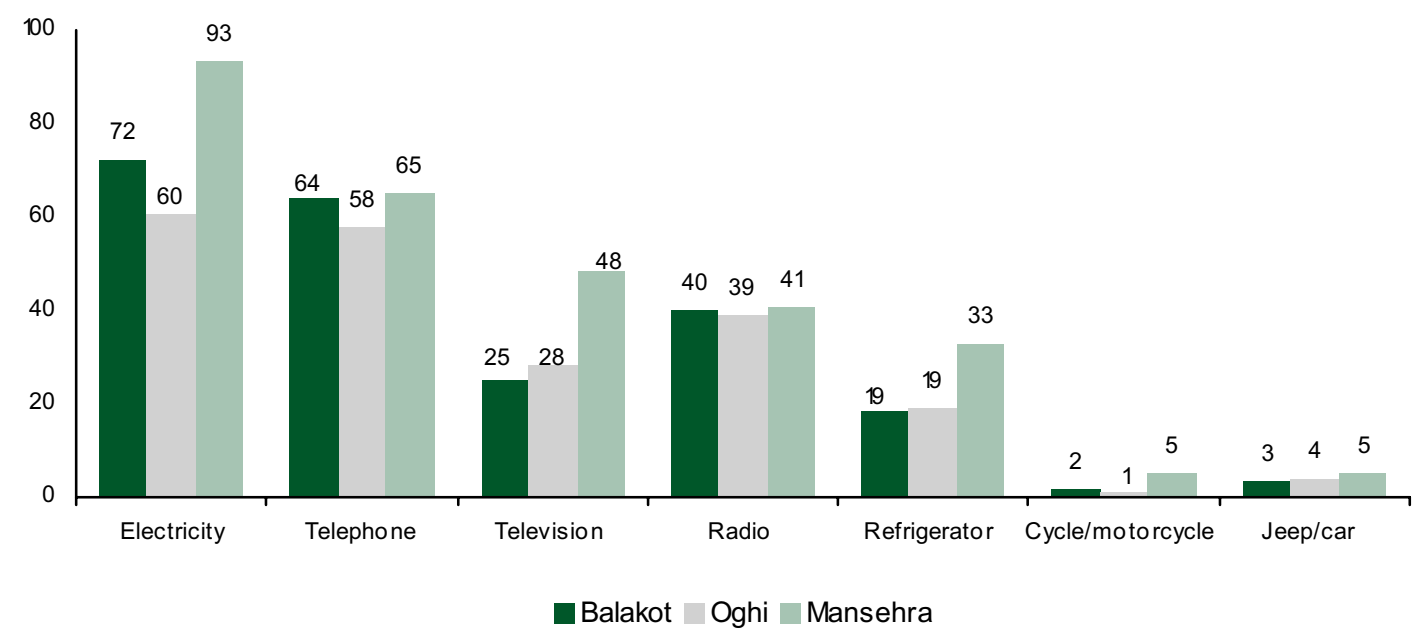

The livestock possessed by a household affects its susceptibility to disease through the transmission of infectious agents to children and mothers. Figure 2.5 gives a comparison of livestock possession by households in the three tehsils. It shows that more households in Balakot and Oghi tended to have livestock than in Mansehra. Chicken/duck, buffalo/cow and goat/sheep are the main livestock in this district.

Figure 2.5: Ownership of livestock, by tehsil (percent)

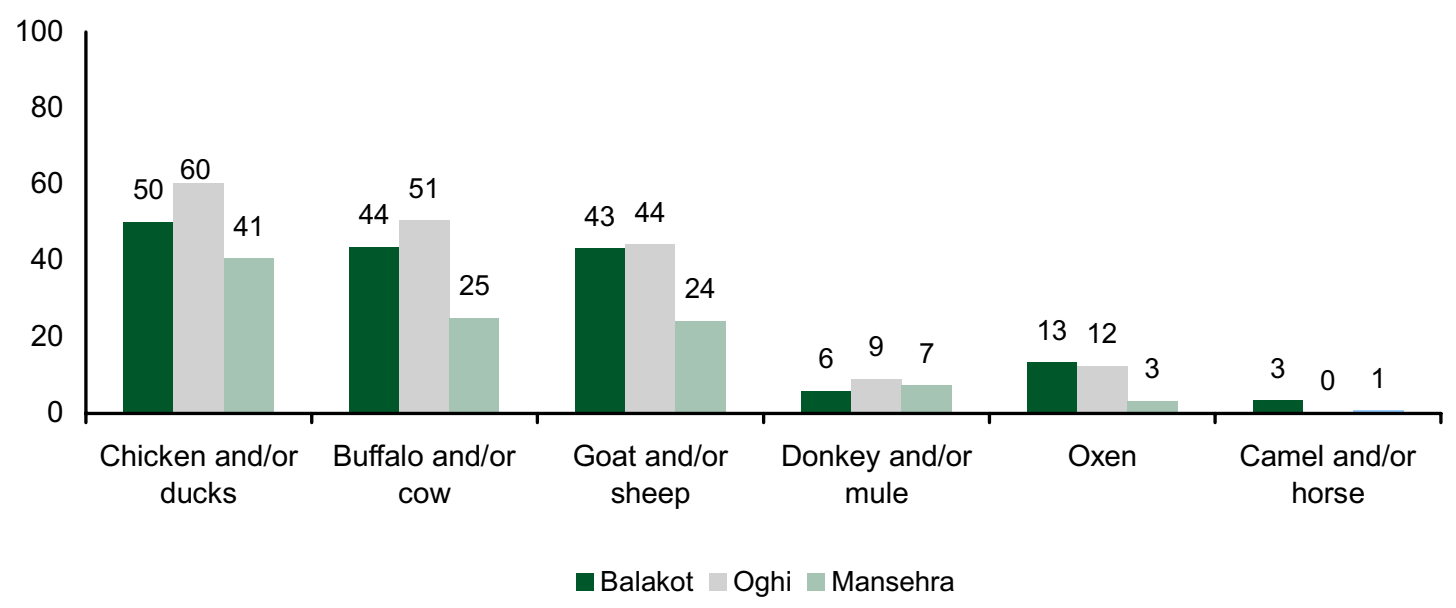




\section{lodine Deficiency}

In areas where there is little iodine in the diet, typically remote inland areas, iodine deficiency gives rise to goiters and cretinism, which results in developmental delays and other health problems. Table salt mixed with a minute amount of sodium/potassium iodide is used to help reduce the chance of iodine deficiency in humans.

Iodine deficiency is a serious problem in Pakistan: "Around 50 million people across the country suffer from it. In many parts of the NWFP, where rain and rivers wash iodine and other minerals out of the soil, up to 90 percent of people are said to suffer from some level of iodine deficiency" (IRIN 2007).

During the PRIDE KPC survey, information was collected from the households on the type of salt they used, and about household awareness of iodine deficiency and its manifestations.

\section{Use of iodized salt}

Table 2.11 shows that overall almost an equal proportion of households reported using iodized salt and powder or rock salt without iodine (50 percent each), although the use of iodized salt was highest in Mansehra (58 percent), followed by Oghi (49 percent). Just under one-third (31 percent) of the households in Balakot used iodized salt.

\section{PRIDE INDICATOR:}

Households where iodized salt was used in cooking: 49.8 percent.

Table 2.11: Type of salt usually used, by tehsil and district

\begin{tabular}{|c|c|c|c|c|c|c|c|c|}
\hline \multirow{3}{*}{ Type of salt } & \multicolumn{6}{|c|}{ Tehsil } & \multirow{2}{*}{\multicolumn{2}{|c|}{ Total }} \\
\hline & Bal & & $\mathrm{O}$ & & Man & & & \\
\hline & $N$ & $\%$ & $N$ & $\%$ & $N$ & $\%$ & $N$ & $\%$ \\
\hline $\begin{array}{l}\text { Powder salt } \\
\text { (without iodine) }\end{array}$ & 197 & 61.0 & 149 & 49.8 & 329 & 39.3 & 675 & 46.2 \\
\hline $\begin{array}{l}\text { Powder salt (with } \\
\text { iodine) }\end{array}$ & 99 & 30.7 & 145 & 48.5 & 483 & 57.6 & 727 & 49.8 \\
\hline Rock salt & 27 & 8.4 & 5 & 1.7 & 26 & 3.1 & 58 & 4.0 \\
\hline Total & 323 & 100.0 & 299 & 100.0 & 838 & 100.0 & 1,460 & 100.0 \\
\hline
\end{tabular}

\section{Awareness and knowledge}

Those who were not using iodized salt were then asked if they had heard about it (see Figure 2.6). Among the non-users, awareness was higher in Mansehra, where 
half the households said they had heard of iodized salt, compared to Balakot and Oghi, where only 38 and 32 percent, respectively, had heard about it.

Figure 2.6: Awareness of iodized salt among non-users, by tehsil (percent)

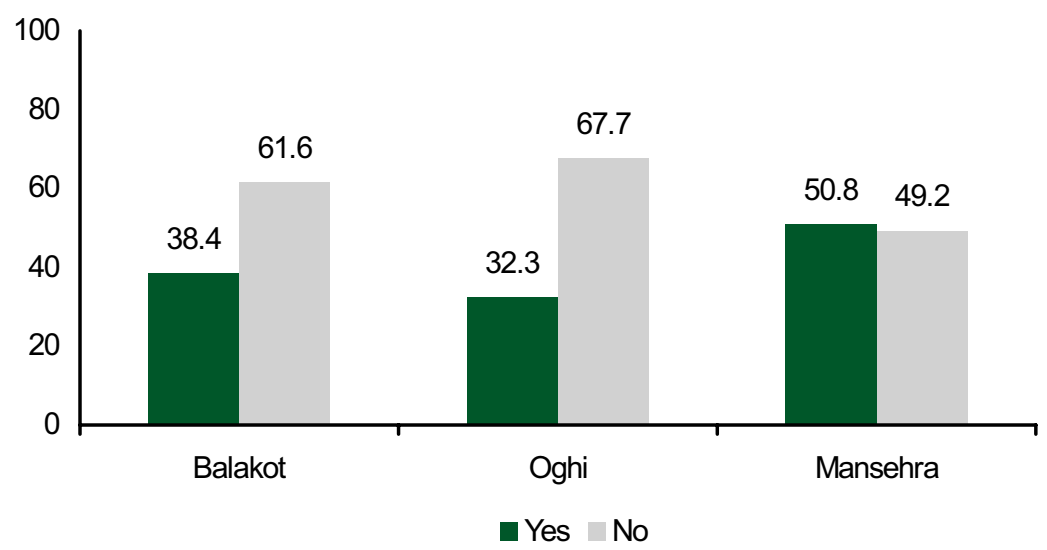

Those who reported not using iodized salt but who reported that they had heard about it were asked about the source of their knowledge: the primary source of information was media (radio, television and newspapers) (61 percent), followed by neighbors and shopkeepers (22 percent each). Table 2.12 gives all sources.

Table 2.12: Source of knowledge about iodized salt, by tehsil and district

\begin{tabular}{lrrrrrrrr} 
& \multicolumn{9}{c}{ Tehsil } \\
\cline { 2 - 8 } Source & \multicolumn{2}{c}{ Balakot } & \multicolumn{2}{c}{ Oghi } & \multicolumn{2}{c}{ Mansehra } & \multicolumn{2}{c}{ Total } \\
\cline { 2 - 9 } Health worker/doctor & $N$ & $\%$ & $N$ & $\%$ & $N$ & $\%$ & $N$ & $\%$ \\
\hline Radio/TV/newspapers & 20 & 23.5 & 13 & 27.7 & 15 & 8.6 & 48 & 15.6 \\
\hline Neighbors & 43 & 50.6 & 26 & 55.3 & 117 & 66.9 & 186 & 60.6 \\
\hline Own child & 18 & 21.2 & 10 & 21.3 & 40 & 22.9 & 68 & 22.1 \\
\hline Shopkeeper & 4 & 4.7 & 3 & 6.4 & 10 & 5.7 & 17 & 5.5 \\
\hline Relatives & 18 & 21.2 & 11 & 23.4 & 39 & 22.3 & 68 & 22.1 \\
\hline From salt pack & 1 & 1.2 & 1 & 2.1 & 3 & 1.7 & 5 & 1.6 \\
\hline Other & 2 & 2.4 & 1 & 2.1 & 1 & 0.6 & 4 & 1.3 \\
\hline Total & 5 & 5.9 & 0 & 0.0 & 3 & 1.7 & 8 & 2.6 \\
\hline
\end{tabular}

na $=$ Not applicable; respondents could name more than one source.

Incomplete knowledge about the impact of iodine deficiency exists: "It is commonly believed that iodine deficiency shows itself only as goiter, but actually it can lead to slow mental development, retardation, and lethargy and reproductive problems, 
including miscarriages or stillbirths among women" (Zafar 2007). When asked about ill effects of iodine deficiency in the body, a majority of respondents named goiter (68 percent), less than a quarter named mental retardation (23 percent), and 12 percent named cretinism (see Figure 2.7). Differences were observed among the tehsils.

A number of respondents (29 percent) described a group of incorrect manifestations of iodine deficiency, such as, polio, calcium deficiency, low and/or high blood pressure, joint-related diseases, etc., indicating that people were not clearly aware of the ill effects of iodine deficiency. A very small number of women ( 2 percent) related the use of iodized salt to family planning; though certainly a small number, it indicates a misconception that iodized salt would reduce fertility.

Figure 2.7: Reported manifestations of iodine deficiency, by tehsil (percent)

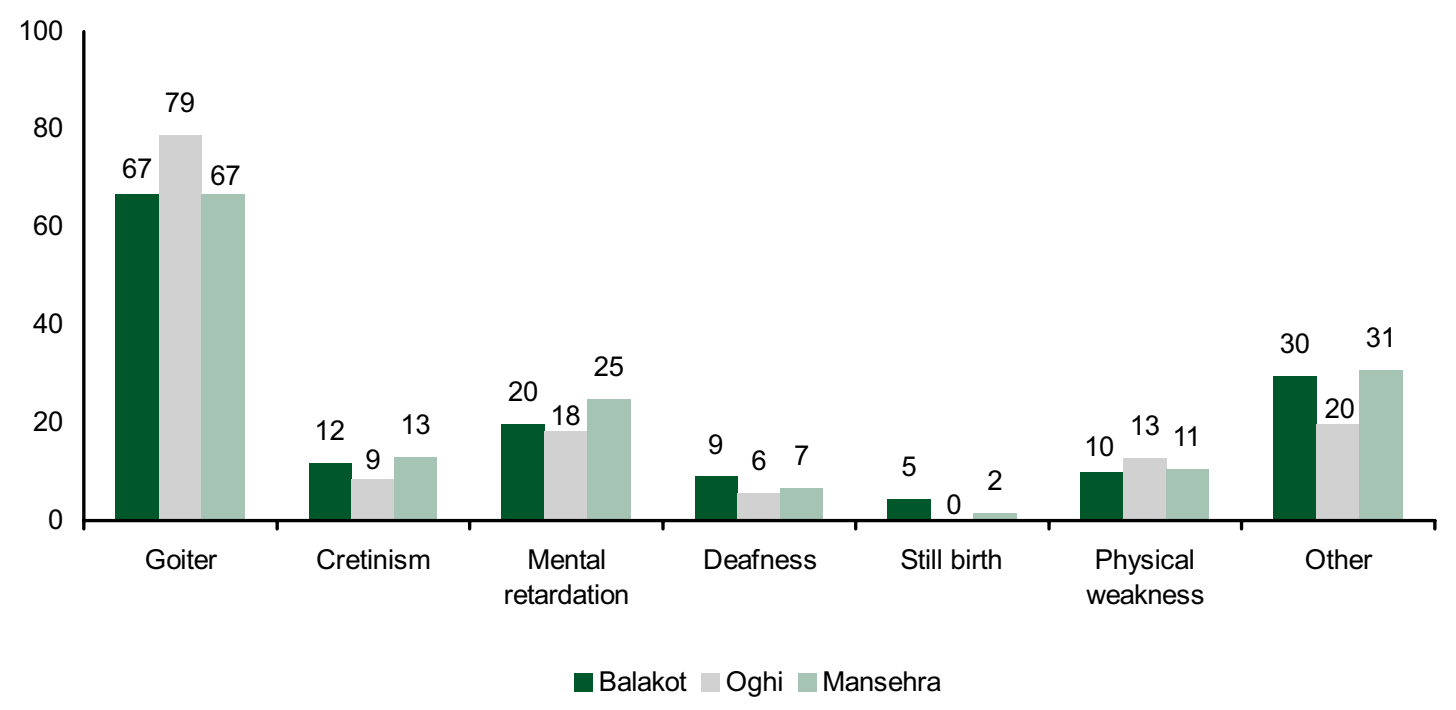

Responses as to correct knowledge and misconceptions about iodine deficiency are compared in Figure 2.8. About one-quarter (27 percent) of respondents in Oghi had incorrect perceptions about the ill effects of iodine deficiency; about one-third had misperceptions in Mansehra and Balakot tehsils (32 and 35 percent, respectively). 
Figure 2.8: Knowledge about ill effects of iodine deficiency, by tehsil (percent)

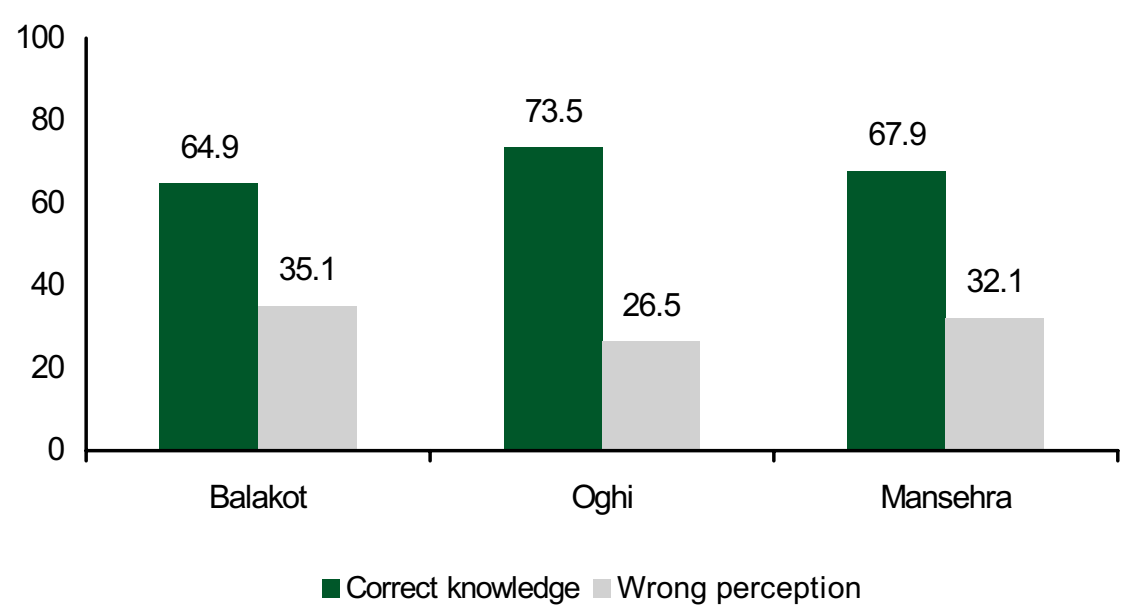

\section{Malaria}

Prevention of malaria may be more cost-effective than treatment of this disease. Therefore, households were asked whether they did anything to avoid mosquito bites, and, if so, what they did.

\section{Awareness and protection}

As shown in Figure 2.9, more than two-thirds (69 percent) of the households in Mansehra tehsil said they took measures to avoid mosquito bites; a third said they took no measures. Slightly lower percents of households took measures in Oghi and Balakot (63 and 61 percent, respectively). Among those who adopted precautionary measures, the most common methods were the use of fans (41 percent), coils (29 percent) and smoke from fires (26 percent) (see Table 2.13). 
Figure 2.9: Action taken or not taken to prevent mosquito bites, by tehsil (percent)

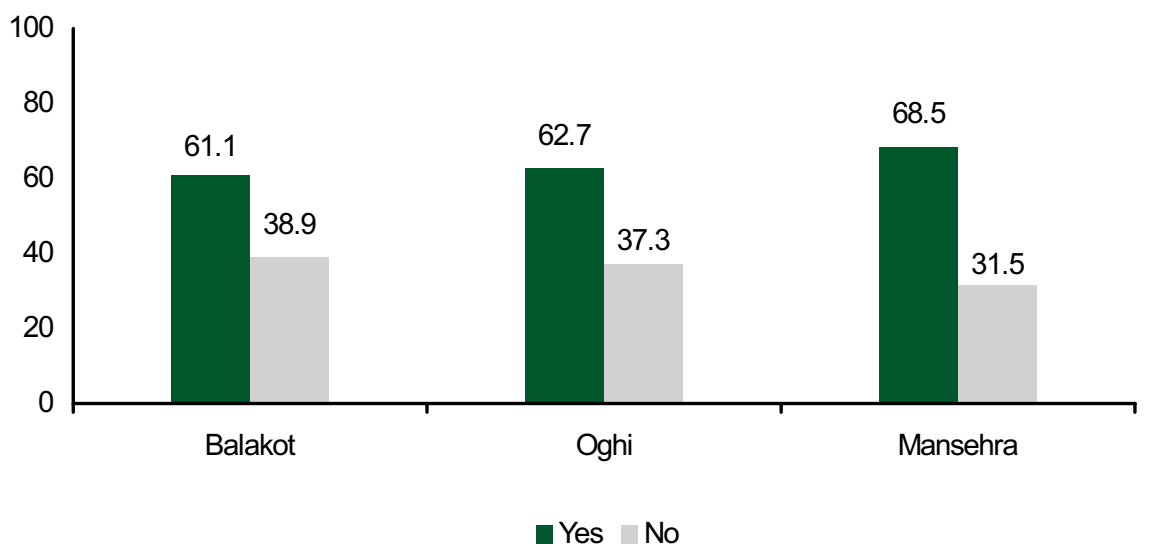

Table 2.13: Measures taken to avoid mosquito bites, by tehsil and district

\begin{tabular}{lrrrrrrrr} 
& \multicolumn{9}{c}{ Tehsil } \\
\cline { 3 - 8 } Measure & \multicolumn{2}{c}{ Balakot } & \multicolumn{2}{c}{ Oghi } & \multicolumn{2}{c}{ Mansehra } & \multicolumn{2}{c}{ Total } \\
\cline { 2 - 8 } Coil & $N$ & $\%$ & $N$ & $\%$ & $N$ & $\%$ & $N$ & $\%$ \\
\hline Mat & 43 & 21.8 & 35 & 18.8 & 200 & 34.7 & 278 & 29.0 \\
\hline Spray & 41 & 20.8 & 37 & 19.9 & 152 & 26.4 & 230 & 24.0 \\
\hline Lotion & 40 & 20.3 & 37 & 19.9 & 97 & 16.8 & 174 & 18.1 \\
\hline Oil & 7 & 3.6 & 1 & 0.5 & 8.0 & 1.4 & 16 & 1.7 \\
\hline Insect repellant & 4 & 2.0 & 3 & 1.6 & 6.0 & 1.0 & 13 & 1.4 \\
\hline Mosquito net & 2 & 1.0 & 3 & 1.6 & 5 & 0.9 & 10 & 1.0 \\
\hline Smoke by fire & 78 & 39.6 & 64 & 34.4 & 103 & 17.9 & 245 & 25.5 \\
\hline Fan & 76 & 38.6 & 67 & 36.0 & 245 & 42.5 & 388 & 40.5 \\
\hline Other & 2 & 1.0 & 1 & 0.5 & 7 & 1.2 & 10 & 1.0 \\
Total & 197 & na & 186 & na & 576 & na & 959 & na
\end{tabular}

na $=$ Not applicable; respondents could name more than one measure.

Mosquito nets help keep mosquitoes away from people, and thus greatly reduce the infection and transmission of malaria. This is particularly true in rural areas where the structure of the dwelling may not be compatible with the use of some measures. For families with low socioeconomic status, a net can also be used exclusively by a mother and newborn who are more vulnerable to malaria infections.

Only 2 percent of the households had mosquito nets; of the few that had nets, over 90 percent in Mansehra and Balakot tehsils indicated that no one slept under a mosquito net during the previous night. This indicates that ownership and use of mosquito nets 
in Mansehra district is negligible. Those who possess the mosquito nets are not in the habit of using them for protection against mosquito bites. Clearly, community health education is needed to promote better health practices. 



\section{Chapter 3}

\section{Characteristics of Married Women of Reproductive Age}

This chapter explores the background characteristics of 1,467 ever-married women of reproductive age (ages 15-49 years) who were interviewed as part of the KPC baseline survey. Table 3.1 shows the number of women interviewed by tehsil. Like the socioeconomic condition of the household, information on basic background characteristics of the respondents is essential for the interpretation of the results. For this purpose, questions about a woman's age, her age at marriage, mother tongue, education (for both husband and wife), and husband's occupation were included in the survey.

Table 3.1: Ever-married women of reproductive age interviewed for the KPC baseline survey, by tehsil and district

\begin{tabular}{lrr}
\multirow{2}{*}{ Tehsil } & Ever-married women of reproductive age \\
Balakot & Number & Percent \\
\hline Oghi & 297 & 20.2 \\
\hline Mansehra & 327 & 22.3 \\
\hline Total & 843 & 57.5 \\
\hline
\end{tabular}

\section{Demographic Characteristics}

\section{Age}

Table 3.2 gives an overview of the age distribution of the respondents. Of the 1,467 eligible women interviewed, a large proportion (57 percent) were ages 25-39 years; one-fifth were ages 25-29 years. A higher proportion of women (10 percent) in Oghi were ages 15-19 years compared to 4 percent in the same age group in Mansehra, indicating earlier marriages in Oghi. 
Table 3.2 also shows the age at marriage for the respondents by tehsil. Age at marriage is important because poor women who get married at an early age and also get pregnant have higher risk of infant mortality, as these mothers have inadequate access to maternal and child health services (Singh and Samara 1996). The overall teenage marriage rate for the district was 66 percent; however, there are differences among the tehsils. In Oghi, almost 4 out of every 5 women (78 percent) were married during their teen years, indicative of early marriages in this area. Females in Balakot and Mansehra were married slightly later: 2 out of every 3 (63 percent) were married during their teens. Slightly more than a quarter ( 27 percent) of the women were married during their early to mid-twenties (20-24 years). Overall, only a small proportion (7 percent) of the women were married after the age of 25.

Table 3.2: Age, age at marriage and mean age at marriage of eligible women, by tehsil and district

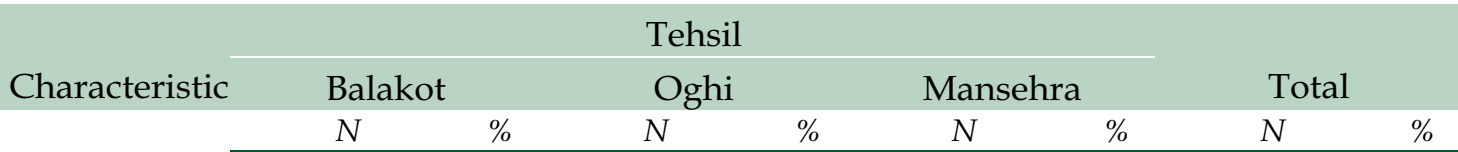

\begin{tabular}{lrrrrrrrr} 
Age & \multicolumn{1}{l}{ 15-19 } & 7.1 & 31 & 9.5 & 31 & 3.7 & 83 & 5.7 \\
\hline $20-24$ & 56 & 18.9 & 50 & 15.3 & 132 & 15.7 & 238 & 16.2 \\
\hline $25-29$ & 59 & 19.9 & 67 & 20.5 & 186 & 22.1 & 312 & 21.3 \\
\hline $30-34$ & 50 & 16.8 & 69 & 21.1 & 143 & 17.0 & 262 & 17.9 \\
\hline $35-39$ & 42 & 14.1 & 54 & 16.5 & 165 & 19.6 & 261 & 17.8 \\
\hline $40-44$ & 42 & 14.1 & 32 & 9.8 & 113 & 13.4 & 187 & 12.7 \\
\hline $45-49$ & 27 & 9.1 & 24 & 7.3 & 73 & 8.7 & 124 & 8.5 \\
Total & 297 & 100.0 & 327 & 100.0 & 843 & 100.0 & 1,467 & 100.0
\end{tabular}

Age at marriage

\begin{tabular}{lrrrrrrrr}
\hline$<15$ & 29 & 9.8 & 45 & 13.8 & 59 & 7.0 & 133 & 9.1 \\
\hline $15-19$ & 158 & 53.4 & 209 & 64.1 & 473 & 56.2 & 840 & 57.4 \\
\hline $20-24$ & 88 & 29.7 & 59 & 18.1 & 242 & 28.7 & 389 & 26.6 \\
\hline $25+$ & 21 & 7.1 & 13 & 4.0 & 68 & 8.1 & 102 & 7.0 \\
$\quad \begin{array}{l}\text { Total } \\
\begin{array}{l}\text { Mean age at } \\
\text { marriage }\end{array}\end{array}$ & 296 & 100.0 & 326 & 100.0 & 842 & 100.0 & 1,464 & 100.0 \\
\hline
\end{tabular}

Table 3.2 also shows the mean age at marriage by tehsil. The average age at marriage of women in Mansehra district was 18.5 years. In the three tehsils, the range was from 17.3 to 18.9 years, with Oghi being the lowest and Mansehra being the highest. Figure 3.1 shows the overall age at marriage for the eligible women in Mansehra district. 
Figure 3.1: Age at marriage (by age groups) of eligible women in Mansehra district

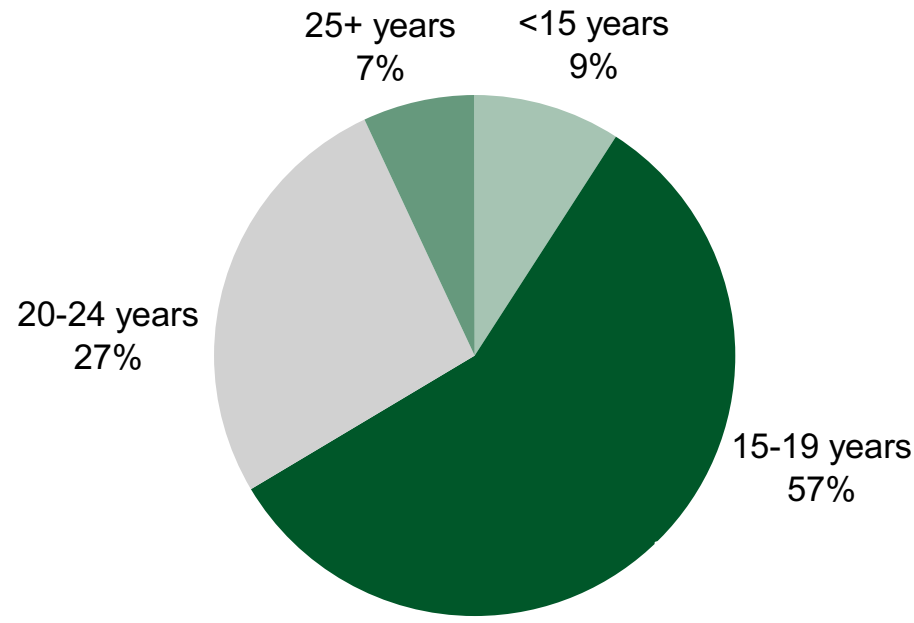

\section{Marital Status}

The married women of reproductive age who were interviewed were required to be either currently married or to have been married at some point in the past. As shown in Table 3.3, 96 percent of these women were currently married, 4 percent were widowed and less than 1 percent were divorced or separated. The same pattern can be seen in both Mansehra and Oghi tehsils. However, in Balakot the proportion of widows was higher (6 percent), which might be due to the vast number of deaths in Balakot during the October 2005 earthquake.

Table 3.3: Marital status of eligible women, by tehsil and district

\begin{tabular}{lrrrrrrrr} 
& \multicolumn{9}{c}{ Tehsil } \\
\cline { 2 - 10 } Marital status & \multicolumn{1}{c}{ Balakot } & \multicolumn{2}{c}{ Oghi } & \multicolumn{2}{c}{ Mansehra } & \multicolumn{2}{c}{ Total } \\
\cline { 2 - 10 } Married & $N$ & $\%$ & $N$ & $\%$ & $N$ & $\%$ & $N$ & $\%$ \\
\cline { 2 - 10 } Widowed & 276 & 92.9 & 314 & 96.0 & 814 & 96.6 & 1,404 & 95.7 \\
\hline Divorced & 19 & 6.4 & 10 & 3.1 & 24 & 2.8 & 53 & 3.6 \\
\hline Separated & 2 & 0.7 & 2 & 0.6 & 3 & 0.4 & 7 & 0.5 \\
Total & 0 & 0.0 & 1 & 0.3 & 2 & 0.2 & 3 & 0.2 \\
\hline & 297 & 100.0 & 327 & 100.0 & 843 & 100.0 & 1,467 & 100.0
\end{tabular}

\section{Education}

The level of education obtained by a woman is a good indicator of her status in society as well as her independent decision making power. "The higher level of education she has obtained, the better she is expected to be concerned about her 
health and that of her family" (Caldwell 1986). The women were asked about their own educational level and that of their husbands.

A vast disparity can be seen between tehsils in women's education (see Table 3.4). In Balakot, two-thirds (66 percent) of the women had never been to school and only 3 percent had more than secondary or higher levels of schooling. Education levels for these women were even lower in Oghi, where 4 out of every 5 women (80 percent) had never attended any school; 13 percent attended only up to the primary level and only 2 percent went up to college level. In Mansehra, where female education was better than in the other two tehsils, only half (51 percent) of the women had attended school; only one-quarter ( 26 percent) had completed at most primary level schooling. Less than 6 percent of the women had more than a secondary level of education.

Table 3.4: Education level of eligible women and their husbands, by tehsil and district

\begin{tabular}{lrrrrrrrr} 
& \multicolumn{9}{c}{ Tehsil } \\
Variable & Balakot & \multicolumn{2}{c}{ Oghi } & \multicolumn{2}{c}{ Mansehra } & \multicolumn{2}{c}{ Total } \\
& $N$ & $\%$ & $N$ & $\%$ & $N$ & $\%$ & $N$ & $\%$ \\
\hline Women & & & & & & & & \\
\hline No education & 197 & 66.3 & 260 & 79.5 & 430 & 51.0 & 887 & 60.5 \\
\hline Primary & 50 & 16.8 & 42 & 12.8 & 219 & 26.0 & 311 & 21.2 \\
\hline Middle & 17 & 5.7 & 9 & 2.8 & 66 & 7.8 & 92 & 6.3 \\
\hline Secondary & 23 & 7.7 & 9 & 2.8 & 82 & 9.7 & 114 & 7.8 \\
\hline Secondary + & 10 & 3.4 & 7 & 2.1 & 46 & 5.5 & 63 & 4.3 \\
\hline Total & 297 & 100.0 & 327 & 100.0 & 843 & 100.0 & 1,467 & 100.0 \\
\hline
\end{tabular}

Husbands

\begin{tabular}{lrrrrrrrr}
\hline No education & 73 & 24.6 & 94 & 29.0 & 193 & 22.9 & 360 & 24.6 \\
\hline Primary & 41 & 13.8 & 59 & 18.2 & 132 & 15.7 & 232 & 15.8 \\
\hline Middle & 55 & 18.5 & 59 & 18.2 & 151 & 17.9 & 265 & 18.1 \\
\hline Secondary & 100 & 33.7 & 78 & 24.1 & 228 & 27.0 & 406 & 27.7 \\
\hline Secondary + & 28 & 9.4 & 34 & 10.5 & 139 & 16.5 & 201 & 13.7 \\
Total & 297 & 100.0 & 324 & 100.0 & 843 & 100.0 & 1,464 & 100.0
\end{tabular}

A higher education level of husbands is also an indicator of better socioeconomic status of the family and can positively impact health matters. In terms of education of husbands, disparities among tehsils were visible. In Mansehra, 1 out of every 6 husbands (17 percent) had secondary plus education compared to Balakot and Oghi, where 9 and 10 percent, respectively, had this level of education. About one-quarter 
of the husbands in Balakot and Mansehra tehsils had no schooling compared to 29 percent in Oghi.

\section{Language}

The main language (mother tongue) of the women in Balakot was Hindko (72 percent) followed by Gojri (26 percent). Hindko was also the main language in Mansehra (73 percent) followed by Pashto (18 percent) and Gojri (7 percent). In Oghi, there was a more even split between Hindko (48 percent) and Pashto (47 percent), with 6 percent speaking Gojri. This information is presented in Figure 3.2 and Table 3.5 .

Figure 3.2: Mother tongue of eligible women in Mansehra district

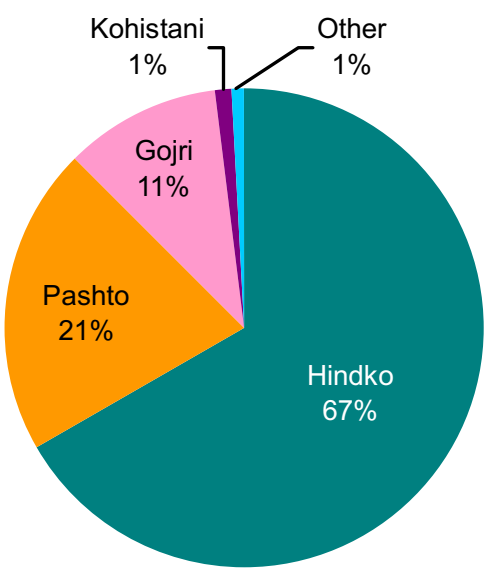

Table 3.5: Mother tongue of eligible women, by tehsil and district

\begin{tabular}{lrrrrrrrr} 
& \multicolumn{9}{c}{ Tehsil } \\
Mother tongue & \multicolumn{2}{c}{ Balakot } & \multicolumn{2}{c}{ Oghi } & \multicolumn{2}{c}{ Mansehra } & \multicolumn{2}{c}{ Total } \\
\cline { 2 - 10 } Hindko & $N$ & $\%$ & $N$ & $\%$ & $N$ & $\%$ & \multicolumn{1}{c}{$\%$} \\
\cline { 2 - 11 } & 213 & 71.7 & 156 & 47.7 & 609 & 72.5 & 978 & 66.8 \\
\hline Pashto & 1 & 0.3 & 152 & 46.5 & 148 & 17.6 & 301 & 20.6 \\
\hline Gojri & 78 & 26.3 & 18 & 5.5 & 59 & 7.0 & 155 & 10.6 \\
\hline Kohistani & 4 & 1.3 & 0 & 0.0 & 15 & 1.8 & 19 & 1.3 \\
\hline Other & 1 & 0.3 & 1 & 0.3 & 9 & 1.1 & 11 & 0.8 \\
Total & 297 & 100.0 & 327 & 100.0 & 840 & 100.0 & 1,464 & 100.0
\end{tabular}




\section{Number of Children}

Fertility trends can be seen from the number of children ever born and the age of the mother. Table 3.6 illustrates the number of children ever born to women in Mansehra district. Women at the end of the reproductive scale generally have more children. This was true in Mansehra, where 4 out of every 5 women who were ages 40-49 had more than 5 live births, and almost half of the women ages 45-49 had given birth to 7 or more children, indicating a high fertility rate among this cohort. One-tenth (10 percent) of the women ages 25-29 already had 5-6 live births. On the other hand, oneseventh (14 percent) of the women ages $25-29$, and almost twice as many women ages 20-24 (30 percent), were found not to have a single live birth as yet.

Table 3.6 also gives the comparison of mean number of children ever born and living to the women of different age groups. Overall, in Mansehra district the mean number of children ever born to a woman was 3.7, with 3.3 children surviving.

A comparison of the ever born and living status of children in the PRIDE KPC survey with 1998 Census data for Mansehra district (Population Census Organization 2000) indicates that mean number of children ever born has decreased from 4.4 to 3.7 children per woman.

Table 3.6: Age of eligible women according to number of children ever born, number of women, and comparison of PRIDE and 1998 Census data for mean number of children (ever born and living)

\begin{tabular}{|c|c|c|c|c|c|c|c|c|c|c|c|}
\hline \multirow[b]{3}{*}{ Age } & \multicolumn{5}{|c|}{ Number of children ever born } & \multirow{3}{*}{$\begin{array}{c}\text { Total } \\
(\%)\end{array}$} & \multirow{3}{*}{$\begin{array}{l}\text { Number } \\
\text { of } \\
\text { women }\end{array}$} & \multicolumn{4}{|c|}{ Mean number of children } \\
\hline & \multirow[b]{2}{*}{0} & \multirow[b]{2}{*}{$1-2$} & \multirow[b]{2}{*}{$3-4$} & \multirow[b]{2}{*}{$5-6$} & \multirow{2}{*}{$\begin{array}{l}7 \text { or } \\
\text { more }\end{array}$} & & & PRIDE ba & ne & $\begin{array}{l}1998 \mathrm{Ce} \\
\text { (Manse }\end{array}$ & $\begin{array}{l}\text { nsus } \\
\text { ara) }\end{array}$ \\
\hline & & & & & & & & Ever born & Living & Ever born & Living \\
\hline $15-19$ & 78.3 & 21.7 & 0.0 & 0.0 & 0.0 & 100.0 & 83 & 0.3 & 0.2 & 1.3 & 1.0 \\
\hline $20-24$ & 29.4 & 52.1 & 17.2 & 1.3 & 0.0 & 100.0 & 238 & 1.4 & 1.3 & 2.4 & 1.6 \\
\hline $25-29$ & 14.1 & 35.6 & 39.1 & 9.6 & 1.6 & 100.0 & 312 & 2.5 & 2.3 & 3.6 & 2.9 \\
\hline $30-34$ & 5.3 & 19.5 & 32.4 & 34.4 & 8.4 & 100.0 & 262 & 4.0 & 3.5 & 4.8 & 4.1 \\
\hline $35-39$ & 3.4 & 7.7 & 26.8 & 36.4 & 25.7 & 100.0 & 261 & 5.2 & 4.5 & 6.0 & 4.8 \\
\hline $40-44$ & 2.7 & 7.0 & 10.7 & 34.8 & 44.9 & 100.0 & 187 & 6.3 & 5.4 & 6.2 & 5.5 \\
\hline $45-49$ & 1.6 & 4.0 & 12.1 & 33.1 & 49.2 & 100.0 & 124 & 6.5 & 5.6 & 6.8 & 5.6 \\
\hline Total & 14.2 & 23.3 & 24.1 & 22.1 & 16.3 & 100.0 & 1,467 & 3.7 & 3.3 & 4.4 & 3.6 \\
\hline
\end{tabular}




\section{Occupation of Husbands}

Almost the same employment pattern of husbands was observed in all three tehsils of Mansehra district (see Table 3.7). A majority (42 percent) were involved in labor work ( 25 percent skilled; 17 percent unskilled). Almost 15 percent were in business. Twelve percent were employed on executive or non-executive levels, and 11 percent were associated with agriculture (land, livestock or poultry).

Among all three tehsils the unemployment rate was a little higher in Balakot, which could be due to the heavy destruction of the infrastructure in Balakot during the earthquake of October 2005.

Table 3.7: Occupation of eligible women's husbands, by tehsil and district

\begin{tabular}{|c|c|c|c|c|c|c|c|c|}
\hline \multirow{4}{*}{$\begin{array}{l}\text { Occupation } \\
\text { Agriculture/livestock/poultry }\end{array}$} & \multicolumn{6}{|c|}{ Tehsil } & & \\
\hline & \multicolumn{2}{|c|}{ Balakot } & \multicolumn{2}{|c|}{ Oghi } & \multicolumn{2}{|c|}{ Mansehra } & \multicolumn{2}{|c|}{ Total } \\
\hline & $N$ & $\%$ & $N$ & $\%$ & $N$ & $\%$ & $N$ & $\%$ \\
\hline & 30 & 10.1 & 36 & 11.0 & 55 & 6.5 & 121 & 8.2 \\
\hline Agriculture (other's land) & 4 & 1.3 & 4 & 1.2 & 30 & 3.6 & 38 & 2.6 \\
\hline Skilled labor & 78 & 26.3 & 79 & 24.2 & 210 & 24.9 & 367 & 25.0 \\
\hline Unskilled labor & 52 & 17.5 & 55 & 16.8 & 142 & 16.8 & 249 & 17.0 \\
\hline Employed non-executive level & 29 & 9.8 & 28 & 8.6 & 95 & 11.3 & 152 & 10.4 \\
\hline Employed executive level & 2 & 0.7 & 2 & 0.6 & 16 & 1.9 & 20 & 1.4 \\
\hline Professional & 11 & 3.7 & 11 & 3.4 & 38 & 4.5 & 60 & 4.1 \\
\hline In army & 7 & 2.4 & 18 & 5.5 & 20 & 2.4 & 45 & 3.1 \\
\hline Small scale business & 38 & 12.8 & 39 & 11.9 & 117 & 13.9 & 194 & 13.2 \\
\hline Large scale business & 4 & 1.3 & 4 & 1.2 & 12 & 1.4 & 20 & 1.4 \\
\hline Retired & 2 & 0.7 & 4 & 1.2 & 14 & 1.7 & 20 & 1.4 \\
\hline Abroad & 12 & 4.0 & 27 & 8.3 & 31 & 3.7 & 70 & 4.8 \\
\hline Unemployed & 25 & 8.4 & 19 & 5.8 & 58 & 6.9 & 102 & 7.0 \\
\hline Other & 3 & 1.0 & 1 & 0.3 & 5 & 0.6 & 9 & 0.6 \\
\hline Total & 297 & 100.0 & 327 & 100.0 & 843 & 100.0 & 1,467 & 100.0 \\
\hline
\end{tabular}





\section{Chapter 4}

\section{Contraceptive Knowledge and Use}

This chapter includes the responses of women about contraceptive knowledge and use. Married women ages 15-49 were asked to name the method(s) a couple can use to avoid or delay pregnancy. Findings in this chapter are given only for the 1,404 currently married women of reproductive age. For each method known, respondents were asked if they had ever used that method and, if so, if they were still using it. The current users were further asked about the source where they obtained their family planning method(s).

The contraceptive prevalence rate (CPR) is one of the main indicators of the PRIDE KPC baseline survey. A section of the questionnaire for women consisted of questions relating to women's knowledge and use of family planning methods.

\section{Knowledge of Methods}

Knowledge of contraceptives among currently married women in Mansehra district was universal. Figure 4.1 shows method-specific knowledge of contraceptives. More than 95 percent of women knew about pills and injectables as family planning methods. Knowledge of female sterilization was also high at 92 percent. More than three-fourths knew about IUDs and condoms. The least known methods were male sterilization and implants (about 27 percent each). Knowledge of traditional methods (withdrawal and rhythm) was not as high as that for most modern FP methods in Mansehra district. 
Figure 4.1: Currently married women's knowledge of specific contraceptive methods (percent)

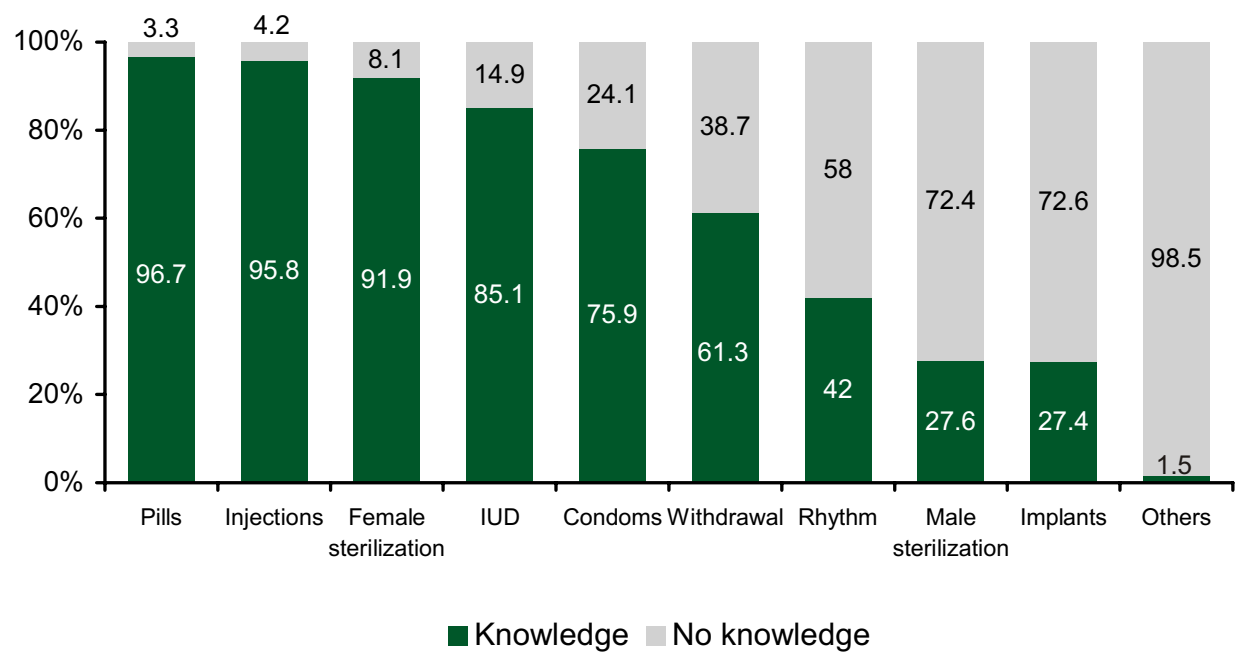

\section{Use of Methods}

\section{Ever Used}

Women who have ever used any contraceptive method, regardless of their current use status are considered ever users of contraceptive methods. KPC survey findings show that the total ever use of contraceptives in Mansehra district for the 1,404 currently married women of reproductive age was 58 percent.

Table 4.1 shows ever use of contraceptives by method used. In Balakot, the most common modern methods ever used were condoms (17 percent) followed by injectables and pills (14 and 11 percent, respectively). In Oghi, pills (24 percent) were most common, followed by injectables and condoms (21 and 20 percent, respectively); in Mansehra, injectables (30 percent), condoms and pills (28 and 25 percent, respectively) were the main ever-used modern FP methods. Among traditional methods ever used, withdrawal was relatively high in all tehsils ( 22 to 29 percent). 
Table 4.1: Contraceptive methods ever used by currently married women, by tehsil and district

\begin{tabular}{|c|c|c|c|c|c|}
\hline \multirow[b]{2}{*}{ Method } & \multicolumn{3}{|c|}{ Tehsil } & \multirow{2}{*}{\multicolumn{2}{|c|}{ Total }} \\
\hline & Balakot & Oghi & Mansehra & & \\
\hline & $\%$ & $\%$ & $\%$ & $\%$ & $N$ \\
\hline Female sterilization & 4.7 & 2.2 & 5.8 & 4.8 & 67 \\
\hline Pills & 10.9 & 23.6 & 24.8 & 21.7 & 304 \\
\hline IUD & 9.8 & 5.1 & 13.5 & 10.8 & 152 \\
\hline Injectables & 13.8 & 20.7 & 29.7 & 24.6 & 344 \\
\hline Condoms & 17.4 & 20.4 & 27.5 & 23.9 & 335 \\
\hline Rhythm & 17.5 & 10.2 & 19.2 & 16.8 & 236 \\
\hline Withdrawal & 25.1 & 21.5 & 28.9 & 26.4 & 370 \\
\hline Other & 1.1 & 0.0 & 0.6 & 0.6 & 8 \\
\hline Overall ever use & 48.9 & 47.5 & 64.9 & 57.8 & 812 \\
\hline$(\mathrm{N})$ & ( 276 ) & (314) & (814) & na & $(1,404)$ \\
\hline
\end{tabular}

na $=$ Not applicable; respondents could name more than one method.

Figure 4.2 shows the overall ever-use status of specific contraceptive methods used by currently married women in Mansehra district. Among the modern methods, the most ever-used method was injectables ( 25 percent) followed by condoms and pills (24 and 22 percent, respectively). Among the traditional methods, the most commonly ever-used method was withdrawal (27 percent), which was also the highest ever-used method among all methods.

Figure 4.2: Ever use of specific contraceptive methods by currently married women (percent)

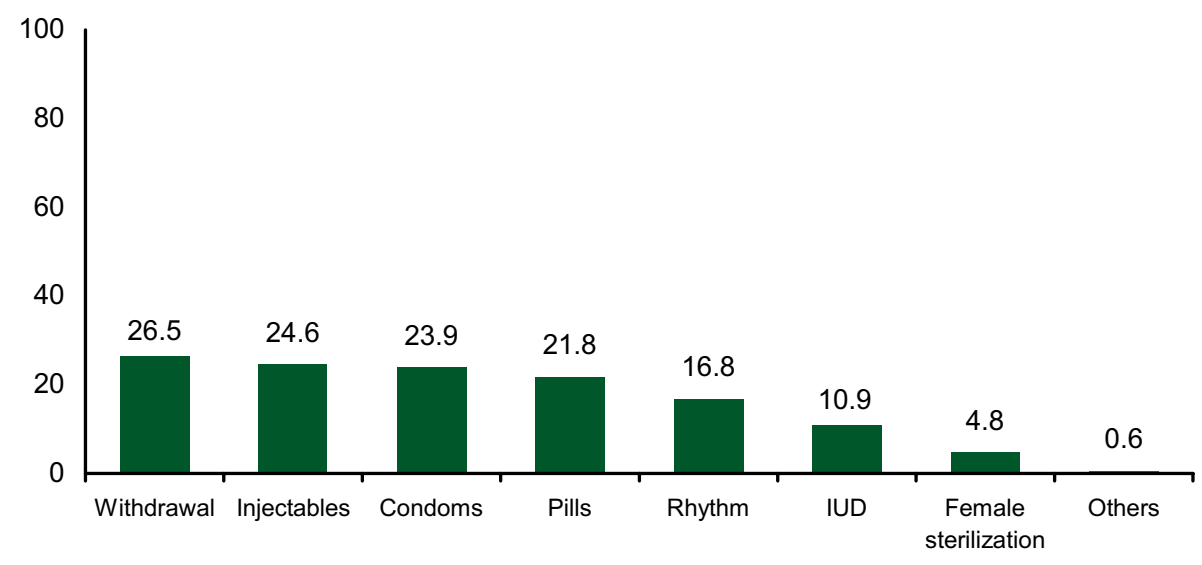




\section{Current Use}

Contraceptive prevalence is the proportion of currently married women aged 15-49 years using any method of family planning at the time of the survey. Table 4.2 shows the percentage distribution of married women currently using specific family planning methods. The overall CPR of the Mansehra district was 31 percent. This reflects that one out of every three women was currently using a family planning method. Differences were obvious among tehsils: the CPR of Oghi was lowest (21 percent), then Balakot (27 percent), and highest was Mansehra (35 percent).

Overall, modern methods of contraception seem to have been more popular than traditional ones ( 23 versus 7 percent). Among the modern methods, condoms (7 percent) and injectables (6 percent) were more common. Male sterilization and implants were not reported by a single woman --

\section{PRIDE INDICATOR:}

Contraceptive prevalence rate for modern methods among currently married women: 23.3 percent. this might be because these two methods were not available in the district.

Interestingly, condom was the most widely used family planning method in Balakot; use was even higher than Mansehra tehsil. In Oghi and Mansehra tehsils, injectable was the most popular method of family planning, followed by condom.

Table 4.2: Percent of current use of contraceptive methods by currently married women, by tehsil and district

\begin{tabular}{lrrrr} 
& \multicolumn{3}{c}{ Tehsil } & \\
\cline { 2 - 4 } Method & Balakot & Oghi & Mansehra & Total \\
\hline Any method & 27.2 & 21.3 & 35.1 & 30.5 \\
\hline Any traditional method & 21.0 & 15.0 & 27.3 & 23.3 \\
\hline Female sterilization & 6.2 & 6.4 & 7.9 & 7.2 \\
\hline Male sterilization & 4.7 & 2.2 & 5.8 & 4.8 \\
\hline Pills & 0.0 & 0.0 & 0.0 & 0.0 \\
\hline IUD & 1.1 & 2.5 & 3.7 & 2.9 \\
\hline Injectables & 2.5 & 1.0 & 3.3 & 2.6 \\
\hline Implants & 4.0 & 5.1 & 7.6 & 6.3 \\
\hline Condom & 0.0 & 0.0 & 0.0 & 0.0 \\
\hline Rhythm & 8.7 & 4.1 & 6.9 & 6.6 \\
\hline Withdrawal & 2.2 & 3.2 & 2.1 & 2.4 \\
\hline Not currently using & 4.0 & 3.2 & 5.8 & 4.8 \\
\hline (N) & 72.8 & 78.7 & 64.9 & 69.5
\end{tabular}




\section{Source of Methods}

The women who were currently using any FP method were asked to indicate the source of the last supply of their contraceptive method. Table 4.3 depicts the sources mentioned. Tehsil-wide differences among government and private facilities were quite obvious. In both Balakot (52 percent) and Oghi (42 percent) private facilities were the most common source for contraceptive supplies, well above other sources. While still the most common source, slightly more than a quarter of the women (28 percent) in Mansehra tehsil had received their contraceptive method from private facilities, only 7 to 8 percent above either lady health workers (LHWs) or government hospitals/RHSCs (rural health services centers).

Lady health workers were an important main source of supplies for the women in Mansehra tehsil, supplying contraceptives to one-fifth (20 percent) of the current users. In Balakot, LHWs provided low coverage: only 3 percent of women received their contraceptives from an LHW. Grocery shops (not pharmacy/chemist) were the main source of supply for more than 15 percent of the women, and were the main source of condoms.

Table 4.3: Percent of currently married women who are current contraceptive users according to the source of their last supply, by tehsil and district

\begin{tabular}{lrrrrr} 
& \multicolumn{3}{c}{ Tehsil } & & \\
Source & Balakot & \multicolumn{1}{c}{ Oghi } & Mansehra & \multicolumn{2}{c}{ Total } \\
\cline { 2 - 6 } Govt. hospital/RHSC & \multicolumn{1}{c}{$\%$} & $\%$ & $\%$ & $\%$ & $\mathrm{~N}$ \\
\cline { 2 - 6 } Rural health center, MCH & 20.7 & 22.2 & 21.2 & 21.2 & 69 \\
\hline Family welfare center & 1.7 & 4.4 & 3.6 & 3.4 & 11 \\
\hline Mobile service camp & 3.4 & 2.2 & 6.8 & 5.5 & 18 \\
\hline Lady health worker & 0.0 & 2.2 & 0.0 & 0.3 & 1 \\
\hline Lady health visitor & 3.4 & 11.1 & 20.3 & 16.0 & 52 \\
\hline Basic health unit & 0.0 & 0.0 & 3.2 & 2.2 & 7 \\
\hline Other public & 5.2 & 8.9 & 9.9 & 8.9 & 29 \\
\hline Private facility/grocery shops & 1.7 & 0.0 & 0.0 & 0.3 & 1 \\
\hline Other & 51.7 & 42.2 & 28.4 & 34.5 & 112 \\
\hline Don't know & 0.0 & 2.2 & 0.5 & 0.6 & 2 \\
\hline Total & 12.1 & 4.4 & 6.3 & 7.1 & 23 \\
(N) & 100.0 & 100.0 & 100.0 & 100.0 & 100.0 \\
\hline
\end{tabular}




\section{Emergency Contraception}

Emergency contraception (EC) refers to contraceptive measures that, if taken after sex, may prevent pregnancy. As its name implies, EC is intended for occasional use when primary means of contraception fail. Figure 4.3 indicates, in Mansehra district, a large number of women (86 percent) were unaware of emergency contraception to avoid pregnancy; only 2 percent had ever used emergency contraception. The everuse status of emergency contraception was lowest in Oghi (under 1 percent) and highest in Mansehra (3 percent).

Figure 4.3: Currently married women's knowledge and ever use of emergency contraception, by tehsil and district (percent)

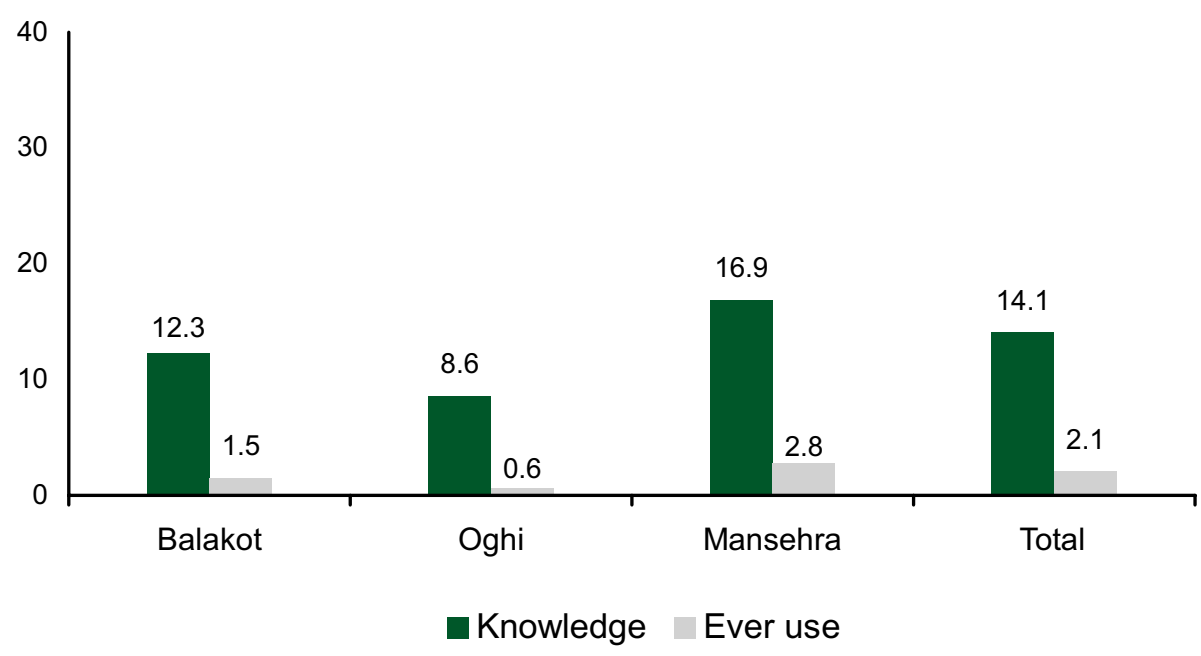

\section{Quality of Care Components}

Since the ethics of quality of care require that some protocols be followed when giving advice to a couple about the type of contraceptive they want to use, women who were currently using any modern family planning method were asked whether they were told about side effects/problems they might have with their specific method, and whether they were told what to do if they experienced any side effects. A question was also included asking them if they were given a briefing by a service provider about all contraceptive methods, whether available or not. Figure 4.4 shows the outcomes of these questions.

Of women currently using any modern family planning method, only 37 percent in Balakot were told about side effects, and fewer were told in Oghi and Mansehra 
tehsils (29 and 22 percent, respectively). Overall in Mansehra district, two out of every five women (40 percent) were briefed about all other FP methods.

Figure 4.4: Quality of care components at ANC visits for currently married women (\%)

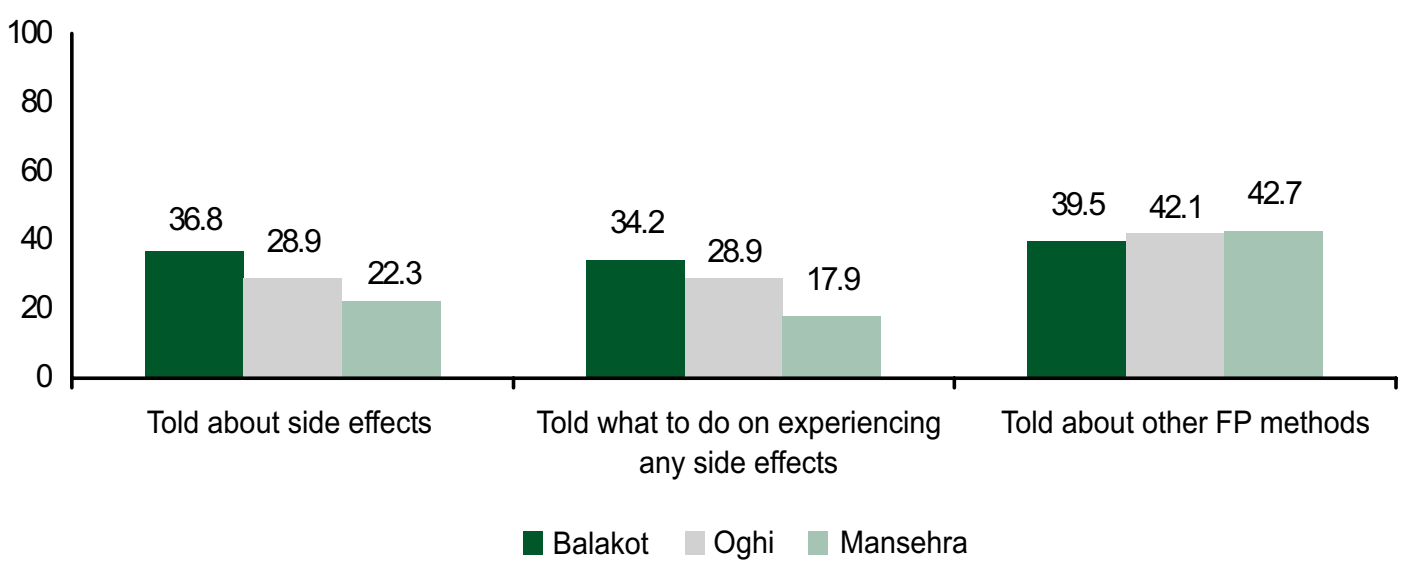

\section{Intentions for Future Use}

Non-users of family planning were asked if they would like to use any method in the future; their answers are presented in Figure 4.5. About three-quarters of the women in Mansehra and Balakot tehsils said that they would like to use a FP method in the future, while in Oghi fewer (64 percent) wanted to use a FP method in the future. For Mansehra district as a whole, these percents indicate possible interest in family planning activities. Fewer than 6 percent of the women in all tehsils were unsure whether they would like to use any contraception in the future or not.

Figure 4.5: Currently married women who were non-users of FP according to their future intention to use a contraceptive method, by tehsil (percent)

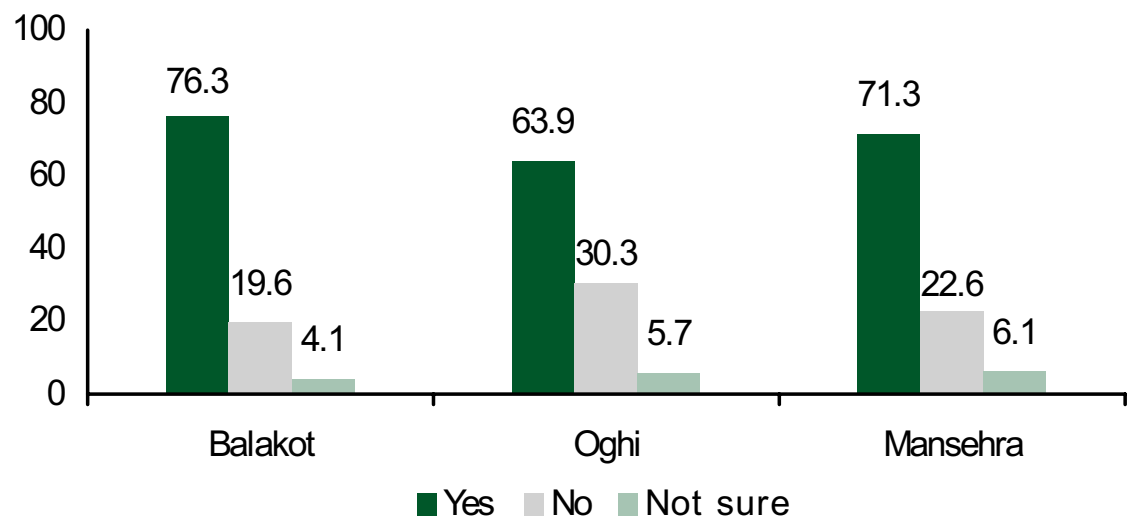




\section{Unmet Need}

The concept of "unmet need for family planning" joins together fertility preferences and contraceptive behavior. Women are said to have unmet need if they wish to avoid getting pregnant (because they want to delay their next child or want to stop childbearing altogether) but are not practicing any form of contraception.

Figure 4.6 depicts the contraceptive need among the currently married women of reproductive age according to whether they were currently pregnant or not. The category 'not in need' in the figure includes currently married women who want to have a birth soon or are infecund, in other words they are not in need of any contraceptive method. In Mansehra district, the total unmet need was 38 percent; 24 percent had unmet need for limiting and 13 percent had unmet need for spacing.

Figure 4.6: Currently married women who were pregnant or non-pregnant, by their contraceptive need (percent)

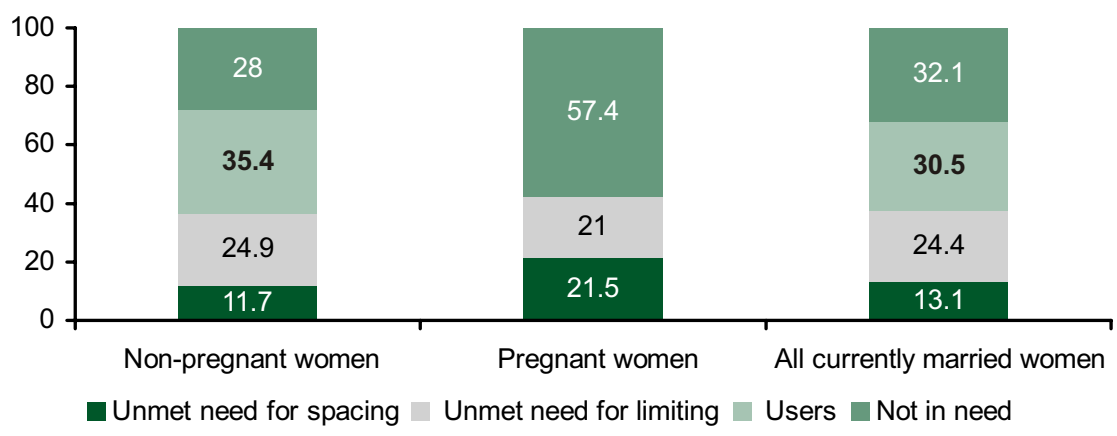




\section{Chapter 5}

\section{Pregnancy, Delivery and Postnatal Care}

This chapter explores the attitude and practice of married women regarding pregnancy, delivery and postnatal care. The information was collected from 702 women of reproductive age (15-49 years) who had a live birth during the three years preceding the study.

\section{Antenatal Care}

In this survey, antenatal care (ANC) was defined according to the type of provider, the number of visits made, stage of pregnancy at the time of the first visit and the services provided during this check-up, including whether or not tetanus toxoid injections were received.

Respondents were asked if they had any ANC visit during their last pregnancy and those who had ANC visits were then asked to indicate the number of visits. Table 5.1 reflects details regarding antenatal visits. KPC survey findings show that of the 702 women, 28 percent (199 women) had no

PRIDE INDICATOR:

Women who delivered in the past three years and had 4 or more antenatal consultations during their last pregnancy: 35 percent. antenatal visits and 72 percent (503 women) had one or more visits. More than onethird of the women (35 percent) had 4 or more visits during their last pregnancy. In Mansehra tehsil, 22 percent of the women had no antenatal visits compared to onethird in Balakot and Oghi. 
Table 5.1: Eligible women according to the number of antenatal visits they had, by tehsil and district

\begin{tabular}{lrrrrrrrrr} 
& \multicolumn{9}{c}{ Tehsil } \\
\cline { 2 - 9 } Number of visits & \multicolumn{1}{c}{ Balakot } & \multicolumn{2}{c}{ Oghi } & \multicolumn{1}{c}{ Mansehra } & \multicolumn{2}{c}{ Total } \\
\cline { 2 - 9 } No ANC visit & $N$ & $\%$ & $N$ & $\%$ & $N$ & $\%$ & $N$ & $\%$ \\
\hline At least 1 ANC visit & 48 & 35.8 & 62 & 36.5 & 89 & 22.4 & 199 & 28.3 \\
\hline Total & 86 & 64.2 & 108 & 63.5 & 309 & 77.6 & 503 & 71.7 \\
\hline At least 2 ANC visits & 734 & 100.0 & 170 & 100.0 & 398 & 100.0 & 702 & 100.0 \\
\hline At least 3 ANC visits & 62 & 46.3 & 67 & 39.4 & 224 & 56.3 & 353 & 50.3 \\
\hline 4+ ANC visits & 42 & 31.3 & 44 & 25.9 & 160 & 40.2 & 246 & 35.0 \\
\hline
\end{tabular}

\section{Place of Antenatal Care}

For the 503 women who had one or more antenatal visits, Table 5.2 shows the locations where they received care. Multiple responses were obtained. Overall in Mansehra, private clinic/hospital and doctor's office (54 percent) were the most visited facilities for ANC followed by government hospital and basic health unit (BHU) (53 percent). Ten percent of women had antenatal check-ups by calling the provider at their homes.

Table 5.2: Eligible women according to the location where antenatal care was given, by tehsil and district

\begin{tabular}{lrrrrrrrr} 
& \multicolumn{9}{c}{ Tehsil } \\
\cline { 2 - 9 } Location & \multicolumn{2}{c}{ Balakot } & \multicolumn{2}{c}{ Oghi } & \multicolumn{2}{c}{ Mansehra } & \multicolumn{2}{c}{ Total } \\
\cline { 2 - 9 } Your home & $N$ & $\%$ & $N$ & $\%$ & $N$ & $\%$ & \multicolumn{1}{c}{} & $\%$ \\
\hline & 1 & 1.2 & 6 & 5.6 & 16 & 5.2 & 23 & 4.6 \\
\hline Other home & 0 & 0.0 & 7 & 6.5 & 18 & 5.8 & 25 & 5.0 \\
\hline Govt. facility & 47 & 54.7 & 50 & 46.3 & 170 & 55.0 & 267 & 53.1 \\
\hline Pvt. hospital/clinic & 50 & 58.1 & 50 & 46.3 & 127 & 41.1 & 227 & 45.1 \\
\hline Pvt. doctor's office/clinic & 4 & 4.7 & 10 & 9.3 & 33 & 10.7 & 47 & 9.3 \\
\hline Other private medical & 4 & 4.7 & 3 & 2.8 & 8 & 2.6 & 15 & 3.0 \\
N & 86 & na & 108 & na & 309 & na & 503 & na
\end{tabular}

na $=$ Not applicable; respondents could name more than one location if they had antenatal visits at different locations.

\section{Provider}

The 503 women who had had antenatal care were asked about the provider of care at their antenatal visits. The women reported seeing doctors 83 percent of the time, 
followed by nurse/midwife/LHV (lady health visitor) 15 percent of the time, and by dai/traditional birth attendants (TBA) 8 percent of the time.

Table 5.3: Providers of antenatal care, by tehsil and district

\begin{tabular}{|c|c|c|c|c|c|c|c|c|}
\hline \multirow{3}{*}{ Provider } & \multicolumn{6}{|c|}{ Tehsil } & & \\
\hline & \multicolumn{2}{|c|}{ Balakot } & \multicolumn{2}{|c|}{ Oghi } & \multicolumn{2}{|c|}{ Mansehra } & \multicolumn{2}{|c|}{ Total } \\
\hline & $N$ & $\%$ & $N$ & $\%$ & $N$ & $\%$ & $N$ & $\%$ \\
\hline Doctor & 75 & 87.2 & 89 & 82.4 & 253 & 81.9 & 417 & 82.9 \\
\hline Nurse/midwife/LHV & 13 & 15.1 & 14 & 13.0 & 50 & 16.2 & 77 & 15.3 \\
\hline Dai-TBA & 5 & 5.8 & 14 & 13.0 & 21 & 6.8 & 40 & 8.0 \\
\hline LHW & 0 & 0.0 & 0 & 0.0 & 8 & 2.6 & 8 & 1.6 \\
\hline Other & 3 & 3.5 & 1 & 0.9 & 4 & 1.3 & 8 & 1.6 \\
\hline $\mathrm{N}$ & 86 & na & 108 & na & 309 & na & 503 & na \\
\hline
\end{tabular}

\section{Components of Antenatal Care}

Details regarding services provided during antenatal visits were obtained from those who had antenatal visits. Measuring blood pressure during antenatal visits was recorded highest, followed by performing or referring for urine tests and ultrasonography. Blood testing remained the lowest among the services provided. A comparison by tehsil reflects the service package during antenatal visits remained highest in Balakot. One of the reasons for the high package of antenatal services in Balakot could be attributable to relief and rehabilitation work initiated by several local and international non-governmental organizations after the 2005 earthquake. 
Figure 5.1: Services performed during antenatal check-up, by tehsil and district (percent)

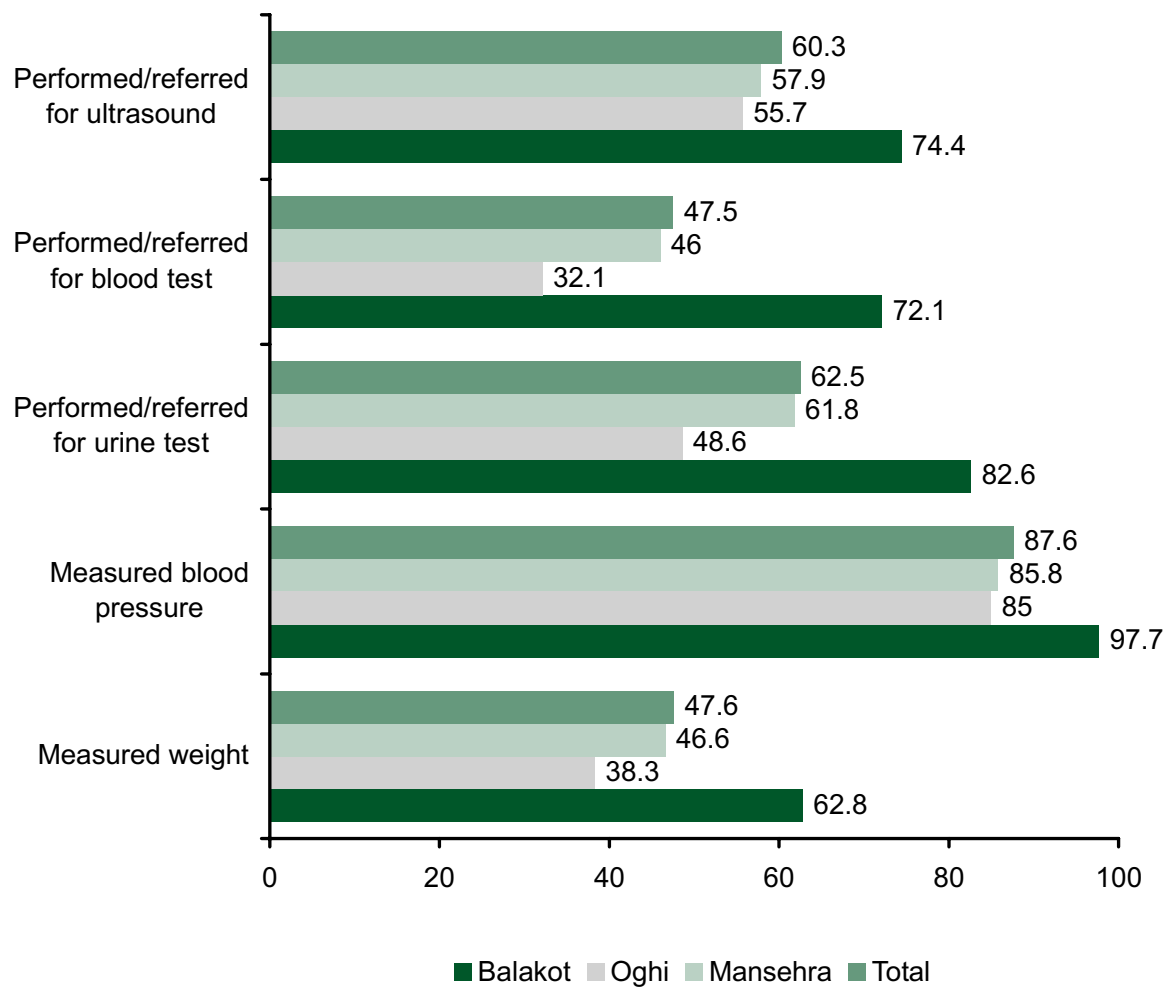

Women who had antenatal check-ups were asked to indicate reason(s) for having their first antenatal check-up to assess whether the visit was made for treatment of a problem that they had experienced during pregnancy or to have a routine medical check-up to ensure that the journey through pregnancy was completed in a safe manner. The chart below indicates that more than 40 percent of the women had conducted their first antenatal visit due to problems during pregnancy, whereas 59 percent of the women had gone for a routine antenatal check-up without a medical problem. 
Figure 5.2: First antenatal care visit according to the reason for the visit, by tehsil and district (percent)

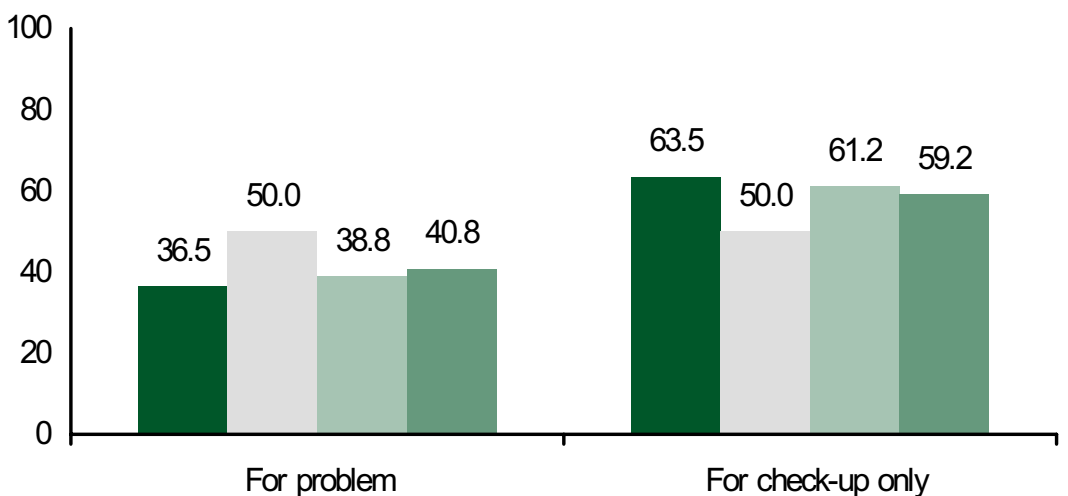

- Balakot Oghi $\backsim$ Mansehra $\square$ Total

Women who made more than one ANC visit were more likely to make those visits for regular checkups than those who only made one visit. Among 702 women who had a live birth during the three years preceding the survey, 30 percent made their first ANC visit due to some problem faced during pregnancy. The other 42 percent went for a regular check-up, while 28 percent made no ANC visits. Of the women who made more than four ANC visits, 14 percent were those who made their first ANC visit for some problem, while 21 percent went for a regular ANC check-up. Table 5.4 gives detailed information about the number of ANC visits and the reasons for them.

Table 5.4: Women who had a live birth in the last 3 years according to number of ANC visits, by reason for first ANC visit

\begin{tabular}{|c|c|c|c|c|c|c|}
\hline \multirow{4}{*}{$\begin{array}{l}\text { Number of visits } \\
\text { No ANC visit }\end{array}$} & \multicolumn{4}{|c|}{ Reason for first ANC visit } & & \\
\hline & \multicolumn{2}{|c|}{ Curative } & \multicolumn{2}{|c|}{ Preventive } & \multicolumn{2}{|c|}{ Total } \\
\hline & $N$ & $\%$ & $N$ & $\%$ & $N$ & $\%$ \\
\hline & 0 & 0.0 & 0 & 0.0 & 199 & 28.3 \\
\hline At least 1 ANC visit & 206 & 29.3 & 297 & 42.3 & 503 & 71.7 \\
\hline Total & & & & & 702 & 100.0 \\
\hline At least 2 ANC visits & 173 & 24.6 & 258 & 36.8 & 431 & 61.4 \\
\hline At least 3 ANC visits & 138 & 19.7 & 215 & 30.6 & 353 & 50.3 \\
\hline $4+$ ANC visits & 98 & 14.0 & 148 & 21.1 & 246 & 35.0 \\
\hline
\end{tabular}




\section{Reasons for Not Having ANC}

Respondents who did not have an antenatal visit during their last pregnancy were asked to indicate reasons for not having antenatal care. Multiple responses were received. More than half of the women who never had an antenatal visit stated that antenatal visits were not necessary. This attitude needs to be addressed at the community level through health education campaigns.

Around one-third of the women indicated that the facility was too far away to go for a check-up. One-fourth of the women had transport problems. Slightly less than onefifth of the women responded that one or more family members did not allow them to have an antenatal check-up. The behavior change communication (BCC) strategy of the project has great potential to address this aspect of social attitudes. Nearly onefifth of the women highlighted the fact that the cost of antenatal check-ups was very high.

Table 5.5: Eligible women according to reason for not having antenatal visits, by tehsil and district

\begin{tabular}{lrrrrrrrr} 
& \multicolumn{9}{c}{ Tehsil } \\
\cline { 2 - 7 } Reason & Balakot & \multicolumn{2}{c}{ Oghi } & \multicolumn{2}{c}{ Mansehra } & \multicolumn{2}{c}{ Total } \\
\cline { 2 - 7 } Not necessary & $N$ & $\%$ & $N$ & $\%$ & $N$ & $\%$ & $N$ & $\%$ \\
\hline Facility too far & 21 & 43.8 & 27 & 44.3 & 52 & 59.1 & 100 & 50.8 \\
\hline No transport & 25 & 52.1 & 12 & 19.7 & 26 & 29.5 & 63 & 32.0 \\
\hline Costs too much & 21 & 43.8 & 12 & 19.7 & 17 & 19.3 & 50 & 25.4 \\
\hline Not allowed to go & 7 & 14.6 & 15 & 24.6 & 13 & 14.8 & 35 & 17.8 \\
\hline Not customary & 7 & 14.6 & 10 & 16.4 & 17 & 19.3 & 34 & 17.3 \\
\hline No time to go & 4 & 8.3 & 10 & 16.4 & 4 & 4.5 & 18 & 9.1 \\
\hline No one to go with & 5 & 10.4 & 9 & 14.8 & 4 & 4.5 & 18 & 9.1 \\
\hline Feel shy & 4 & 8.3 & 5 & 8.2 & 3 & 3.4 & 12 & 6.1 \\
\hline Do not want male doctor & 2 & 4.2 & 2 & 3.3 & 3 & 3.4 & 7 & 3.6 \\
\hline Service not good & 1 & 2.1 & 0 & 0.0 & 5 & 5.7 & 6 & 3.0 \\
\hline Do not know where to go & 2 & 4.2 & 0 & 0.0 & 3 & 3.4 & 5 & 2.5 \\
\hline Long waiting time & 1 & 2.1 & 2 & 3.3 & 0 & 0.0 & 3 & 1.5 \\
\hline Total & 0 & 0.0 & 0 & 0.0 & 1 & 1.1 & 1 & 0.5 \\
\hline
\end{tabular}

na $=$ Not applicable; respondents could name more than one reason. 


\section{Tetanus Toxoid Injections}

At least one tetanus toxoid injection (TT) was received by 56 percent of women during their last pregnancy; 48 percent had two or more TT injections. Forty-four percent of women had no TT injections during their last pregnancy. Oghi had the highest number of women not having TT injections during their last pregnancy.

Figure 5.3: Tetanus toxoid injections received during last pregnancy, by tehsil and district (percent)

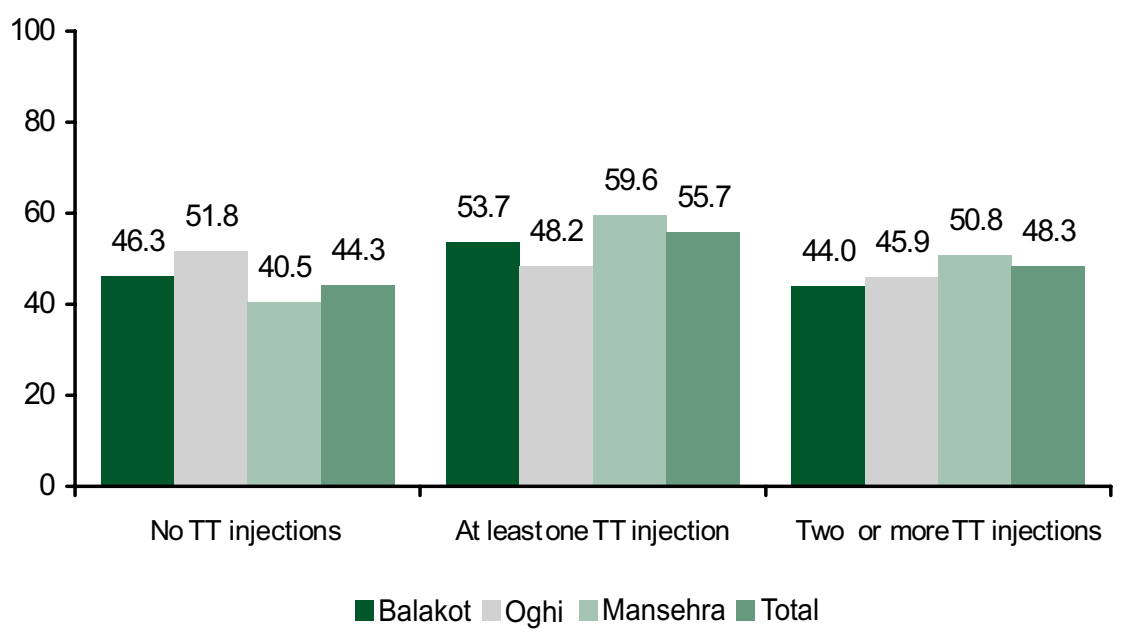

\section{Delivery/ Childbirth}

\section{Place of Delivery}

Home-based delivery for the last birth was reported by 72 percent of respondents; 28 percent gave birth at a health facility. Oghi, with 84 percent of the women giving birth at home, ranked first in home deliveries. This high level of home-based deliveries could be attributed to local culture, non-affordability of health facilities in the tehsil, and difficulty in approaching these facilities. Mansehra and Balakot had an equal percentage of home-based deliveries at 69 percent. In Balakot, 32 percent of the women had their last birth at a health facility. The reason for this could be due to better maternal services at health facilities provided by the government and NGOs after the 2005 earthquake than was available in the other tehsils.
Percentage of women who received at least two tetanus toxoid injections: 48.3 percent. 
Figure 5.4: Place of last delivery, by tehsil and district (percent)

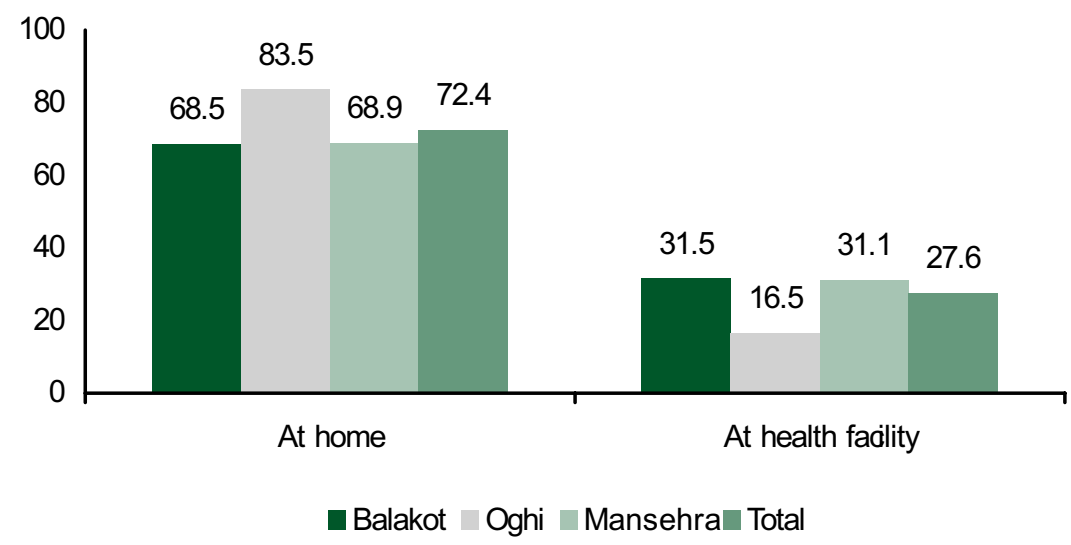

\section{Assistance During Delivery}

Table 5.6 shows the category of birth attendant who assisted women at their last delivery. Thirty-four percent of women were assisted at delivery by trained birth attendants, whereas 66 percent of women utilized the services of unskilled birth attendants. Dai/TBAs, who are considered unskilled birth attendants, topped the list of those assisting women at their last delivery (43 percent). Twenty percent of women were assisted by friends or relatives. Among skilled birth attendants, doctors delivered 24 percent of women, and nurse/midwife/LHV accounted for 11 percent of deliveries.

A comparison of tehsils indicates that in Balakot relatives and friends had the greatest share in assisting women during childbirth (45 percent). This high level of participation of relatives and

PRIDE INDICATOR: Percentage of births attended by a skilled birth attendant: 34.4 percent.

friends could be due to the joint family system and trust in family members or difficulty in accessing trained birth attendants. In Oghi, dai/TBAs assisted at more than half of the births. Dai/TBAs were also a great resource in Mansehra tehsil, assisting at deliveries of 45 percent of the women. 
Table 5.6: Eligible women according to type of person attending at delivery and skill level, by tehsil and district

\begin{tabular}{|c|c|c|c|c|c|c|c|c|}
\hline \multirow{3}{*}{$\begin{array}{l}\text { Birth attendant } \\
\text { and skill level }\end{array}$} & \multicolumn{6}{|c|}{ Tehsil } & & \\
\hline & \multicolumn{2}{|c|}{ Balakot } & \multicolumn{2}{|c|}{ Oghi } & \multicolumn{2}{|c|}{ Mansehra } & \multicolumn{2}{|c|}{ Total } \\
\hline & $N$ & $\%$ & $N$ & $\%$ & $N$ & $\%$ & $N$ & $\%$ \\
\hline Doctor & 31 & 23.1 & 23 & 13.5 & 112 & 28.2 & 166 & 23.7 \\
\hline Nurse/midwife/LHV & 17 & 12.7 & 15 & 8.8 & 43 & 10.8 & 75 & 10.7 \\
\hline Dai-TBA & 24 & 17.9 & 100 & 58.8 & 180 & 45.3 & 304 & 43.4 \\
\hline $\begin{array}{l}\text { Relative/friend (not a } \\
\text { dai) }\end{array}$ & 60 & 44.8 & 32 & 18.8 & 50 & 12.6 & 142 & 20.3 \\
\hline Other & 2 & 1.5 & 0.0 & 0.0 & 12 & 3.0 & 14 & 2.0 \\
\hline Total & 134 & 100.0 & 170 & 100.0 & 397 & 100.0 & 701 & 100.0 \\
\hline \multicolumn{9}{|c|}{ Skill level of birth attendant: } \\
\hline Skilled birth attendant & 48 & 35.8 & 38 & 22.4 & 155 & 39.0 & 241 & 34.4 \\
\hline $\begin{array}{l}\text { Unskilled birth } \\
\text { attendant }\end{array}$ & 86 & 64.2 & 132 & 77.6 & 242 & 61.0 & 460 & 65.6 \\
\hline Total & 134 & 100.0 & 170 & 100.0 & 397 & 100.0 & 701 & 100.0 \\
\hline
\end{tabular}

\section{Problems During Delivery and Postpartum}

The women were asked to respond regarding medical problems they had experienced during their last delivery, including the postpartum period. Multiple responses were obtained from the women (see Figure 5.5). Severe headache was mentioned by 40 percent of women and blurred vision and high fever were reported by 37 and 36 percent, respectively. Swelling of face and hands were reported by 11 percent of women. Vaginal discharge (foul smell) and dribbling of urine were reported by 11 and 6 percent, respectively. These figures are indicative of unhygienic practices and deliveries by unskilled practitioners. Heavy vaginal bleeding was one of the leading causes of maternal deaths and this was reported by 9 percent of women. 
Figure 5.5: Women who experienced a problem(s) during their last delivery and postpartum period, by type of problem experienced (percent)

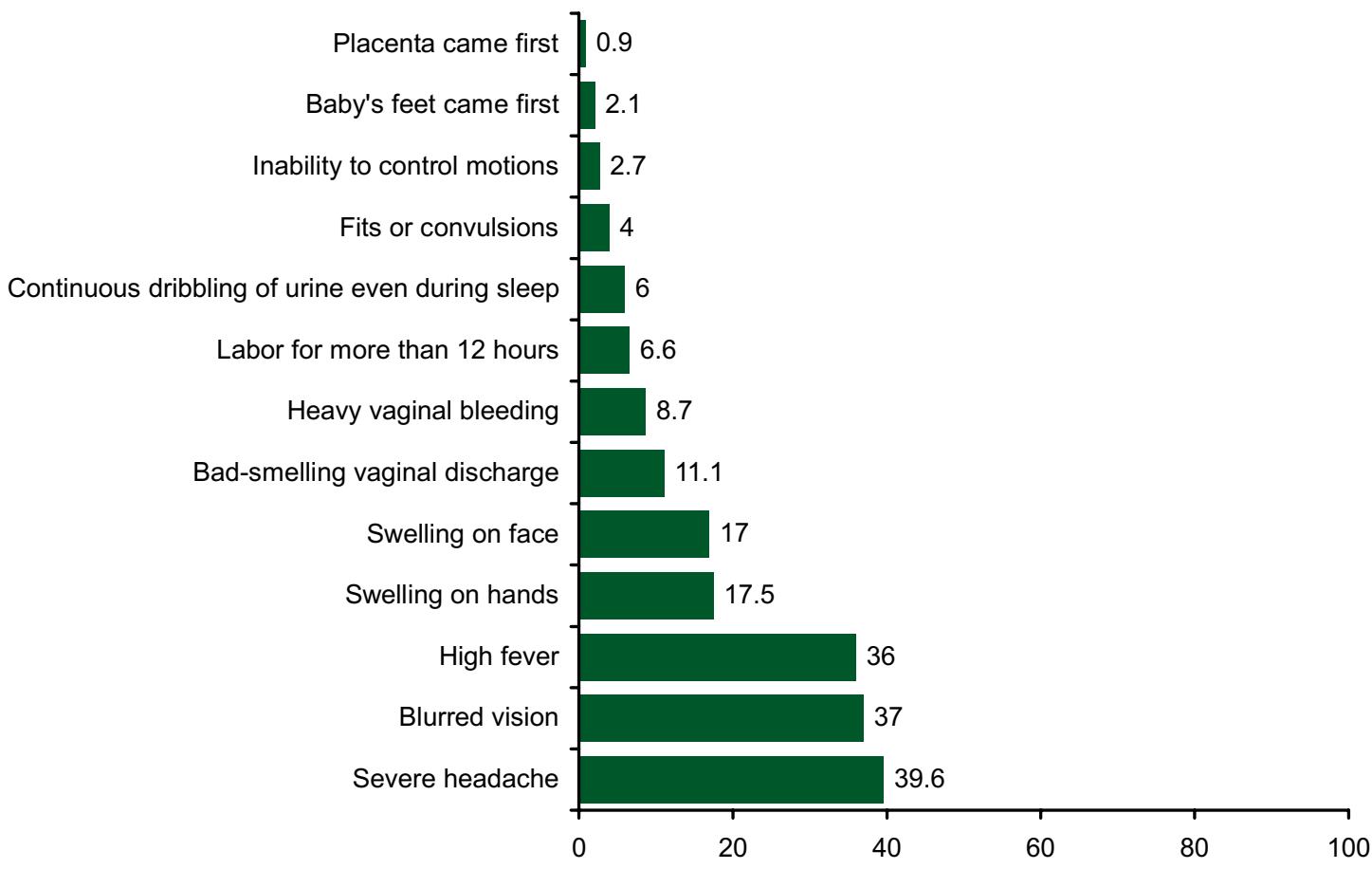

\section{Clean Delivery Practices}

The 504 women who had delivered their babies at home were asked questions related to safe birth practices (see Figure 5.6). In Oghi, only 10 percent of the women were delivered using clean delivery kits compared to Mansehra (25 percent). The percentage of women who reported the use of a new blade to cut the umbilical cord was lower in Oghi (18 percent) compared to Balakot and Mansehra (21 and 23 percent, respectively). Similarly the proportion of women who reported the use of new/boiled thread to tie the cord was 20 percent in Mansehra followed by Balakot and Oghi (11 and 9 percent, respectively). 
Figure 5.6: Safe delivery practices used at home births, by tehsil and district (percent)

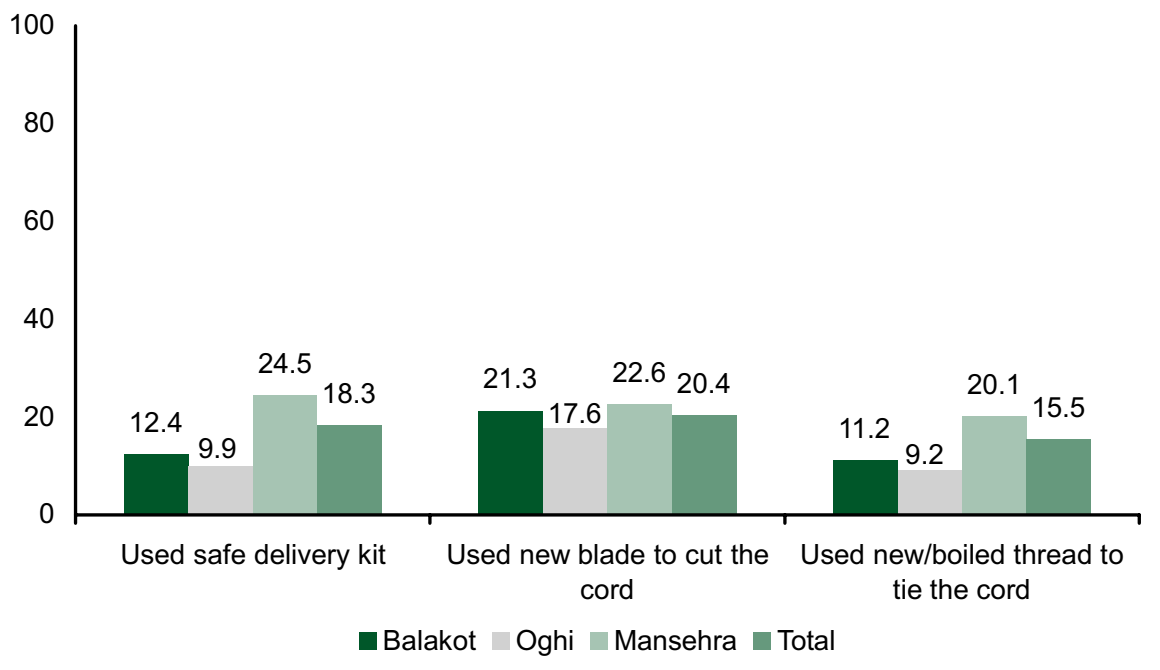

\section{Postpartum Care}

In the KPC survey, the postpartum period is defined as the 40 days after the childbirth. The postpartum period is a critical time for both the mother and the newborn. Respondents were asked about the postpartum care they received after their last

\section{PRIDE INDICATOR:}

Percentage of mothers who had at least one postnatal visit within 40 days of delivery: 22.6 percent.

delivery. Table 5.7 shows that many women did not receive any post-natal check-ups after their last delivery. More than three-quarters (77 percent) had no post-natal check-up; this figure was highest in Oghi, where 82 percent received no postpartum care. Among those who went for postnatal care, the highest percent (less than half, 48 percent) went within 24 hours after childbirth. 
Table 5.7: History of postnatal care

\begin{tabular}{lllllllll} 
& \multicolumn{9}{c}{ Tehsil } & & & & \\
History & Balakot & Oghi & Mansehra & Total & \\
\hline & $N$ & $\%$ & $N$ & $\%$ & $N$ & $\%$ & $N$ & $\%$ \\
\hline
\end{tabular}

Had postnatal check-up

\begin{tabular}{lrrrrrrrr}
\hline Yes & 30 & 22.4 & 30 & 17.6 & 99 & 24.9 & 159 & 22.6 \\
\hline No & 104 & 77.6 & 140 & 82.4 & 299 & 75.1 & 543 & 77.4 \\
Total & 134 & 100 & 170 & 100 & 398 & 100.0 & 702 & 100.0 \\
\hline
\end{tabular}

Number of days after delivery before first check-up

\begin{tabular}{lrrrrrrrr}
\hline Same day & 19 & 63.3 & 12 & 40.0 & 46 & 46.5 & 77 & 48.4 \\
\hline Within 7 days & 4 & 13.3 & 6 & 20.0 & 23 & 23.2 & 33 & 20.8 \\
\hline Within 40 days & 1 & 3.3 & 2 & 6.7 & 6 & 6.1 & 9 & 5.7 \\
\hline Don't remember & 6 & 20.0 & 10 & 33.3 & 24 & 24.2 & 40 & 25.2 \\
Total & 30 & 100.0 & 30 & 100.0 & 99 & 100.0 & 159 & 100.0
\end{tabular}

\section{Knowledge of Danger Signs in Newborns}

Respondents were asked an unprompted question about the danger signs in the newborn that need medical attention. Figure 5.7 depicts the percentage of respondents who believed that each complication listed required medical attention. Overall, it is apparent that knowledge regarding the health of newborn is very poor in Mansehra district. Differences among the tehsils in respondents' knowledge can be seen in the figure. The most widely recognized danger sign for newborns in Oghi was 'baby did not cry/weak cry' (37 percent); in Mansehra it was 'blue skin color of the baby' (33 percent); and in Balakot 'fever' (36 percent) and 'baby was very cold/ shivering' (31 percent) were the most known danger signs in newborns. 
Figure 5.7: Percentage of respondents who had knowledge about danger signs in newborns, by tehsil and district (percent)

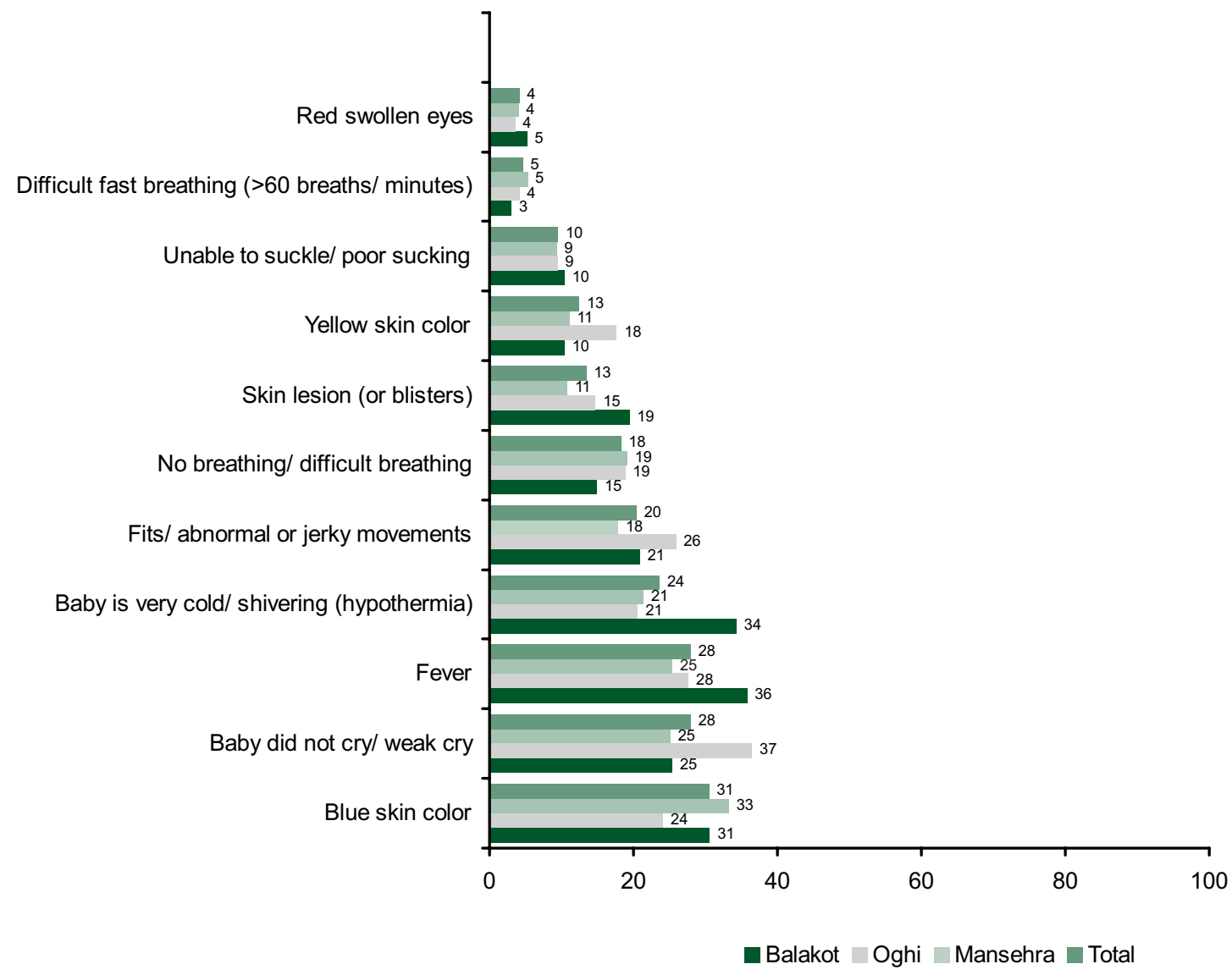

Figure 5.8 shows that no more than 33 percent of the women in Mansehra district knew three or more danger signs in newborns. Thirty percent in Mansehra tehsil could not identify one danger sign; 22 percent in both Balakot and Oghi could not.

\section{PRIDE INDICATOR:}

Mothers who had knowledge about three or more danger signs in the newborn: 33 percent 
Figure 5.8: Women's knowledge of the number of danger signs in a newborn within one hour of birth, by tehsil and district (percent)

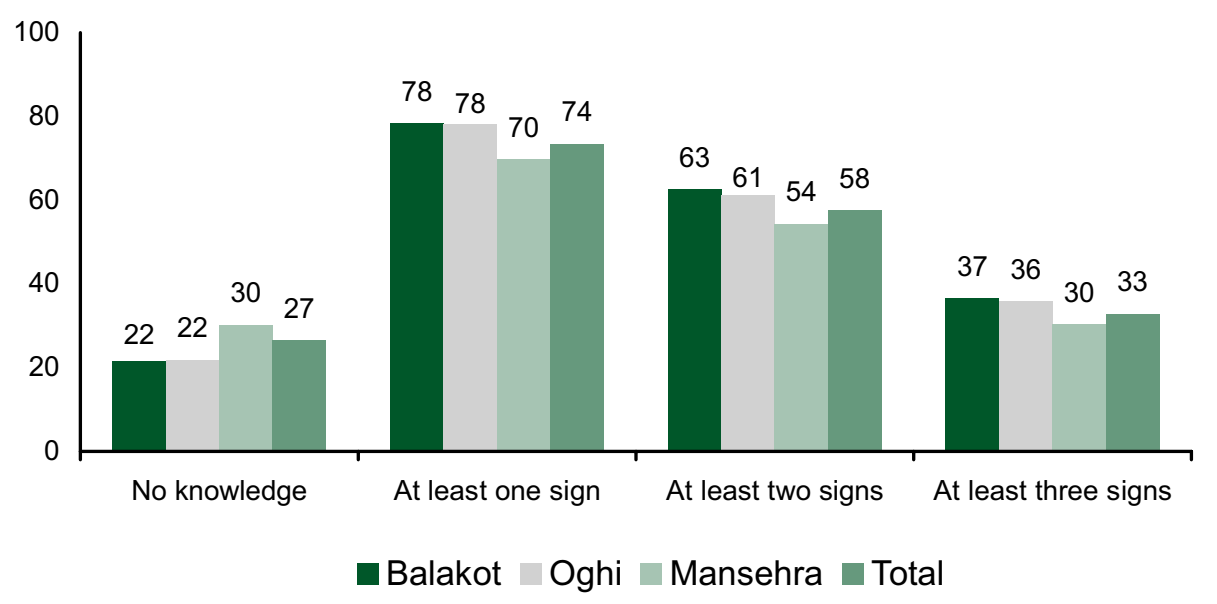




\section{Chapter 6}

\section{Child Health}

This chapter provides information from the married women of reproductive age who had a live birth in the three years preceding the survey, and whose child/children were alive and under the age of 36 months at the time of the KPC survey. Information is presented primarily on the children ages 0-23 months.

\section{Immunization}

A child is considered fully vaccinated if s/he has received a bacille Calmette-Guérin (BCG) vaccination against tuberculosis, three doses of DPT vaccine to prevent diphtheria, pertussis and tetanus, at least three doses of polio vaccine and one dose of measles vaccine. During the KPC survey, information was collected on vaccination among all children ages 12-23 months. Measuring immunization coverage at the household level is not an easy task. Parents often do not have an immunization card with full information on the immunizations received; therefore, an immunization rate based on card information often underestimates the coverage rate. However, calculating the coverage rate using recall from parents, especially mothers, is problematic as they may confuse the vaccine injection with another type of injection, etc. Neither of these measures of immunization is ideal. Therefore, information on immunization is presented here using information collected both from immunization records and recall of the mothers.

\section{Full immunization}

Figure 6.1 presents the information on vaccination coverage for children aged 12-23 months who were fully vaccinated against six preventable childhood illnesses. The result is based both on health card

PRIDE INDICATOR: Children ages 12-23 months who were fully immunized: 39.4 percent information and mother recall. Overall, 39 percent of children ages 12-23 months 
were fully vaccinated for tuberculosis (BCG), measles and polio. In Mansehra tehsil, full vaccination coverage was highest, at about half (48 percent); in Oghi, the coverage rate for fully immunized children was lowest (28 percent).

Figure 6.1: Children ages 12-23 months who were fully immunized, based on records and recall, by tehsil and district (percent)

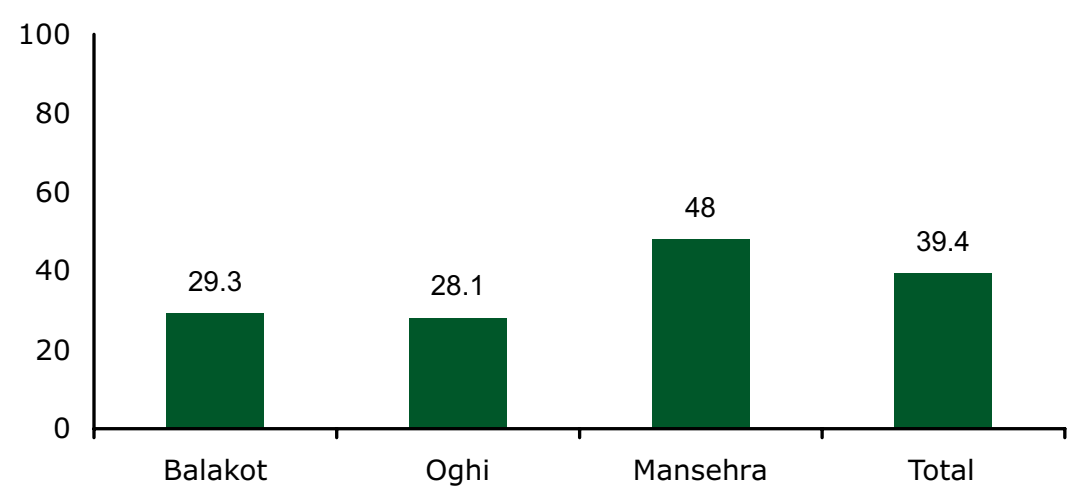

Figure 6.2 reflects the antigen-specific coverage rate by tehsil, as shown below:

BCG. Seven out of every ten children (70 percent) had received the BCG vaccination at birth: highest in Mansehra tehsil (75 percent) and lowest in Oghi (61 percent).

Polio. Almost 96 percent of district children had received complete polio vaccinations (3 doses). Polio vaccination was recorded as highest in Oghi (100 percent) and lowest in Balakot (90 percent).

DPT. The recommended three doses were received by 47 percent of district children. However, tehsil variations were observed in DPT vaccination rates: Mansehra had the highest rate (53 percent), followed by Oghi (40 percent), and Balakot had the lowest vaccination rate ( 37 percent).

Measles. The total vaccination rate for measles was recorded as 52 percent. Mansehra tehsil had a much higher vaccination rate (58 percent) than Oghi (46 percent) or Balakot (44 percent). 
Figure 6.2: Children ages 12-23 months according to immunizations received, by tehsil and district (percent)

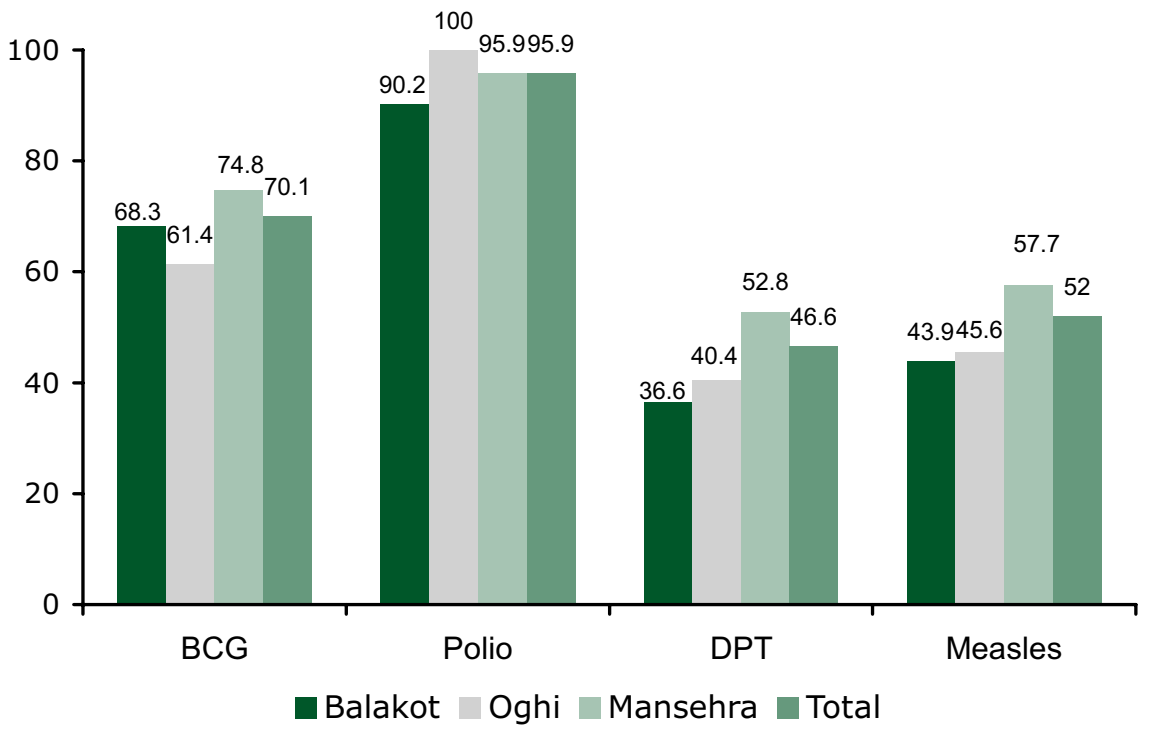

Respondents were asked if their child had received polio vaccine during national immunization campaigns. The responses by age of the child are presented in Table 6.1. Eighty-eight percent of the children under three years of age were immunized during the national polio day campaigns.

Table 6.1: Children under age 3 who received polio vaccination during national immunization day campaigns

\begin{tabular}{lrrrrr} 
Age in & \multicolumn{2}{c}{} & \multicolumn{2}{c}{ Not vaccinated } & Total \\
months & $N$ & $\%$ & $N$ & $\%$ & $N$ \\
\cline { 2 - 6 } $0-11$ & 213 & 74.0 & 75 & 26.0 & 288 \\
\hline $12-23$ & 211 & 98.6 & 3 & 1.4 & 214 \\
\hline $24-35$ & 142 & 97.9 & 3 & 2.1 & 145 \\
Total & 566 & 87.5 & 81 & 12.5 & 647
\end{tabular}

Information was also obtained about the availability of immunization cards/health cards for the children ages 12-23 months. Figure 6.3 shows that a total of 71 percent of the mothers claimed to have a vaccination card. However, a vaccination card was seen and confirmed with only one-quarter of the mothers (26 percent), while 44 percent of mothers could not show an immunization card. Some 28 percent of mothers responded that they had no immunization card for their children. 
Figure 6.3: Status of immunization cards of mothers of children ages 12-23 months, by tehsil and district (percent)

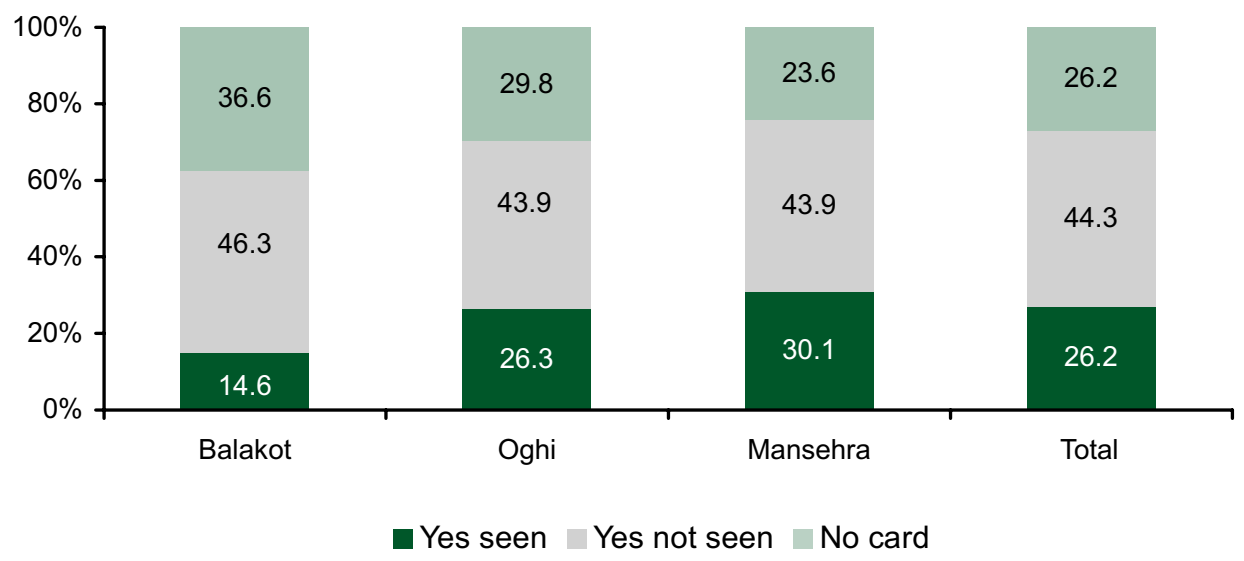

\section{Diarrhea}

Dehydration caused by severe diarrhea is one of the major causes of child mortality in Pakistan. Prompt medical attention is crucial to reduce child deaths from diarrhea. Information was obtained from mothers on their knowledge about diarrhea and the episodes of the illness in their children (ages 0-23 months).

In Figure 6.4, the results show that altogether 31 percent of these children had experienced diarrhea in the last two weeks. Balakot had experienced more diarrhea cases as compared to Mansehra and Oghi tehsils.

Figure 6.4: Children ages 0-23 months according to whether or not they had had diarrhea during the last two weeks, by tehsil and district (percent)

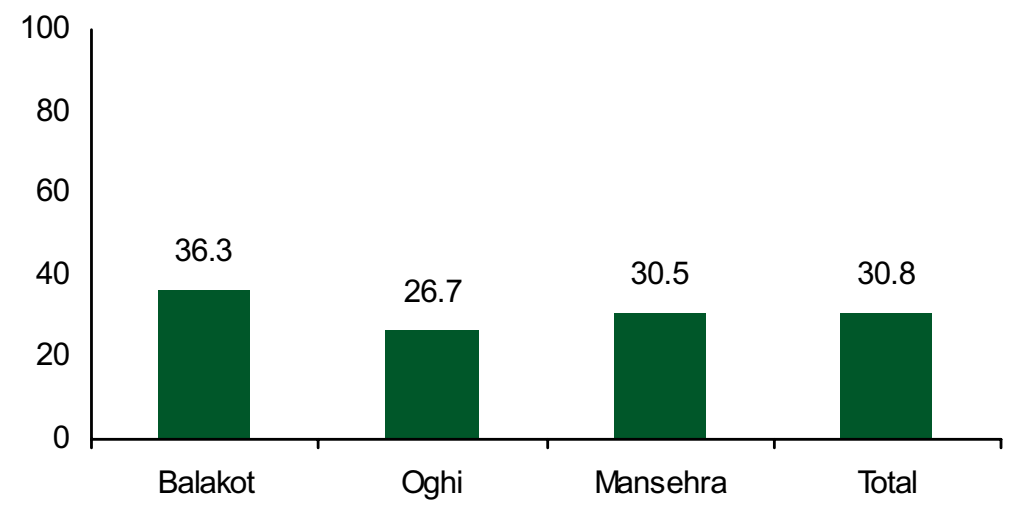


Among the children ages 0-23 months who had experienced diarrhea in the last two weeks, 48 percent had diarrhea episodes during the last 24 hours. Again, Balakot had the highest number of cases of diarrhea during the 24 hours preceding the survey team's visit.

Seventy-three percent of mothers of children ages 0-23 months who had diarrhea in the last two weeks obtained advice or treatment for their children's diarrhea from either a government facility or private health practitioner. The treatment or advice seeking behavior was highest in Oghi (81 percent) and lowest in Mansehra tehsil (70 percent) (see Figure 6.5).

Figure 6.5: Mothers of children ages 0-23 months who sought advice or treatment from service providers for episodes of diarrhea, by tehsil and district (percent)

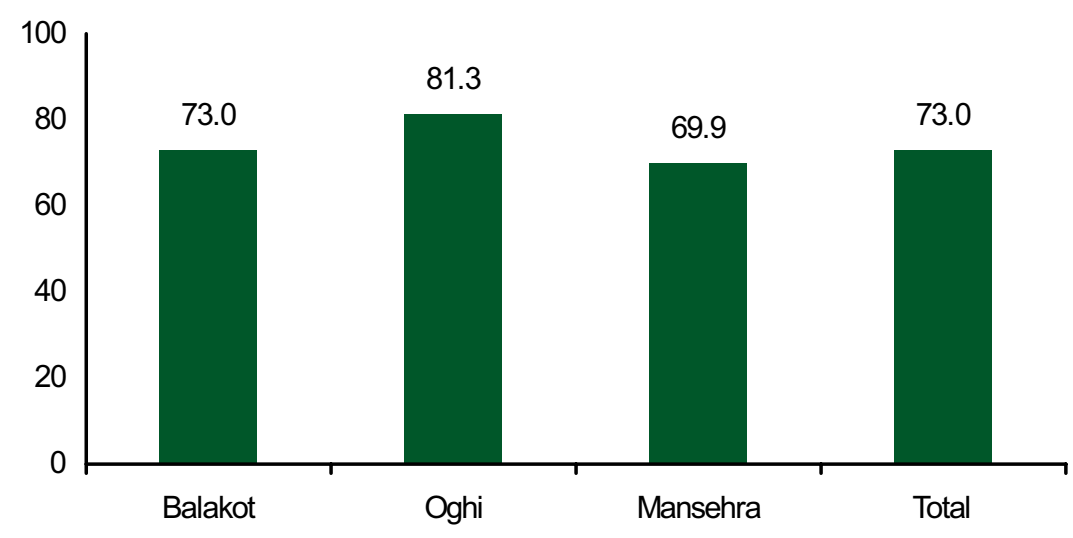

The use of oral rehydration therapy (ORT) promptly increases the intake of a child's fluids, which is a simple and effective response to diarrhea. Mothers reported (see Figure 6.6) during the survey that more than half of their children ages 0-23 months

\section{PRIDE INDICATOR:}

Children ages 0-23 months treated with oral rehydration therapy (ORT) during their last bout of diarrhea: 54.6 percent.

(55 percent) were treated with some form of ORT.

The use of ORT was higher in Mansehra tehsil ( 59 percent) and lower in Balakot and Oghi (49 and 50 percent, respectively). 
Figure 6.6: Mothers according to whether or not they treated the last bout of diarrhea in their children ages 0-23 months with ORT, by tehsil and district (percent)

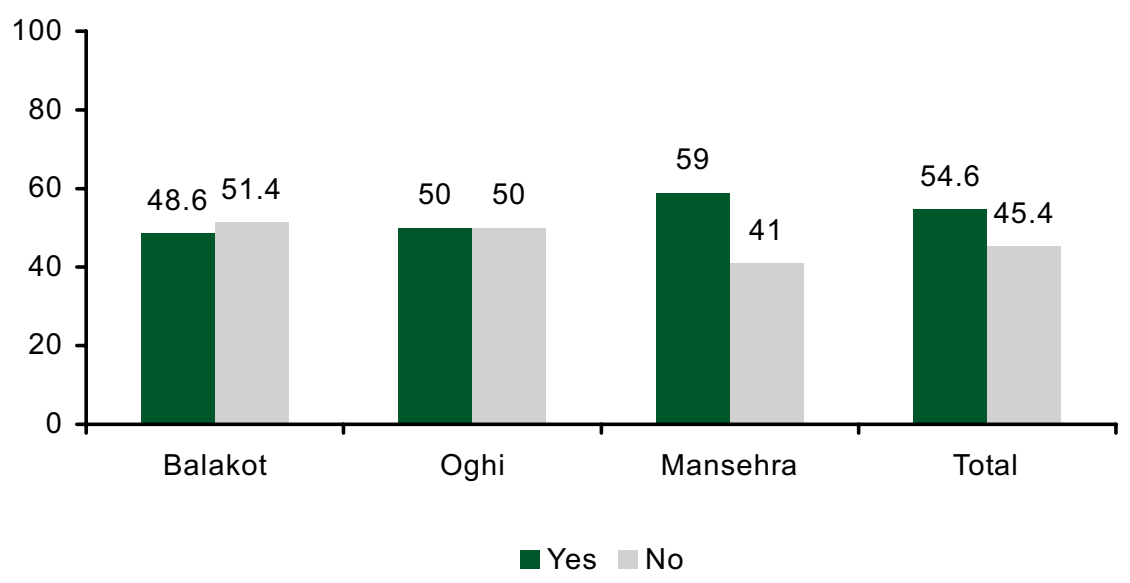

Mothers were asked if they recognized a single danger sign for diarrhea that requires immediate treatment at a health facility: 85 percent indicated that they did (Table 6.2). In terms of specific signs named: severe dehydration (shortage of water inside the body, shortage of vitamins, minerals and salt were grouped together to indicate severe dehydration) was mentioned by a majority of mothers as one of the danger sign of diarrhea followed by weakness, sunken eyes and unconsciousness. Mothers in Balakot had the highest (90 percent) knowledge of danger signs of diarrhea that require immediate treatment at a health facility. Mothers in Mansehra and Oghi tehsils were somewhat less knowledgeable of danger signs (84 and 85 percent, respectively)

PRIDE INDICATOR:

Mothers of children ages $0-23$ months who can cite at least one danger sign of diarrhea: 85.2 percent. 
Table 6.2: Danger signs of diarrhea requiring immediate treatment cited by mothers of children ages 0-23 months, by tehsil and district

\begin{tabular}{|c|c|c|c|c|c|c|c|c|}
\hline \multirow{3}{*}{ Sign } & \multicolumn{6}{|c|}{ Tehsil } & & \\
\hline & \multicolumn{2}{|c|}{ Balakot } & \multicolumn{2}{|c|}{ Oghi } & \multicolumn{2}{|c|}{ Mansehra } & \multicolumn{2}{|c|}{ Total } \\
\hline & $N$ & $\%$ & $N$ & $\%$ & $N$ & $\%$ & $N$ & $\%$ \\
\hline $\begin{array}{l}\text { Can recognize at least one } \\
\text { danger sign of diarrhea }\end{array}$ & 91 & 90.1 & 101 & 84.9 & 228 & 83.5 & 420 & 85.2 \\
\hline Sunken eyes & 19 & 20.9 & 22 & 21.8 & 55 & 24.1 & 96 & 22.9 \\
\hline Severe dehydration & 76 & 83.5 & 67 & 66.3 & 182 & 79.8 & 325 & 77.4 \\
\hline Depress anterior fontanel & 0 & 0.0 & 3 & 3.0 & 5 & 2.2 & 8 & 1.9 \\
\hline Dry mouth and tongue & 6 & 6.6 & 7 & 6.9 & 12 & 5.3 & 25 & 6.0 \\
\hline No tears on weeping & 10 & 11.0 & 1 & 1.0 & 17 & 7.5 & 28 & 6.7 \\
\hline Dry skin & 8 & 8.8 & 25 & 24.8 & 20 & 8.8 & 53 & 12.6 \\
\hline Unconsciousness & 28 & 30.8 & 24 & 23.8 & 52 & 22.8 & 104 & 24.8 \\
\hline Restless & 14 & 15.4 & 14 & 13.9 & 30 & 13.2 & 58 & 13.8 \\
\hline Weakness & 40 & 44.0 & 19 & 18.8 & 55 & 24.1 & 114 & 27.1 \\
\hline $\begin{array}{l}\text { Change of color (e.g. } \\
\text { yellow skin color) }\end{array}$ & 2 & 2.2 & 3 & 3.0 & 6 & 2.6 & 11 & 2.6 \\
\hline Fever & 10 & 11.0 & 6 & 5.9 & 14 & 6.1 & 30 & 7.1 \\
\hline Baby cries & 2 & 2.2 & 2 & 2.0 & 4 & 1.8 & 8 & 1.9 \\
\hline Pain in abdomen & 3 & 3.3 & 3 & 3.0 & 2 & 0.9 & 8 & 1.9 \\
\hline Loss of appetite & 1 & 1.1 & 1 & 1.0 & 7 & 3.1 & 9 & 2.1 \\
\hline Vomiting & & & 4 & 4.0 & 5 & 2.2 & 9 & 2.1 \\
\hline Other & 3 & 3.3 & 2 & 2.0 & 4 & 1.8 & 9 & 2.1 \\
\hline Total & 91 & na & 101 & na & 228 & na & 420 & na \\
\hline
\end{tabular}

na $=$ Not applicable; respondents could name more than one sign/symptom.

\section{Pneumonia}

Mothers of children ages 0-23 months were asked whether they had heard about pneumonia: 9 out of 10 mothers had (see Figure 6.7). However, differences among tehsils were noted in the

PRIDE INDICATOR:

Mothers of children ages 0-23 month who had heard about pneumonia: 92.2 percent. responses of mothers: Balakot was highest, where 97 percent of mothers had heard about pneumonia, and Mansehra was lowest (89 percent). 
Figure 6.7: Mothers of children ages 0-23 months who had heard about pneumonia, by tehsil and district (percent)

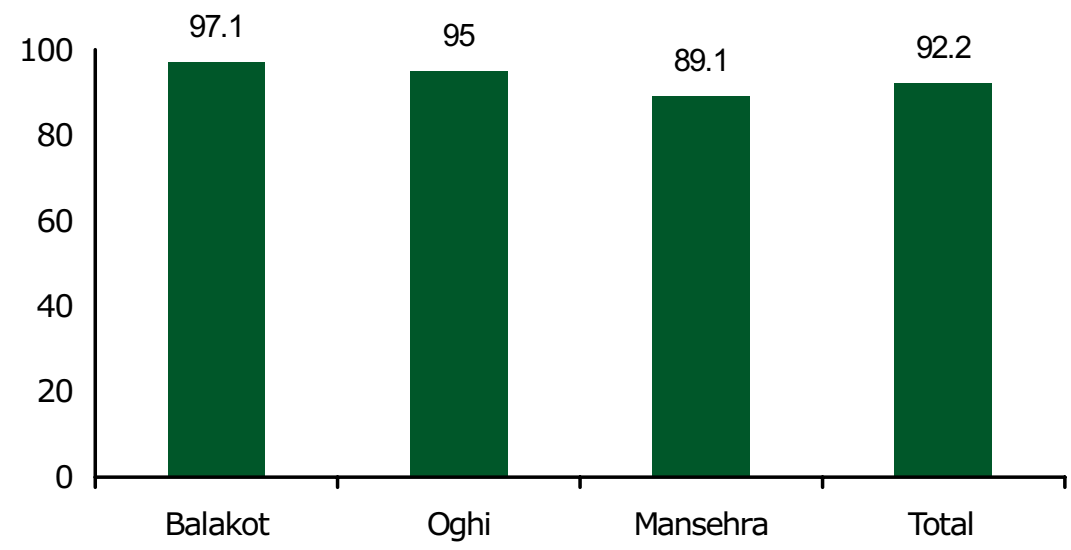

Mothers of children 0-23 months who had heard about pneumonia were also asked to identify symptoms of pneumonia in children. Table 6.3 shows these results for the 459 mothers who had heard about pneumonia and could name one or more signs. Overall, the most frequently mentioned signs/symptoms were rapid or difficult breathing (73 percent), followed by high fever (59 percent), chest indrawing (49 percent) and severe cough (37 percent). Not many mothers mentioned other signs.

Table 6.3: Identification of signs/symptoms of pneumonia by mothers of children $0-23$ months, by tehsil and district

\begin{tabular}{|c|c|c|c|c|c|c|c|c|}
\hline \multirow{3}{*}{ Symptom } & \multicolumn{6}{|c|}{ Tehsil } & & \\
\hline & \multicolumn{2}{|c|}{ Balakot } & \multicolumn{2}{|c|}{ Oghi } & \multicolumn{2}{|c|}{ Mansehra } & \multicolumn{2}{|c|}{ Total } \\
\hline & $N$ & $\%$ & $N$ & $\%$ & $N$ & $\%$ & $N$ & $\%$ \\
\hline Rapid or difficult breathing & 73 & 73.0 & 84 & 73.0 & 178 & 73.0 & 335 & 73.0 \\
\hline High fever/low temperature & 65 & 65.0 & 72 & 62.6 & 135 & 55.3 & 272 & 59.3 \\
\hline Severe cough & 45 & 45.0 & 41 & 35.7 & 84 & 34.4 & 170 & 37.0 \\
\hline Blue skin color & 5 & 5.0 & 9 & 7.8 & 4 & 1.6 & 18 & 3.9 \\
\hline Chest indrawing & 41 & 41.0 & 49 & 42.6 & 136 & 55.7 & 226 & 49.2 \\
\hline Pain & 3 & 3.0 & 5 & 4.3 & 12 & 4.9 & 20 & 4.4 \\
\hline Baby cries & 15 & 15.0 & 12 & 10.4 & 11 & 4.5 & 38 & 8.3 \\
\hline Loss of appetite & 2 & 2.0 & 1 & 0.9 & 4 & 1.6 & 7 & 1.5 \\
\hline Other & 10 & 10.0 & 3 & 2.6 & 13 & 5.3 & 26 & 5.7 \\
\hline Total & 100 & na & 115 & na & 244 & na & 459 & na \\
\hline
\end{tabular}

na $=$ Not applicable; respondents could name more than one symptom. 
The mothers were asked about what should be done in case their child had difficult and fast breathing. The responses are shown in Figure 6.8. Overall, a total of 83 percent said that the child should be immediately taken to a health facility. This response was highest in Balakot, where 89 percent of the mothers said that the child be immediately taken to a health facility, and lowest in Mansehra tehsil, where 80 percent gave this response. Around 32 percent of mothers in the district also mentioned that they should treat the child by themselves and 21 percent thought that the child should be kept warm if s/he developed rapid and difficult breathing.

Figure 6.8: Mothers of children ages $0-23$ months according to what should be done if their child breathes fast with difficulty, by tehsil and district (percent)

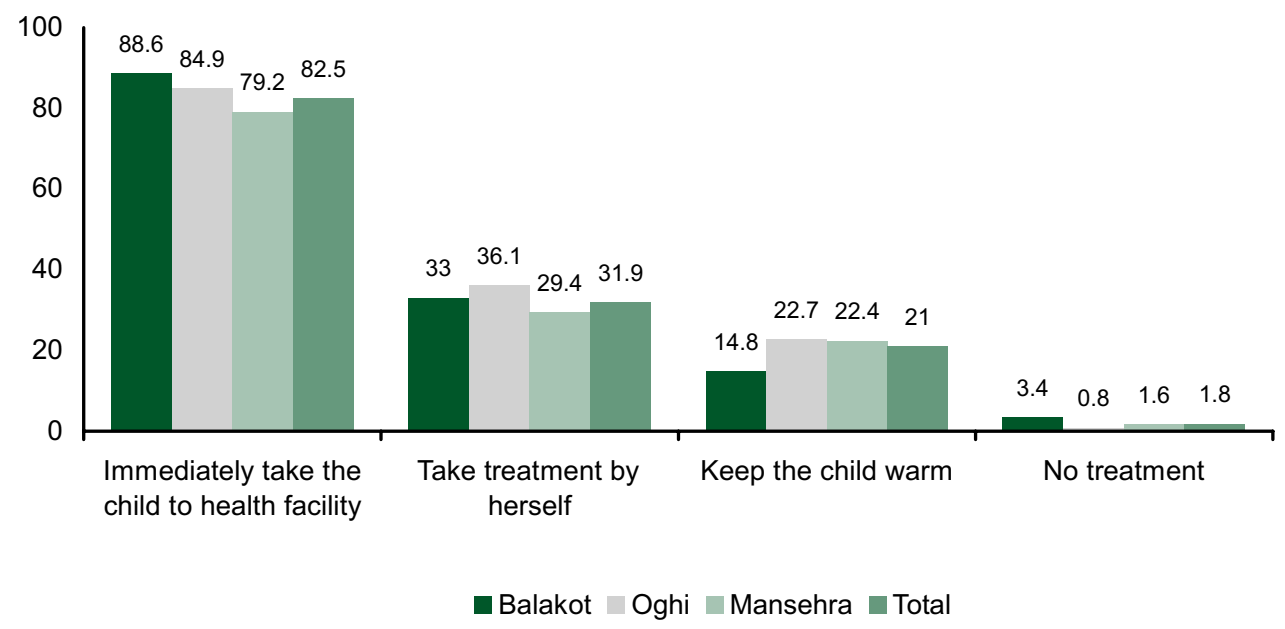

\section{Infant and Under-five Mortality}

Sample size of the survey was not sufficient to estimate infant and under-five mortality for Mansehra alone; mortality rates were estimated only for the two PRIDE project districts combined (Mansehra and Bagh) (see Chapter 1 on sample). Infant and under-five mortality estimates were calculated from information that was collected by the questionnaire for women. The information provided by the women for the live births that occurred during one year prior to the survey was used to estimate the infant and under-five mortality rates. The following definitions are used to estimate infant and under-five mortality: 
Infant mortality: the probability of dying during the first year of life, per thousand live births in a year.

Under-five mortality: the probability of dying before the fifth birthday, per thousand live births in a year.

The reliability of infant and under-five mortality estimates derived from the birth information data is affected by a number of factors as given below.

1. The completeness with which deaths of children are reported.

2. The extent to which birth dates and ages at death are accurately reported by the women.

3. Omissions of either births or deaths are a more serious problem since they affect the level of the mortality estimates.

The KPC survey findings show that there were 676 live births in one year prior to the survey; 55 infants who died during the previous year

\section{PRIDE INDICATOR:}

Under-5 mortality rate: 99 deaths for every 1,000 live births before their first birthday; and 67 children who died during the previous year aged less than 5 years. This gives an estimated infant mortality rate of 81 deaths per 1,000 live births, and an under-five mortality rate of 99 deaths per 1,000 live births in the two PRIDE project districts combined. 


\section{Chapter 7}

\section{Tuberculosis}

According to the World Health Organization (WHO), one-third of the world's population is currently infected with tuberculosis and every second this disease infects one more person in the world. This chapter presents the knowledge about TB of the 1,467 ever-married women of reproductive age (15-49 years) in the KPC survey.

\section{Knowledge}

\section{Awareness}

When the respondents were asked if they had ever heard of tuberculosis, about 9 out of every 10 women in Mansehra district responded that they had. Those who had not heard of tuberculosis ranged from 6 to 10 percent in the 3 tehsils.

Figure 7.1: Ever-married women who had or had not heard about tuberculosis, by tehsil (percent)

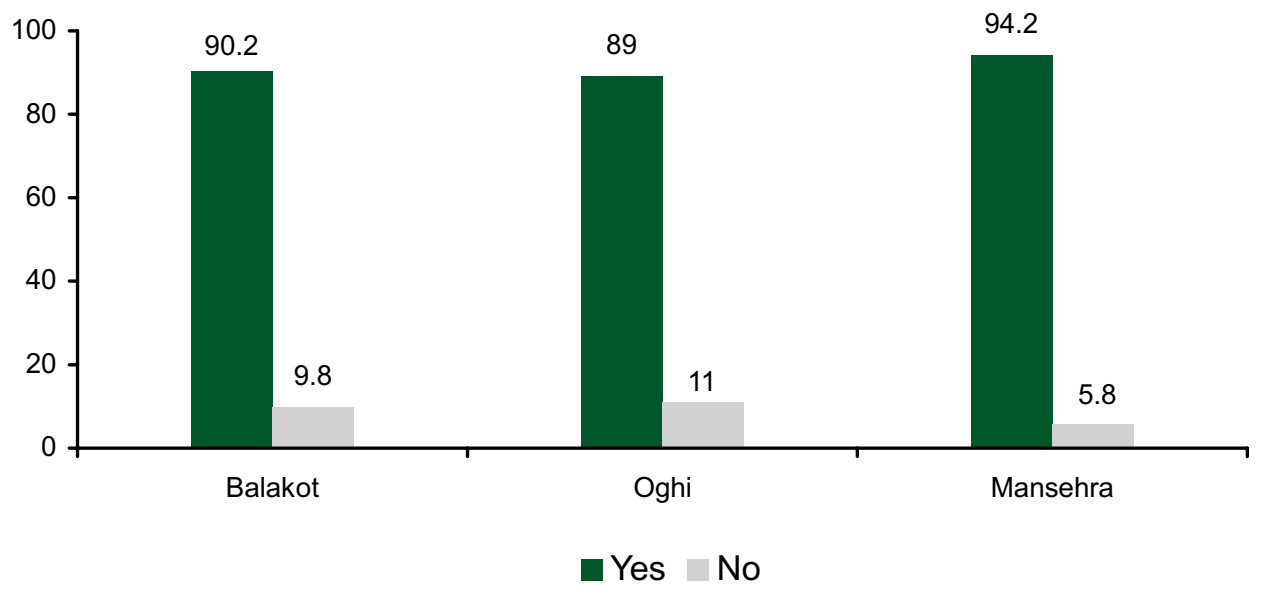




\section{Contagion}

The spread of tuberculosis is a major problem: "Tuberculosis (TB) is a contagious disease. Like the common cold, it spreads through the air. When infectious people cough, sneeze, talk or spit, they propel TB germs into the air. A person needs only to inhale a small number of these to be infected" (WHO 2007).

Those women who had heard of TB were asked to name ways TB can spread from person to person. The majority responded that TB could spread by sharing food and utensils (69 and 61 percent, respectively). Around one-half (53 percent) said TB could spread through the air when a TB patient coughed or sneezed. About 8 percent did not know any ways in which TB could be spread. About 14 percent of the women stated incorrectly that TB could be spread through sexual contact or mosquito bites. No knowledge and incorrect knowledge are issues because, "A person with active but untreated tuberculosis can infect 10-15 other people per year" (WHO 2007).

Table 7.1: Ever-married women who knew about TB according to their knowledge about ways in which TB can be spread from person to person, by tehsil and district

\begin{tabular}{|c|c|c|c|c|c|c|c|c|}
\hline \multirow{4}{*}{$\begin{array}{l}\text { Mode of transmission } \\
\text { Through the air when } \\
\text { coughing or sneezing }\end{array}$} & \multicolumn{6}{|c|}{ Tehsil } & & \\
\hline & \multicolumn{2}{|c|}{ Balakot } & \multicolumn{2}{|c|}{ Oghi } & \multicolumn{2}{|c|}{ Mansehra } & \multicolumn{2}{|c|}{ Total } \\
\hline & $N$ & $\%$ & $N$ & $\%$ & $N$ & $\%$ & $N$ & $\%$ \\
\hline & 136 & 51.1 & 147 & 50.5 & 426 & 53.7 & 709 & 52.5 \\
\hline Sharing utensils & 170 & 63.9 & 168 & 57.7 & 491 & 61.9 & 829 & 61.4 \\
\hline Touching person with $\mathrm{TB}$ & 29 & 10.9 & 9 & 3.1 & 94 & 11.9 & 132 & 9.8 \\
\hline Sharing food & 193 & 72.6 & 225 & 77.3 & 508 & 64.1 & 926 & 68.6 \\
\hline Sexual contact & 47 & 17.7 & 43 & 14.8 & 98 & 12.4 & 188 & 13.9 \\
\hline Mosquito bite & 0 & 0.0 & 3 & 1.0 & 1 & 0.1 & 4 & 0.3 \\
\hline Sputum of TB patient & 23 & 8.6 & 13 & 4.5 & 76 & 9.6 & 112 & 8.3 \\
\hline Using bed of TB patient & 9 & 3.4 & 4 & 1.4 & 31 & 3.9 & 44 & 3.3 \\
\hline $\begin{array}{l}\text { Using possessions of } \mathrm{TB} \\
\text { patient }\end{array}$ & 3 & 1.1 & 2 & 0.7 & 7 & 0.9 & 12 & 0.9 \\
\hline $\begin{array}{l}\text { Sitting with TB patient/ } \\
\text { through breath }\end{array}$ & 6 & 2.3 & 0 & 0.0 & 23 & 2.9 & 29 & 2.1 \\
\hline Other & 6 & 2.3 & 3 & 1.0 & 16 & 2.0 & 25 & 1.9 \\
\hline Don't know & 21 & 7.9 & 23 & 7.9 & 67 & 8.4 & 111 & 8.2 \\
\hline$(\mathrm{N})$ & (266) & na & (291) & na & (793) & na & $(1,350)$ & na \\
\hline
\end{tabular}




\section{Treatment}

Respondents were asked a couple of questions about treatment for TB. First, they were asked whether they knew about TB treatment. Women evidenced strong knowledge that TB was treatable (from 94 to 98 percent over the three tehsils). From 2 to 6 percent of the women did not know that TB was curable.

Figure 7.2: Ever-married women according to whether or not they knew that TB was a treatable disease, by tehsil (percent)

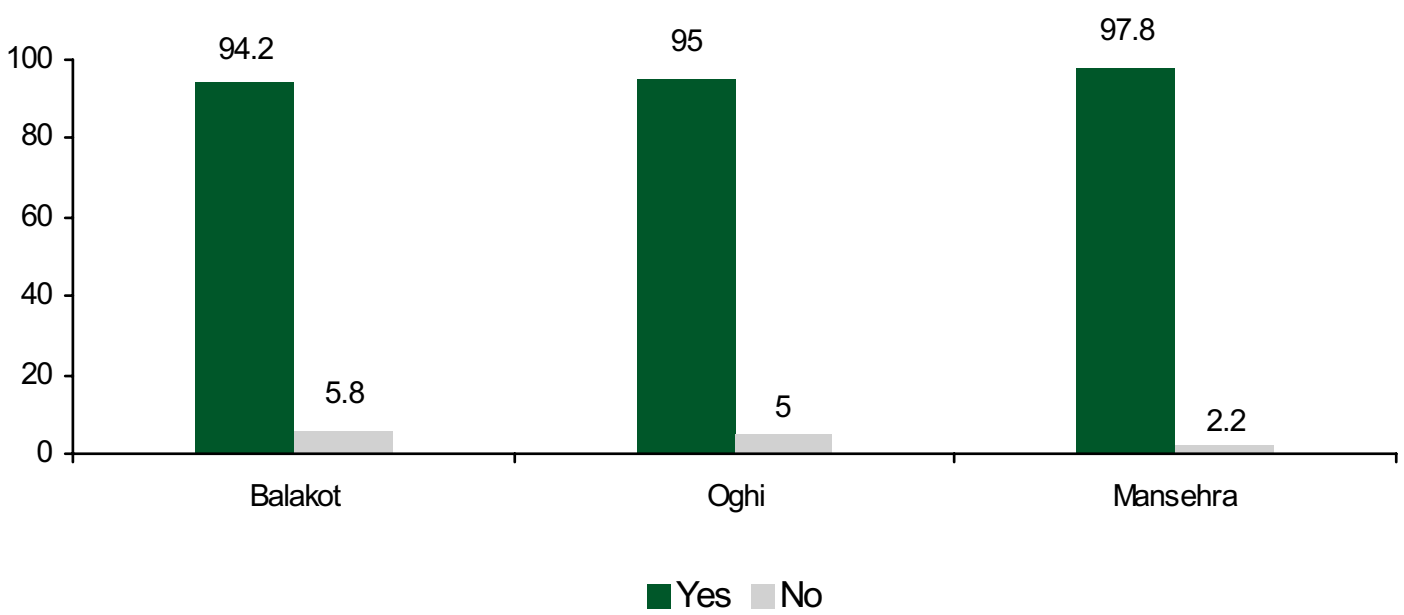

Of respondents who believed TB to be treatable, less than half (around 46 percent) said TB treatment takes eight or more months. Over one-fifth (22 percent) believed taking treatment for four to seven months could fully cure TB. Another fifth (20 percent) said they did not know about the duration of TB treatment.

Table 7.2: Ever-married women who believed TB to be treatable according to their beliefs about the duration of TB treatment, by tehsil and district

\begin{tabular}{lrrrrrrrr} 
Length of treatment & \multicolumn{9}{c}{ Tehsil } \\
in months & \multicolumn{1}{c}{ Balakot } & \multicolumn{2}{c}{ Oghi } & \multicolumn{2}{c}{ Mansehra } & \multicolumn{2}{c}{ Total } \\
\cline { 2 - 8 } $0-3$ & $N$ & $\%$ & $N$ & $\%$ & $N$ & $\%$ & $N$ & $\%$ \\
\hline $4-7$ & 27 & 11.1 & 29 & 10.8 & 94 & 12.6 & 150 & 11.9 \\
\hline 83 & 25.8 & 53 & 19.8 & 166 & 22.2 & 282 & 22.4 \\
\hline 8 or more & 116 & 47.5 & 121 & 45.1 & 348 & 46.5 & 585 & 46.4 \\
\hline Don't know & 38 & 15.6 & 65 & 24.3 & 141 & 18.8 & 244 & 19.3 \\
Total & 244 & 100.0 & 268 & 100.0 & 749 & 100.0 & 1,261 & 100.0
\end{tabular}




\section{Exposure in Family / Knowledge of Signs}

It is assumed that if someone in a family has ever suffered from a contagious disease the rest of the family members would have better knowledge than other people of the disease symptoms and would also be at higher risk of being infected. The respondents were asked if any person in their family had ever been diagnosed with TB. Table 7.3 shows that the highest number was in Oghi, where almost 18 percent said yes, compared to 13 percent in Balakot and 11 percent in Mansehra tehsil.

Table 7.3: Ever-married women according to whether or not anyone in their family ever suffered from TB, by tehsil and district

\begin{tabular}{|c|c|c|c|c|c|c|c|c|}
\hline \multirow{3}{*}{ Response } & \multicolumn{6}{|c|}{ Tehsil } & \multicolumn{2}{|c|}{ Total } \\
\hline & \multicolumn{2}{|c|}{ Balakot } & \multicolumn{2}{|c|}{ Oghi } & \multicolumn{2}{|c|}{ Mansehra } & & \\
\hline & N & $\%$ & N & $\%$ & $N$ & $\%$ & $N$ & $\%$ \\
\hline Yes & 34 & 12.8 & 51 & 17.6 & 84 & 10.7 & 169 & 12.6 \\
\hline No & 232 & 87.2 & 239 & 82.4 & 700 & 89.3 & 1,171 & 87.4 \\
\hline Total & 266 & 100.0 & 290 & 100.0 & 784 & 100.0 & 1,340 & 100.0 \\
\hline
\end{tabular}

\section{Symptoms}

Respondents who reported that they had heard about TB were also asked if they could identify at least one symptom of TB. Overall, about 88 percent of the women who had heard about TB said yes. Responses can be seen in Figure 7.3.

Figure 7.3: Ever-married women who reported whether or not they could identify at least one symptom of TB, by tehsil (percent)

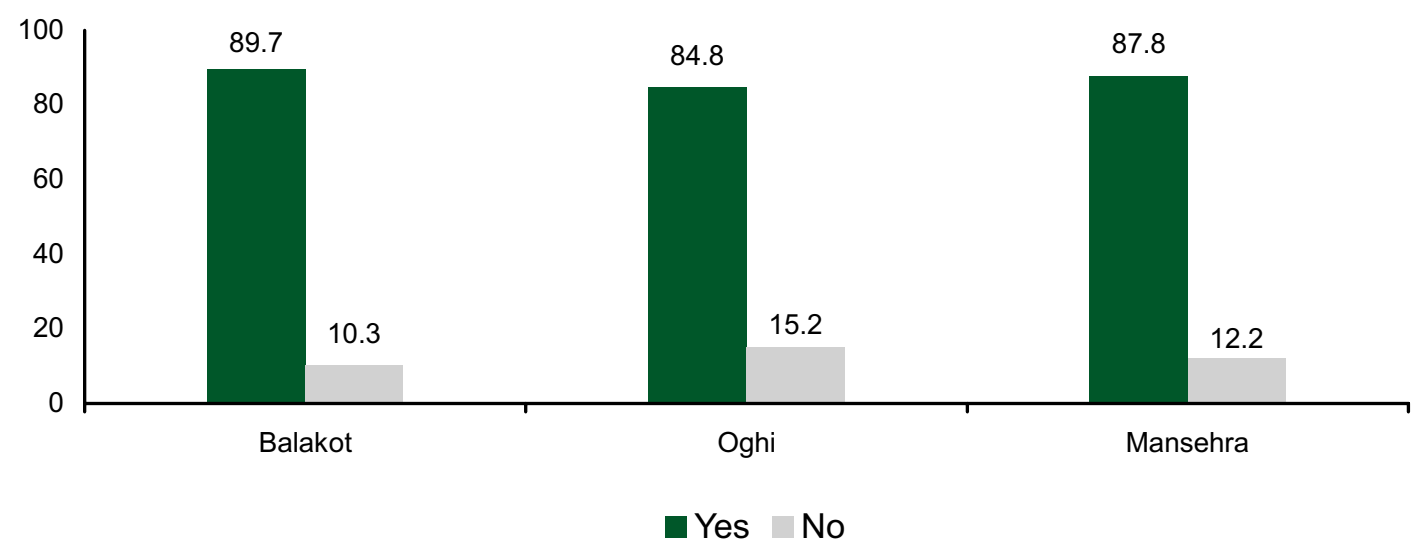


The main symptoms of TB include chest pain, coughing up blood, and a productive, prolonged cough for more than three weeks. Systemic symptoms include fever, chills, night sweats, appetite loss, weight loss, pallor, and often a tendency to fatigue very easily. Table 7.4 shows the responses of women when asked to name the symptoms of TB. A vast majority named chronic cough (93 percent), followed by fever, loss of weight/weakness and sputum with blood (50, 41 and 31 percent, respectively).

Table 7.4: Ever-married women who cited symptoms of TB according to symptom, by tehsil and district

\begin{tabular}{lrrrrrrrr} 
& \multicolumn{9}{c}{ Tehsil } \\
\cline { 2 - 9 } Symptom & \multicolumn{2}{c}{ Balakot } & \multicolumn{2}{c}{ Oghi } & \multicolumn{2}{c}{ Mansehra } & \multicolumn{2}{c}{ Total } \\
\cline { 2 - 9 } Chronic cough & $N$ & $\%$ & $N$ & $\%$ & $N$ & $\%$ & $N$ & $\%$ \\
\hline Sputum with blood & 209 & 88.9 & 232 & 96.3 & 624 & 92.7 & 1,065 & 92.7 \\
\hline Loss of weight/weakness & 125 & 31.1 & 81 & 33.6 & 205 & 30.5 & 359 & 31.2 \\
\hline Fever & 53.2 & 73 & 30.3 & 278 & 41.3 & 476 & 41.4 \\
\hline Loss of appetite & 20 & 8.5 & 16 & 6.6 & 23 & 3.4 & 59 & 5.1 \\
\hline Pain in body/chest/ribs & 11 & 4.7 & 15 & 6.2 & 36 & 5.3 & 62 & 5.4 \\
\hline Change of complexion & 31 & 13.2 & 18 & 7.5 & 53 & 7.9 & 102 & 8.9 \\
\hline Problem in breathing & 13 & 5.5 & 13 & 5.4 & 30 & 4.5 & 56 & 4.9 \\
\hline Vomiting/motions & 6 & 2.6 & 7 & 2.9 & 15 & 2.2 & 28 & 2.4 \\
\hline Fatigue & 2 & 0.9 & 2 & 0.8 & 4 & 0.6 & 8 & 0.7 \\
\hline Other & 12 & 5.1 & 5 & 2.1 & 29 & 4.3 & 46 & 4.0 \\
\hline Don't know & 1 & 0.4 & 0 & 0.0 & 3 & 0.4 & 4 & 0.3 \\
(N) & $(235)$ & na & $(241)$ & na & $(673)$ & na \\
\hline
\end{tabular}

na $=$ Not applicable; respondents could more than one symptom. 



\section{Chapter 8}

\section{Community Involvement in Health}

The involvement of any community in local health planning and management is very important to improving the health delivery system and to ensuring that a better health services package is available, especially for women and children. Through participation in local health planning and management, communities can bridge the gap between the health facilities and the intended recipients of service (the community population), helping to ensure that facilities serve the health needs of the community.

\section{Presence of LHWs/CHWs}

In Mansehra, 63.3 percent of the communities (38 out of 60 communities) reported the presence of lady health workers and community health workers (LHWs and CHWs) in their respective areas.

\section{Health Committees}

Local influential community members from 60 selected communities in Mansehra district responded to questions about local health management. These respondents were asked to indicate their involvement in the planning and management of local health facilities either individually or through an organized forum/committee.

Out of the 60 communities represented, 52 communities (87 percent) had no committee or forum working on health issues (Figure 8.1). However, eight village health committees (VHCs) and community-based organizations (CBOs) (13 percent) were on record to work with the local health authority. These included two community-based organizations and six other non-profit, non-government organizations. Out of these eight committees/organizations, one was not functional while the other seven were functional. In Balakot there were two committees and 
both were functional. Mansehra tehsil had four functional committees. Oghi had two committees, one functional and one non-functional.

Figure 8.1: Percentage of 60 selected communities that have VHCs/CBOs

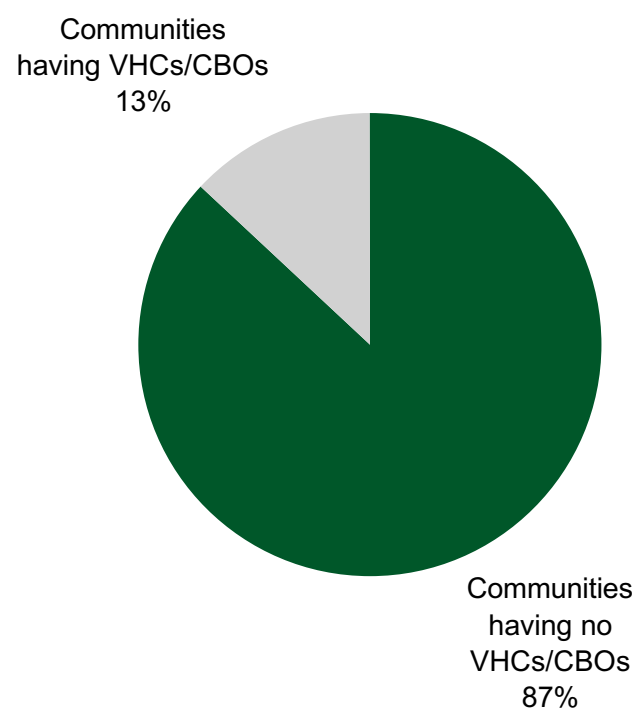

\section{Awareness and Activity Level}

The influential community members from the communities that had VHCs/CBOs were asked if they were aware of the terms of reference (TOR) of the village health committee in their community. In the case of seven out of the eight VHCs, they were aware of the TOR of their respective committees.

When further probed about the frequency of the meetings of the seven VHCs they reported being aware of, it was indicated that one committee met once a week, five met once a month and one did not meet.

In response to a question regarding the interaction of VHC members with health department officers/staff, it was reported that four committees had interacted with health managers (EDO-H and $\mathrm{ADHO}$ ) and service providers (MO BHU). During these meetings they were reported to have discussed issues related to the health of mothers and children, and to have given suggestions for improvements in health in their communities. 


\section{Chapter 9}

\section{Discussion of KPC Baseline Findings for Mansehra District}

\section{Comparisons with Other Surveys}

The PRIDE indicators intended to be measured by the KPC survey have been estimated in various other household surveys in Pakistan, whether at national, provincial, or district levels. Estimates at district levels should be similar to the KPC findings, except for allowance for the passage of time. Estimates for NWFP and for Pakistan as a whole shed light on Mansehra's place in relation to its province and country; in the absence of other district-level data, they can also shed some light on the credibility of the estimates.

Table 9.1 shows national estimates from various sources for most of the PRIDE indicators for which household survey estimates are available, ${ }^{1}$ as well as selected general socioeconomic indicators. Two sources of national data for which several PRIDE indicators are available are the 2006-2007 Demographic and Health Survey (DHS), and the 2005-2006 Pakistan Social and Living Standards Measurement Survey (PSLM). Selected other sources are given, especially where indicators are not available for the two prime sources.

On the whole, data from the Mansehra KPC are comparable to national data, suggesting that Mansehra is neither particularly well developed nor particularly poor. On indicators such as electricity and availability of flush toilets, Mansehra is fairly close to national data and provincial data from NWFP (not shown). Education is also comparable to national levels, and for males, to NWFP levels; but female

\footnotetext{
${ }^{1}$ Alternative survey data are unavailable for two PRIDE indicators: recognition that rapid/difficult breathing of infants requires immediate treatment and the proportion of mothers recognizing at least one danger sign of diarrhea.
} 
education, while similar to national levels, is notably higher than the levels found in NWFP; that is, the "gender gap" between males and females is similar to the national gap, and less than that for NWFP as a whole.

Table 9.1: Comparison of Mansehra KPC indicators with selected national survey data

\begin{tabular}{|c|c|c|c|c|}
\hline \multirow[b]{2}{*}{ Indicator } & \multirow[b]{2}{*}{$\begin{array}{r}\text { Mansehra } \\
\text { KPC }\end{array}$} & \multicolumn{3}{|c|}{ National surveys } \\
\hline & & $\begin{array}{r}\text { DHS } \\
2006-07\end{array}$ & $\begin{array}{r}\text { PSLM } \\
2005-06\end{array}$ & Other \\
\hline & $\%$ & $\%$ & $\%$ & $\%$ \\
\hline Female literacy & 44.0 & $34.8^{1}$ & $42.0^{2}$ & $21.1^{3}$ \\
\hline Electricity connection & 81.9 & na & $83.9^{4}$ & $86.0^{5}$ \\
\hline Flush toilet & 58.7 & na & 60.0 & $46.0^{5}$ \\
\hline Under-5 mortality rate & 996 & $94^{6}$ & na & na \\
\hline Infant mortality rate & $81^{6}$ & $78^{6}$ & na & na \\
\hline CPR (all methods) & 30.5 & 29.6 & 26.0 & $31.5^{7}$ \\
\hline CPR (modern) & 23.3 & 21.7 & na & $23.1^{7}$ \\
\hline Antenatal visits $(1+)$ & 71.7 & 60.9 & 52.0 & $49.8^{5}$ \\
\hline Tetanus immunization $(2+)$ & 48.3 & 58.3 & 55.0 & $39.8^{5}$ \\
\hline Skilled birth attendance & 34.4 & 38.8 & 56.0 & $37.3^{5}$ \\
\hline Postnatal visits $(1+)$ & 22.6 & na & 22.0 & $23.6^{5}$ \\
\hline Knowledge of $3+$ newborn danger signs & 32.9 & na & na & $34.8^{4}$ \\
\hline BCG (children 12-23 months) & 70.1 & 80.3 & 82.0 & $82.0^{4}$ \\
\hline Polio (children $12-23$ months) & 95.9 & 83.1 & 96.0 & $81.0^{4}$ \\
\hline DPT (children 12-23 months) & 46.6 & 58.5 & 77.0 & $80.0^{4}$ \\
\hline Measles (children 12-23 months) & 52.0 & 59.9 & 76.0 & $78.0^{4}$ \\
\hline $\begin{array}{l}\text { Fully immunized (children 12-23 } \\
\text { months) }\end{array}$ & 39.4 & 47.3 & 71.0 & $77.0^{4}$ \\
\hline $\begin{array}{l}\text { Last diarrhea treated with ORT (children } \\
0-23 \text { months) }\end{array}$ & 54.6 & 47.2 & $71.6^{8}$ & na \\
\hline Households using iodized salt & 49.8 & na & na & $26.0^{9}$ \\
\hline $\begin{array}{l}\text { na }=\text { Not available or not provided. } \\
{ }^{1} \text { Only for females ages } 15-49 \text { years. } \\
{ }^{2} \text { Only for females ages } 10 \text { years and older. } \\
{ }^{3} \text { Provincial data from the Multiple Indicator } \\
\text { Cluster Survey (MICS), } 2001 . \\
{ }^{4} \text { National data from PSLM, 2004-2005. } \\
{ }^{5} \text { National data from PAIMAN, 2005-06. }\end{array}$ & $\begin{array}{r}{ }^{6} \text { Per } \\
{ }^{7} \text { Nati } \\
\text { Hea } \\
\text { (PR } \\
8 \text { Data } \\
{ }^{9} \text { Data } \\
200\end{array}$ & $\begin{array}{l}0 \text { live births } \\
1 \text { data from } \\
\text { and Family } \\
\text { PS), 2000-01 } \\
\text { ailable only } \\
\text { m National } \\
\text { ). }\end{array}$ & $\begin{array}{l}\text { kistan Rep } \\
\text { anning Sur } \\
\text { treatment } \\
\text { dtrition Su }\end{array}$ & $\begin{array}{l}\text { tive } \\
\text { RS. } \\
\text { NNS), }\end{array}$ \\
\hline
\end{tabular}


The contraceptive prevalence rate is close to that of the DHS, generally accepted as the national standard. Among maternal care measures, antenatal care visits are notably higher than the national average; on the other hand, tetanus toxoid protection and delivery by skilled birth attendants are somewhat low, while the proportion reporting at least one postnatal visit is close to the national figure for the PSLM. Among indicators of childcare, levels of coverage for full immunization as well as most individual antigens are somewhat lower than national estimates; polio, however, shows higher coverage in Mansehra. Levels of treatment of last diarrhea episodes with ORS is higher in the Mansehra KPC than in the national DHS, but lower than in the national or provincial PSLM surveys. Use of iodized salt is high in the Mansehra KPC compared with other surveys. Infant and under-5 mortality are similar in the KPC to estimates from other sources.

Table 9.2 compares indicators from the KPC with indicators specific to Mansehra district from the MICS of 2001 and the PSLM of 2004-05, the only other published data available for Mansehra. As with national and provincial data, comparisons are mixed; KPC data are not consistently higher or lower than other district-level data. 
Table 9.2: Comparison of Mansehra KPC data with MICS 2001 and PSLM 2004-05 data from Mansehra district

\begin{tabular}{l|r|r|r}
\multirow{2}{*}{ Topic } & \multicolumn{3}{c}{ Indicator value for Mansehra district } \\
\cline { 2 - 4 } & KPC 2007 & MICS 2001 & PSLM 2004-05 \\
\hline Female literacy & $\%$ & $\%$ & $\%$ \\
\hline Electricity connection & 44.0 & 31.4 & 26.0 \\
\hline Flush toilet & 81.9 & 65.0 & 73.0 \\
\hline Under-5 mortality rate & 58.7 & 35.9 & 48.0 \\
\hline Infant mortality rate & 991 & na & na \\
\hline CPR (all methods) & $81^{1}$ & 70.91 & na \\
\hline CPR (modern methods) & 30.5 & 26.5 & na \\
\hline Antenatal visits (1+) & 23.3 & 17.7 & na \\
\hline Tetanus immunization (2+) & 71.7 & 48.8 & 60.0 \\
\hline Skilled birth attendance & 48.3 & na & na \\
\hline Postnatal visits (1+) & 34.4 & 19.2 & 15.0 \\
\hline BCG (children 12-23 months) & 22.6 & na & 33.0 \\
\hline Polio (children 12-23 months) & 70.1 & 59.3 & 86.0 \\
\hline DPT (children 12-23 months) & 95.9 & na & 82.0 \\
\hline Measles (children 12-23 months) & 46.6 & na & 82.0 \\
\hline Fully immunized (children 12-23 months) & 52.0 & na & 82.0 \\
\hline Last diarrhea treated with ORT (children 0-23 & 39.4 & 45.5 & 80.0 \\
months) & 54.6 & na & $79.5^{2}$ \\
\hline
\end{tabular}

na $=$ Not available.

${ }^{1}$ Per 1,000 live births.

${ }^{2}$ Data available only for treatment by ORS.

There is reason to believe that the quality of the various sources is not even. The Demographic and Health Survey and the PAIMAN surveys, for example, were undertaken with highly trained female interviewers under international supervision, and were specific to health issues. The MICS and PSLM data, on the other hand, were collected for a wide variety of purposes (and therefore focus less on health), and interviewers are less intensively trained and often male.

As these comparisons (national and district) show, consistency among the various sources is far from complete. On any given indicator, the KPC data may be higher than other estimates, or lower, or between them; and then other estimates are not particularly consistent with each other. Some trends, however, can be stated. For some maternal health indicators - e.g., ANC, skilled birth attendance - national levels are increasing fairly rapidly according to a variety of sources, and the Mansehra KPC data appear to reflect these trends. In other areas, Mansehra data look broadly 
comparable to those for Pakistan as a whole. Of particular interest, infant and child mortality estimates are similar to the best estimates for Pakistan.

\section{Strengths and Limitations}

Household sample surveys have important strengths, which is why they are so commonly used. They also have important limitations, which is why they are useful only for certain variables and topics. The PRIDE KPC surveys share the strengths and limitations of household surveys generally.

\section{Target group}

The data from the PRIDE KPC were obtained from married women of reproductive age (MWRA), i.e., ever-married women aged 15-49. Information obtained from such women is of considerable interest to a public health program. They are the best informants available regarding their own health, knowledge and experience, and are usually the best informants available regarding the health of their children. They are also the primary target audience for many health education messages. In addition, MWRA are also usually reliable respondents regarding the social, educational, and general economic situation of the household.

\section{Sample}

A probability sample such as the Mansehra KPC provides a sound representative sample of all the households/MWRA in the district. It is, however, subject to some degree of random variance due to the chance that this particular group of households was selected rather than some other; this random variance decreases as sample size increases. The Mansehra KPC, with 1,496 households, is somewhat larger than other samples intended to provide reliable district-level estimates; for example, the MICS, PSLM, and PAIMAN surveys all obtained data on fewer than 1,000 households per district. Sampling errors, taking into account the sample size and design, are shown in Chapter 10 in the form of 95 percent confidence intervals around the point estimates. 


\section{Respondent Accuracy}

Respondents in a household survey can be expected to provide better answers on some questions than others. On factual questions, respondents will obviously answer better when they are more knowledgeable; for example, MWRA in Mansehra are not generally informants for medical diagnosis, or for functioning of the health system. They also tend to provide better answers on questions that are important (e.g., an episode of childhood diarrhea is more likely to be reported if the mother considered it serious), non-sensitive (e.g., births are more likely to be reported than induced abortions), and specific (e.g., a question on "last time" will generally be answered more often than a question about usual behavior). Data on knowledge and attitudes are particularly sensitive to the skill of the interviewer as well as the wording of the question; it is often useful to think of such answers less as factual information than as the body of answers women give when asked a particular question in a particular place.

Despite the limitations of household survey data, they are frequently the best feasible source of data. For example, although Census data are indispensable for providing complete data on a whole population, they may be less accurate on many topics because questionnaires are shorter and interviewers less well trained; in addition, as in the present case, census data may be out of date. Data from the health system itself - e.g., the Health Management Information System (HMIS) - are necessary for some indicators - e.g., clinic attendance - but tend not to be able to collect accurate information on the health of the general population, since they are generally limited to the individuals they serve directly. The Mansehra KPC has focused its attention on those topics for which it was believed that the household survey would provide the best available data.

\section{Perspectives}

The Mansehra KPC data reflect the strengths and weaknesses of the Pakistan health system as a whole. On a variety of indicators of general social and economic status, Mansehra appears slightly better developed than Pakistan as a whole, or NWFP as a whole. Regarding primary health care, the areas that need attention are generally those of the country as a whole, and the priorities are similar.

Within Mansehra district, there is considerable variability on many indicators by tehsil. On the whole, Mansehra tehsil (which contains the only town in the district) is 
better developed than Balakot and Oghi. For example, ownership of most household amenities (other than animals) is substantially higher for Mansehra than Balakot or Oghi; women in Mansehra are more likely to be literate; and so on. These are reflected in better health indicators for Mansehra, including family planning, maternal health, and infant/child health. Balakot tehsil ranks higher on some indicators than Oghi, but this is not consistent.

Whether at the tehsil level or the individual household/woman level (not analyzed in this report), the variability shown in these indicators generally reflects the ease or difficulty in addressing problems at both facility and community levels. The better infrastructure in Mansehra tehsil, along with proximity to the town, will make it easier to bring facilities up to standard. At the community level, variation in socioeconomic status doubtless reflects in part that smaller, more fragmented and more isolated communities are generally harder to reach and organize than larger and more prosperous places. In some cases these also reflect cultural differences, which should be described and studied in the qualitative research.

Family planning use in Mansehra, at about 30 percent of MWRA, is similar to Pakistan generally. But with more than 70 percent of non-users expressing intent to use in the future, and about one-third of respondents with current unmet need for family planning, there is clearly an opportunity to increase family planning use. There would appear to be substantial scope in particular for strengthening the family planning activities of the Ministry of Health.

There is evidence in Mansehra, as elsewhere, that use of professional providers for maternity care (ANC, tetanus immunization, skilled attendance at birth) is rising, suggesting that the traditional view that childbirth is a natural process not requiring medical care may be waning. Efforts to reinforce this trend are likely to be productive. Most important, perhaps, will be to meet the need for rapid diagnosis and effective treatment of obstetric emergencies.

A key issue for Mansehra, as elsewhere, is improving delivery care. While the proportion of babies delivered by health professionals is rising, it is still only about one-third of deliveries, and improvements here are desirable. However, it is important to focus as well on home deliveries by non-professionals, which are the majority of deliveries. One possibility is to implement effective training of dais (traditional birth attendants), who conduct the largest share of all deliveries. Another 
national development that PRIDE should consider is the plan to train a national cadre of community midwives; while the numbers will not be large during the life of the PRIDE project, some trained midwives will be available, and efforts to determine how best to utilize them may be of considerable value for the future. Another issue requiring attention is the 20 percent of deliveries conducted by untrained friends and relatives. It is programmatically difficult to train such persons, who individually conduct only a few deliveries each. How to advise mothers who may wish to be delivered by these informal providers is a topic that needs to be addressed by the Intermediate Result 3 team.

The low levels of postnatal care and knowledge of newborn emergencies suggests that priority attention should be given to strengthening neonatal care, both through better preparation (training and facilities) in the health system and through community education. Experience elsewhere in Pakistan (as well as internationally) indicates that efforts to treat the mother and her newborn baby as a dyad, with focus on both, may be more effective than sole focus on the mother.

Data on childcare - immunization, diarrhea, pneumonia, etc. - suggest the need for better linkage between the family and the health system. Except for polio, immunization levels are disappointing, and indicate the need for better coordination between the community and the public health system. Better education as well as service is needed to deal with diarrhea and pneumonia, which (based on other evidence in Pakistan) are probably two of the leading causes of infant and child mortality.

Awareness of malaria and tuberculosis is quite high. However, better solutions are needed to improve prevention and cure. Community-level operations research efforts may point the way for better ways to meet these needs.

It is important to examine and utilize the potential for harnessing care in the private sector. Judging by family planning and antenatal care, recourse to the private sector may be less dominant in Mansehra than in Pakistan generally. However, about onethird of family planning and half of antenatal care are provided by the private sector, and probably a higher proportion of curative care is provided by private sources. The public sector should not be expected to provide all the medical care in Mansehra; strengthening the quality of private sector care should be a priority for the PRIDE project. 


\section{Chapter 10}

\section{Key Indicators for KPC Baseline Survey Mansehra District}

The KPC survey served to collect baseline information on key PRIDE indicators.

Table 10.1 presents a summary of the baseline data for these key indicators, they are also highlighted throughout this report:

Table 10.1: PRIDE key indicators from KPC baseline survey, Mansehra district

\begin{tabular}{|c|c|c|c|c|}
\hline \multirow[b]{2}{*}{ Indicator } & \multirow[b]{2}{*}{ Sub-indicator } & \multirow{2}{*}{$\begin{array}{r}\text { KPC } \\
\text { baseline } \\
\text { data } \\
(\%)\end{array}$} & \multicolumn{2}{|c|}{ Confidence interval } \\
\hline & & & $\begin{array}{r}\text { Lower } \\
\text { boundary } \\
(\%)\end{array}$ & $\begin{array}{r}\text { Upper } \\
\text { boundary } \\
(\%)\end{array}$ \\
\hline $\begin{array}{l}\text { Contraceptive } \\
\text { prevalence rate }\end{array}$ & $\begin{array}{l}\text { - Use of modern methods } \\
\text { - Use of any method }\end{array}$ & $\begin{array}{l}23.3 \\
30.5\end{array}$ & $\begin{array}{l}20.1 \\
27.2\end{array}$ & $\begin{array}{l}26.8 \\
34.0\end{array}$ \\
\hline Use of iodized salt & & 49.8 & 44.2 & 55.4 \\
\hline $\begin{array}{l}\text { Ante-natal visit in last } \\
\text { pregnancy }\end{array}$ & $\begin{array}{l}\text { - One or more visits } \\
\text { - } \quad \text { Four or more visits }\end{array}$ & $\begin{array}{l}71.7 \\
35.0 \\
\end{array}$ & $\begin{array}{l}66.1 \\
29.8 \\
\end{array}$ & $\begin{array}{l}76.4 \\
40.1 \\
\end{array}$ \\
\hline $\begin{array}{l}\text { TT injection during } \\
\text { last pregnancy }\end{array}$ & $\begin{array}{l}\text { - One or more injections } \\
\text { - Two TT injections }\end{array}$ & $\begin{array}{l}53.4 \\
48.3\end{array}$ & $\begin{array}{l}47.7 \\
42.9\end{array}$ & $\begin{array}{l}59.1 \\
54.0\end{array}$ \\
\hline $\begin{array}{l}\text { Delivery attended by } \\
\text { skilled birth } \\
\text { attendants }\end{array}$ & & 34.4 & 29.0 & 40.0 \\
\hline Post-natal visit $(1+)$ & $\begin{array}{l}\text { At least one visit within } \\
40 \text { days after delivery }\end{array}$ & 22.6 & 18.5 & 27.4 \\
\hline $\begin{array}{l}\text { Knowledge of danger } \\
\text { signs in newborns }\end{array}$ & $\begin{array}{l}\text { - One or more danger signs } \\
\text { - Three or more danger } \\
\text { signs }\end{array}$ & $\begin{array}{l}73.5 \\
32.9\end{array}$ & $\begin{array}{l}68.2 \\
27.9\end{array}$ & $\begin{array}{l}78.0 \\
38.3\end{array}$ \\
\hline
\end{tabular}




\begin{tabular}{|c|c|c|c|c|}
\hline \multirow[b]{2}{*}{ Indicator } & \multirow[b]{2}{*}{ Sub-indicator } & \multirow{2}{*}{$\begin{array}{r}\text { KPC } \\
\text { baseline } \\
\text { data } \\
(\%)\end{array}$} & \multicolumn{2}{|c|}{ Confidence interval } \\
\hline & & & $\begin{array}{r}\text { Lower } \\
\text { boundary } \\
(\%)\end{array}$ & $\begin{array}{r}\text { Upper } \\
\text { boundary } \\
(\%)\end{array}$ \\
\hline $\begin{array}{l}\text { Immunization of } \\
\text { children ages 12-23 } \\
\text { months }\end{array}$ & $\begin{array}{l}\text { - Fully vaccinated } \\
\text { - } \text { BCG } \\
\text { - Polio } \\
\text { - DPT } \\
\text { - } \text { Measles }\end{array}$ & $\begin{array}{l}39.4 \\
70.1 \\
95.9 \\
46.6 \\
52.0\end{array}$ & $\begin{array}{l}32.4 \\
61.4 \\
89.2 \\
39.4 \\
44.9\end{array}$ & $\begin{array}{l}46.8 \\
77.6 \\
98.5 \\
54.0 \\
59.1\end{array}$ \\
\hline $\begin{array}{l}\text { Mothers knowledge } \\
\text { and identification of } \\
\text { pneumonia }\end{array}$ & $\begin{array}{l}\text { - Heard about pneumonia } \\
\text { - Rapid/difficult breathing } \\
\text { needs immediate } \\
\text { treatment at facility }\end{array}$ & $\begin{array}{l}92.2 \\
82.5\end{array}$ & $\begin{array}{l}89.6 \\
76.8\end{array}$ & $\begin{array}{l}94.2 \\
86.5\end{array}$ \\
\hline $\begin{array}{l}\text { Childrens last bout of } \\
\text { diarrhea treated with } \\
\text { ORS/ORT }\end{array}$ & & 54.6 & 46.2 & 62.1 \\
\hline $\begin{array}{l}\text { Mothers recognize at } \\
\text { least one danger sign } \\
\text { of diarrhea }\end{array}$ & & 85.2 & 81.1 & 88.7 \\
\hline Child mortality & $\begin{array}{l}\text { - Under } 5 \text { years mortality } \\
\text { per } 1,000 \text { live births } \\
\text { - Infant mortality per } 1,000 \\
\text { live births }\end{array}$ & $\begin{array}{l}99 \\
81\end{array}$ & $\begin{array}{l}84 \\
66\end{array}$ & $\begin{array}{r}117 \\
97\end{array}$ \\
\hline
\end{tabular}

The baseline information gathered will serve as an important part of designing program interventions and activities. For example, when examing data for family planning, the current use of modern methods is only 23 percent, highlighting that there is a great unmet need for family planning. Focusing PRIDE interventions at both community and health facility levels will be necessary to address this.

The baseline information will also be crucial to setting program targets that the PRIDE project will use to monitor progress. The KPC survey will be repeated at the end of the project; baseline and endline data will be used to evaluate the achievements of PRIDE. 


\section{References}

Caldwell, John C. Routes to low mortality in poor countries. Population and Development Review, Vol. 12, No. 2 (June 1986), pp. 171-220.

Federal Bureau of Statistics [Pakistan]. 2006. Pakistan Social and Living Standards Measurement Survey, 2004 -2005. Islamabad: Federal Bureau of Statistics, Statistics Division.

Government of NWFP. A district based multiple indicators cluster survey, 2001. Government of NWFP, P\&D department.

Hobcraft, J. Child Spacing and Child Mortality in Proceedings of the Demographic and Health Surveys World Conference, 1991, Vol. 2, Columbia, Md., USA, 1991, pp. 1157-1182.

IRIN. PAKISTAN: Iodine deficiency affecting children in northwest. Asia English Reports, www.irinnews.org, 9 July 2007.

Mahmood, Arshad. Infant and child mortality estimates from Pakistan Population Census 1998, in Abdul Razzaq Kemal, M. Irfan, and Naushin Mahmood (eds.), Population of Pakistan: An Analysis of 1998 Population and Housing Census. Islamabad: Pakistan Institute of Development Economics, 2003.

National Institute of Population Studies (NIPS). 2007. Pakistan Demographic and Health Survey 2006 -2007, Preliminary Report. Islamabad: NIPS.

Population Census Organization. District Census Report Mansehra. Government of Pakistan, Statistics Division, 2000.

Population Council. 2006. PAIMAN Baseline Household Survey Reports, 2006. Islamabad: The Population Council Pakistan.

Singh S. and R. Samara. Early Marriage Among Women in Developing Countries. International Family Planning Perspectives, Vol. 22, No. 4 (Dec. 1996), pp. 148157.

WHO. WHO Global TB Control Report 2007. www.who.int/tb/publications/ global_report/2007.

Zafar, Faiza. IRIN. PAKISTAN: Iodine deficiency affecting children in northwest. Asia English Reports, www.irinnews.org, 9 July 2007. 


\section{PRIDE (0)}

Primary Healthcare Revitalization, Integration and Decentralization in Earthquake-affected areas

House \# 138, St \# 14, E-7, Islamabad, PAKISTAN, Tel: + 92(0)51-2654142

Field Offices:

House No.3, Sector - B, Ghazikot Township, Mansehra, Ph: 0997 302899, 303160 Fax:0997 303049 )

Qandeel Colony, Bagh, Ph:58720-43128 \& 992-519028 Fax: 58720-43128 